\begin{tabular}{|c|c|c|c|}
\hline $\begin{array}{l}\text { 2. ECN Category (mark one) } \\
\text { Supplemental } \\
\text { Direct Revision }\end{array}$ & $\begin{array}{l}\text { 3. Originator's Name, Organization, MSIN, and Telepho } \\
\text { K. D. Gibson, Nuclear Safety, R3- } \\
\text { 373-7365 }\end{array}$ & $\begin{array}{l}\text { 4. USQ Required? } \\
\text { Yes } \bigcirc \text { no }\end{array}$ & $\begin{array}{l}\text { 5. Date } \\
\text { 2/15/99 }\end{array}$ \\
\hline $\begin{array}{l}\text { Change ECN } \\
\text { Temporary }\end{array}$ & $\begin{array}{l}\text { 6. Project Title/No. Work Order No. } \\
\text { Spent Nuclear Fuel Project - } \\
\text { K Basin }\end{array}$ & $\begin{array}{l}\text { 7. Bldg./Sys./Fac. No. } \\
100 \mathrm{~K}\end{array}$ & $\begin{array}{l}\text { 8. Approval Designator } \\
\text { SQE }\end{array}$ \\
\hline $\begin{array}{l}\text { Standby } \\
\text { Supersedure } \\
\text { CancelNoid }\end{array}$ & $\begin{array}{l}\text { 9. Document Numbers Changed by this ECN (includes } \\
\text { sheet no. and rev.) } \\
\text { SNE-2671, Revision } 2\end{array}$ & $\begin{array}{l}\text { 10. Related ECN No(s). } \\
\text { NA }\end{array}$ & $\begin{array}{l}\text { 11. Related PO No. } \\
\text { NA }\end{array}$ \\
\hline $\begin{array}{l}\text { 12a. Modification Work } \\
\text { Yes (fill out Blk. 12b) } \\
\text { No (NA Blks. 12b, } \\
\text { 12c, 12d) }\end{array}$ & $\begin{array}{l}\text { 12c. Modification Work Co } \\
\text { NA } \\
\text { Design Authority/Cog. En } \\
\text { Date }\end{array}$ & \begin{tabular}{l|l} 
leted & $\begin{array}{l}12 \mathrm{~d} . \begin{array}{r}\text { Restored } \\
\text { or Stand }\end{array} \\
\text { eer Signature \& }\end{array}$ \\
\cline { 1 - 2 }
\end{tabular} & $\begin{array}{l}\text { to Original Condition (Temp. } \\
\text { y ECNs only) } \\
\text { rity/Cog. Engineer Signature \& } \\
\text { Date }\end{array}$ \\
\hline $\begin{array}{l}\text { 13a. Description of Change } \\
\text { This revision of } \\
\text { installed over th } \\
\text { to the main repor } \\
\text { limiter) provides } \\
\text { limiter (defense } \\
\text { to the four-inch } \\
\text { measures) and the } \\
\text { valve (10-3 to } 10 \\
\text { include a safety } \\
\text { which illustrates } \\
\text { the PGA of the Ba } \\
\text { the K Basin concr }\end{array}$ & $\begin{array}{l}\text { 13b. Design Baseline Do } \\
\text { fe report (Revision }(\boldsymbol{Z} \text { ) } \text { includes } \\
\text { four-inch drain valve in the SLO } \\
\text { to discuss the added protection } \\
\text { A new section was added to Appe } \\
\text { depth measures) and the added } \\
\text { cain valve (Section D. } 6 \text { ) to discu } \\
\text { added protection that the impact } \\
\text { ) for objects that may be droppe } \\
\text { ctor of structure failure capaci } \\
\text { hat if a seismic event were to } \\
\text { in's DBE, the concrete structure } \\
\text { e structure were re-evaluated co }\end{array}$ & $\begin{array}{l}\text { scussion of the impa } \\
\text { A new section (Sect } \\
\text { t the defense in dep } \\
\text { x D (Section D. } 6 \text { ) to } \\
\text { ection that the impa } \\
\text { the impact limiter } \\
\text { iter provides to the } \\
\text { n Region I. Appendi } \\
\text { for the K Basin cono } \\
\text { r whose PGA was less } \\
\text { ld not f ail. The } \\
\text { dering this safety }\end{array}$ & $\begin{array}{l}\text { ct limiter that is } \\
\text { ion } 6.0 \text { ) was added } \\
\text { th measure (impact } \\
\text { discuss the impact } \\
\text { ct limiter provides } \\
\text { defense in depth } \\
\text { four-inch drain } \\
\text { x E was modified to } \\
\text { rete structure } \\
\text { than or equal to } \\
\text { ragility curves for }\end{array}$ \\
\hline
\end{tabular}

\begin{tabular}{|c|c|}
\hline 14a. Justification (mark one) & 14b. Justification Details \\
\hline Criteria Change & Revision to the ARES Corporation report was necessary to document changes \\
\hline Design Improvement & directed by RL letter, to R. D. Hanson, EDH, from J. D. Wagoner, \\
\hline Environmental & RL," CONTRACT NO. DE-AC06-96RL132 - K BASINS SAFETY ANALYSIS REPORT (SAR) \\
\hline Facility Deactivation & WHC-SD-SE-SAR-062, PROPOSED REVISION 3F, AND K BASINS TECHNICAL SAFETY \\
\hline Pefound & REQUIREMENTS (TSR) WHC-SD-SNF-TSR-O01, PROPOSED REVISION 0-D, UNREVIEWED \\
\hline As-Found & SAFETY QUESTION (USQ) AND JUSTIFICATION FOR CONTINUED OPERATION (JCO)", \\
\hline Facilitate C & (98-SFD-187), dated September 18, 1998. \\
\hline Const. Err & \\
\hline & \\
\hline
\end{tabular}

15. Distribution (include name, MSIN, and no. of copies)

See attached Distribution Cover Sheet

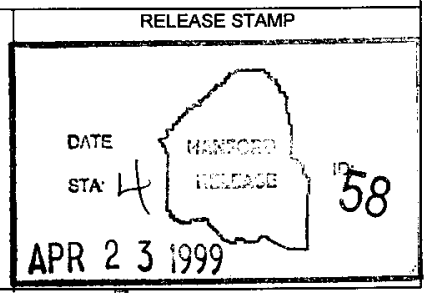




\section{ENGINEERING CHANGE NOTICE}

16. Design Verification 17. Cost Impact Required

\section{Y Yes \\ (No}

ENGINEERING

Additional $\bigcirc \$ N A$

Savings $O \$ N A$
Page 2 of 2 CONSTRUCTION

Additional $\bigcirc \$ N A$

Savings $O \$ N A$
1. ECN (use no. from pg. 1)

637200

18. Schedule impact (days)

\begin{tabular}{ll} 
Improvement $\bigcirc$ & $\mathrm{NA}$ \\
Delay & $\mathrm{NA}$ \\
\hline
\end{tabular}

19. Change Impact Review: Indicate the related documents (other than the engineering documents identified on Side 1) that will be affected by the change described in Block 13 . Enter the affected document number in Block 20 .

$\begin{array}{llll}\text { SDD/DD } & \square & \text { Seismic/Stress Analysis } & \square \\ \text { Functional Design Criteria } & \square & \text { Stress/Design Report } & \square \\ \text { Operating Specification } & \square & \text { Interface Control Drawing } & \square \\ \text { Criticality Specification } & \square & \text { Calibration Procedure } & \square \\ \text { Conceptual Design Report } & \square & \text { Installation Procedure } & \square \\ \text { Equipment Spec. } & \square & \text { Maintenance Procedure } & \square \\ \text { Const. Spec. } & \square & \text { Engineering Procedure } & \square \\ \text { Procurement Spec. } & \square & \text { Operating Instruction } & \square \\ \text { Vendor Information } & \square & \text { Operating Procedure } & \square \\ \text { OM Manual } & \square & \text { Operational Safety Requirement } & \square \\ \text { FSAR/SAR } & \square & \text { IEFD Drawing } & \square \\ \text { Safety Equipment List } & \square & \text { Cell Arrangement Drawing } & \square \\ \text { Radiation Work Permit } & \square & \text { Essential Material Specification } & \square \\ \text { Environmental Impact Statement } & \square & \text { Fac. Proc. Samp. Schedule } & \square \\ \text { Environmental Report } & \square & \text { Inspection Plan } & \square \\ \text { Environmental Permit } & \square & \text { Inventory Adjustment Request } & \square\end{array}$

Tank Calibration Manual Health Physics Procedure Spares Multiple Unit Listing

Test Procedures/Specification Component Index ASME Coded Item Human Factor Consideration Computer Software Electric Circuit Schedule ICRS Procedure Process Control Manual/Plan Process Flow Chart Purchase Requisition Tickler File

Other Affected Documents: (NOTE: Documents listed below will not be revised by this ECN.) Signatures below indicate that the signing organization has been notified of other affected documents listed below.

Signature

Date

Design Authority

Cog. Eng. K.D. Gibson

K. D. Fitser.

Cog.Mgr. J.E. Truax

QA

Safety

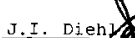

Environ. R.G. Gant

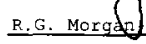

Other

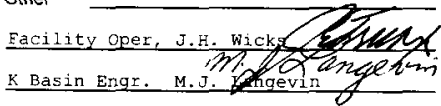

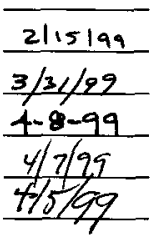

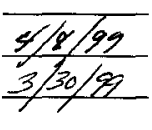

Signature

Date

Design Agent ARES CORPORATION

PE

QA

Safety

Design

Environ

Other

\section{DEPARTMENT OF ENERGY}

Signature or a Control Number that tracks the Approval Signature

ADOITIONAL

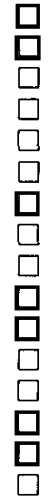




\title{
Risk Assessment of Drain Valve Failure in the K-West Basin South Loadout Pit
}

\author{
R. G. Morgan
}

Richland, WA 99352

U.S. Department of Energy Contract DE-AC06-96RL13200

EDT/ECN: 637200

Org Code: 2 F2 00

B\&R Code: EW 31354040
UC: 510

Charge Code: LCOAB

Total Pages: 118

Key Words: K Basin Imersion Pail Structure, CTFM, South Loadout Pit, Cask, Transportation, Drain Valve, Risk Assessment

Abstract: This document identifies the risks associated with working in the south loadout pit during construction by SNF Facility projects.

TRADEMARK DISCLAIMER. Reference herein to any specific commercial product, process, or service by trade name, trademark, manufacturer, or otherwise, does not necessarily constitute or imply its endorsement, recommendation, or favoring by the United States Government or any agency thereof or its contractors or subcontractors.

Printed in the United States of America. To obtain copies of this document, contact: Document Control Services, P.O. Box 950, Mailstop H6-08, Richland WA 99352, Phone (509) 372-2420; Fax (509) 376-4989.

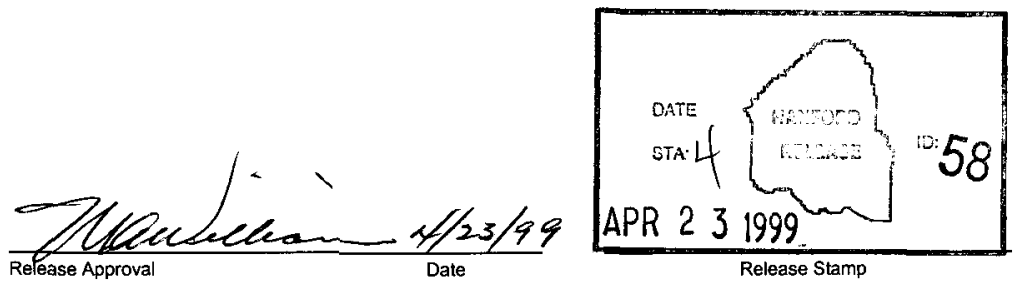




\section{RECORD OF REVISION}

\begin{tabular}{|c|c}
\hline $\begin{array}{c}\text { (1) Document Number } \\
\text { SNF-2671, Rev } 1\end{array}$ & Page 1 \\
\hline
\end{tabular}

(2) Tikle

Risk Assessment of Drain Valve Failure in the K-West Basin South Loadout Pit

\section{Change Control Record}

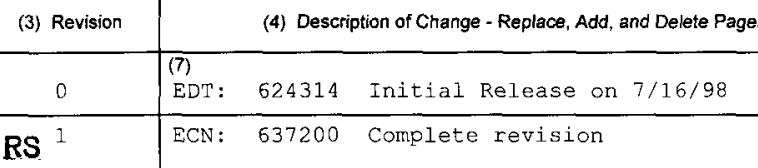

\begin{tabular}{l|l|}
\multirow{2}{*}{} & \multicolumn{2}{|c}{ Authorized } \\
\cline { 2 - 3 } & (5) Cog. Engr. \\
\hline & JL Weamer \\
\hline & KD Gibson \\
\hline
\end{tabular}


SNF-2671, Rev. 1

\title{
RISK ASSESSMENT OF DRAIN VALVE FAILURE IN THE K-WEST BASIN SOUTH LOADOUT PIT
}

Prepared for

\author{
DE\&S Hanford, Inc. \\ Purchase Order MRB-SLB-A06272 \\ Line Item 14 \\ Report No. 984515-001 \\ Revision 3 \\ (Revision 3 completed under Contract 263, Line Item 42)
}

February 1999

Prepared by

\section{ARES CORPORATION}

636 Jadwin Avenue Suite B

Richland, Washington 99352 


\title{
RISK ASSESSMENT OF DRAIN VALVE FAILURE IN THE K-WEST BASIN SOUTH LOADOUT PIT
}

\author{
Prepared for
}

DE\&S Hanford, Inc.

Purchase Order MRB-SLB-A06272

Line Item 14

Report No. 984515-001

Revision 3

(Revision 3 completed under Contract 263, Line Item 42)

February 1999

Prepared by

Prepared by: Dr. Lewis D. Muhlestein Scott R. Pierce Approved by: $\frac{R \operatorname{Lnz}}{\text { Robert L. Fot }}$

Date: $4-13-99$ 


\section{EXECUTIVE SUMMARY AND BRIEFING}

The drain valve located in the bottom of the K-West Basin South Loadout Pit (SLOP) could provide an additional leak path from the $\mathrm{K}$ Basins if the drain valve were damaged during construction, installation, or operation of the cask loading system. For the K-West Basin SLOP the immersion pail support structure (IPSS) has already been installed, but the immersion pail has not been installed in the IPSS.

The objective of this analysis is to evaluate the risk of damaging the drain valve during the remaining installation activities or operation of the cask loading system. Valve damage, as used in this analysis, does not necessarily imply large amounts of the water will be released quickly from the basin; rather valve damage implies that the valve's integrity has been compromised. The analysis process is a risk-based uncertainty analysis where best engineering judgement is used to represent each variable in the analysis. The uncertainty associated with each variable is represented by a probability distribution. The uncertainty is propagated through the analysis by Monte Carlo convolution techniques. The corresponding results are developed as a probability distribution and the risk is expressed in terms of the corresponding complementary cumulative distribution function ("risk curve"). The total risk is the area under the "risk curve".

The risk of potentially dropping a cask into or on the IPSS and damaging the drain valve is approximately $1 \times 10^{-4}$ to $2 \times 10^{-5}$ per year. The risk of objects falling behind the IPSS and damaging the valve is $3 \times 10^{-2}$ to $6 \times 10^{-3}$ per year. Both risks are expressed as drain value failure frequencies. The risk of objects falling behind the IPSS and damaging the valve can be significantly reduced by an impact limiter and/or installing a grating or plate over the area bounded by the back of the IPSS and the wall of the SLOP. With either of these actions there is a 90 percent confidence that the frequency of drain valve failure would be less than $1 \times 10^{-6}$ per year. 


\section{TABLE OF CONTENTS}

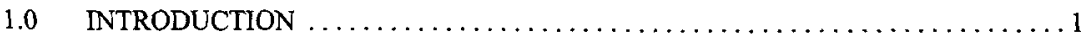

2.0 RISK BACKGROUND AND UNCERTAINTY ANALYSIS PROCESS $\ldots \ldots \ldots \ldots 2$

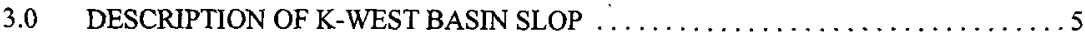

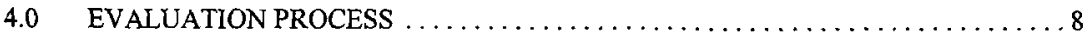

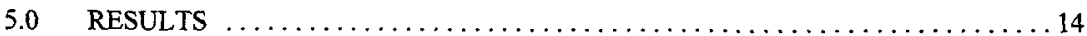

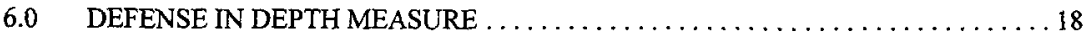

7.0 CONCLUSIONS AND RECOMMENDATIONS $\ldots \ldots \ldots \ldots \ldots \ldots \ldots \ldots$

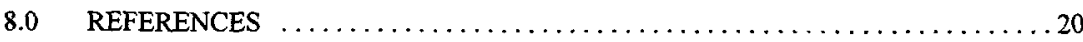

\section{APPENDICES}

Appendix A

Summary of K-West Basin SLOP Drop Analyses $\ldots \ldots \ldots \ldots \ldots \ldots \ldots \ldots \ldots$ A-1 Appendix B

Risk of a Load Drop Per Crane Lift $\ldots \ldots \ldots \ldots \ldots \ldots \ldots \ldots \ldots \ldots \ldots$. Appendix C

Probability of Drain Valve Failure Due to an Impact Load $\ldots \ldots \ldots \ldots \ldots \ldots \ldots$. Appendix D

Analysis and Results $\ldots \ldots \ldots \ldots \ldots \ldots \ldots \ldots \ldots \ldots \ldots \ldots \ldots \ldots \ldots \ldots$ Appendix E

K Basin Seismic Risk . . . . . . . . . . . . . . . . . . . . . . E-1 Appendix F

Validation of Analysis Models $\ldots \ldots \ldots \ldots \ldots \ldots \ldots \ldots \ldots \ldots \ldots$ F-1 


\section{FIGURES}

Figure 1. Example of a Distribution of Consequences and the Associated "Risk Curve" . .... 3

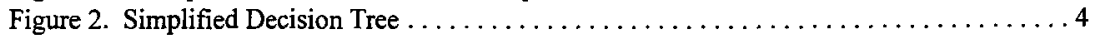

Figure 3. Schematic of Risk-Based Uncertainty Analysis. . . . . . . . . . . . . . . . 5

Figure 4. Plan View of the K-West Basin SLOP

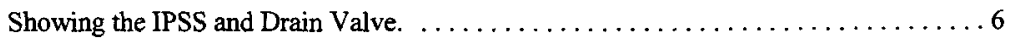

Figure 5. Partial Elevation View of the K-West Basin SLOP

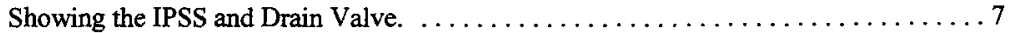

Figure 6. Logic Diagram and Schematic Representing Events That

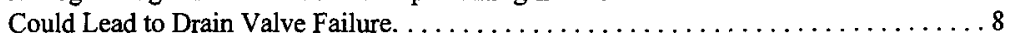

Figure 7. Flow Diagram for Objects Falling Behind the IPSS $\ldots \ldots \ldots \ldots \ldots \ldots \ldots$

Figure 8. Event Tree for Objects Falling Behind the IPSS $\ldots \ldots \ldots \ldots \ldots \ldots \ldots \ldots$

Figure 9. Flow Diagram for Objects Falling Within the Footprint

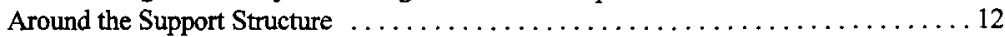

Figure 10. Event Tree for Objects Falling Within the Footprint Around the IPSS $\ldots \ldots \ldots 13$

Figure 11. Risk Curves for the Frequency of Drain Valve Failure Per Year

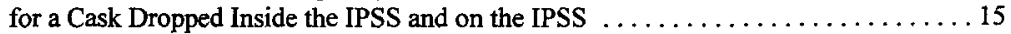

Figure 12. Risk Curves for the Frequency of Drain Valve Failure Per Year

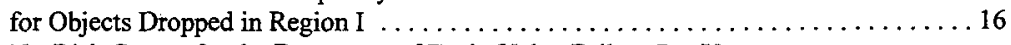

Figure 13. Risk Curves for the Frequency of Drain Valve Failure Per Year

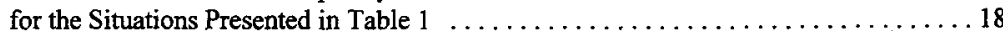

\section{TABLES}

Table 1. Summary of the Drain Valve Failure Frequencies Per Year . . . . . . . . . . . 17

Table 2. Summary of the Drain Valve Failure Frequencies Per Year for Objects Falling in Region I. 


\section{ACRONYMS}

$\begin{array}{ll}\text { ASTM } & \text { American Society of Testing and Materials } \\ \text { DBA } & \text { design basis accident } \\ \text { DBE } & \text { design basis earthquake } \\ \text { CCDF } & \text { Complementary Cumulative Density Function } \\ \text { IPSS } & \text { Immersion Pail Support Structure } \\ \text { MCO } & \text { Multi-Canister Overpack } \\ \text { NRC } & \text { U.S. Nuclear Regulatory Commission } \\ \text { PDF } & \text { Probability Density Function } \\ \text { PGA } & \text { Peak Ground Acceleration } \\ \text { RCR } & \text { Review Comment Record } \\ \text { SLOP } & \text { South Loadout Pit } \\ \text { SNF } & \text { Spent Nuclear Fuel } \\ \text { UNS } & \text { Unified Numbering System }\end{array}$




\subsection{INTRODUCTION}

The Spent Nuclear Fuel (SNF) Project will transfer SNF using a Multi-Canister Overpack (MCO) loaded into a cask. In the case of the K-West Basin, the fuel transfer will be conducted through the South Loadout Pit (SLOP) using a cask loading system. The empty MCO and cask will be lifted from the transport truck and placed into an immersion pail that is contained in the immersion pail support structure (IPSS). The immersion pail is used to minimize contamination of the MCO and cask during the fuel loading operation. The IPSS is used to suspend and support the immersion pail containing the MCO and cask at the desired elevation in the SLOP.

The initial basis for the design, fabrication, installation, and operation of the cask handling and loading system in the SLOP was that the worst case cask drop event would not result in basin leakage rates that are excessive relative to recovery operations. Therefore, drop analyses have been completed to evaluate the potential for a cask drop event damaging the basin concrete and creating a sufficient leak path through the basin floor.

An additional leak path of water from the $\mathrm{K}$-Basins is potentially through the basin drain valves. Each basin was constructed with eight (8) drain valves. Four-inch valves are located in the Weasel Pit, the two loadout pits, the technical view pit, and the discharge chute. Twelve-inch valves are located in the main basin bays. The sumps containing the valves are filled with concrete, partially covering the valves. Visual observations suggest that only a few inches of the valve's bonnet is exposed in the SLOP. It was recognized that damage of the drain valve bonnet or stem during construction, installation, or operation of the cask loading system would provide a potential leak path of water from the K-West Basin.

The objective of this activity is to evaluate the risk of damaging the drain valve during installation or operation of the cask loading system. In the analysis it was assumed that a damaged drain valve would lead to the potential for water being released from the $\mathrm{K}$ Basin. The scope of the risk evaluation is to specifically consider the risk of drain valve damage in the SLOP of the K-West Basin only. For the K-West Basin SLOP, the IPSS has already been installed but the immersion pail has not been installed in the IPSS.

The drain valve damage risk assessment is a risk-based uncertainty analysis where best engineering judgement is used to represent each variable in the analysis. The uncertainty associated with each variable is represented by a probability distribution (probability density function). Uncertainty exists because of the normal randomness associated with the distribution of values that a variable may assume, and because of a lack of knowledge concerning a variable. Engineering judgement and technical information are used to develop the variable probability density functions, while the bounds of the probability density function are based on physical 
limitations. The uncertainty, described by probability distributions, is propagated through the analysis by Monte Carlo convolution techniques. The corresponding results are developed as a probability distribution and the risk is expressed in terms of the corresponding complementary cumulative distribution function (CCDF) ("risk curve"). The total risk is the area under the "risk curve".

The following sections provide summaries of: 1) background information relative to the risk analysis process, 2) a description of the K-West Basin SLOP cask loading system, 3) the evaluation process, and 4) the results of the risk analysis process. Technical details and specific analyses required to support the information provided in the main sections of this document are provided in Appendices A, B, C, D, and E. Documentation that the models were validated and independently reviewed is provided in Appendix $\mathrm{F}$.

\subsection{RISK BACKGROUND AND UNCERTAINTY ANALYSIS PROCESS}

The conventional concept of risk is defined by the triplet questions (Kaplan and Garrick 1981):

What can go wrong?

How likely is it to happen?

If it does happen, what are the consequences?

What can go wrong is defined by a complete set of events, $\left\{\mathrm{E}_{\mathrm{f}}\right\}$. How likely is each event is defined by either the event probability or the event frequency, $P_{j}$ or $f_{j}$. The consequence of the event is defined by $\mathrm{C}_{j}$. The risk is defined by the complete set of triplets;

$$
\mathbf{R} \equiv\left\{\left[\mathbf{E}_{\mathbf{j}}, \mathbf{P}_{\mathrm{j}}, \mathrm{C}_{\mathrm{j}}\right]\right\} .
$$

The "risk curve" for the complete set of triplets given in Equation 1 is the CCDF of the event probabilities (or frequencies) as a function of the event consequences. The risk curve provides the probability (or frequency) of exceeding a specific consequence (exceedance probability or exceedance frequency), and the area under the risk curve is the total risk. An example of a distribution for a complete set of consequences and the corresponding "risk curve" (CCDF) are given in Figure 1. 


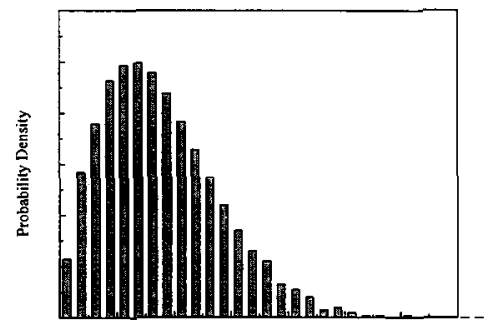

Consequence

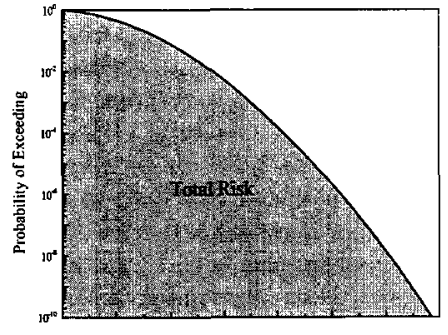

Consequence

Figure 1. Example of a Distribution of Consequences and the Associated "Risk Curve".

For this analysis, the consequence is defined as the potential for water being released from the $\mathrm{K}$ Basin via the drain valve system. Specifically,

Drain Valve Failure is defined as the loss of the drain valve pressure boundary integrity such that water may be released from the $\mathrm{K}$ Basin via the drain system.

A drain valve failure does not imply that large leakage rates will occur from the basin, rather a failure is defined as a condition where the integrity of the valve has been compromised. The objective of this risk-based uncertainty evaluation is to determine if the risk of drain valve failure is low enough to allow installation and operational activities in the K-West Basin to proceed with an unprotected drain valve. Figure 2 provides a simplified decision tree which illustrates the decision that must be made. 


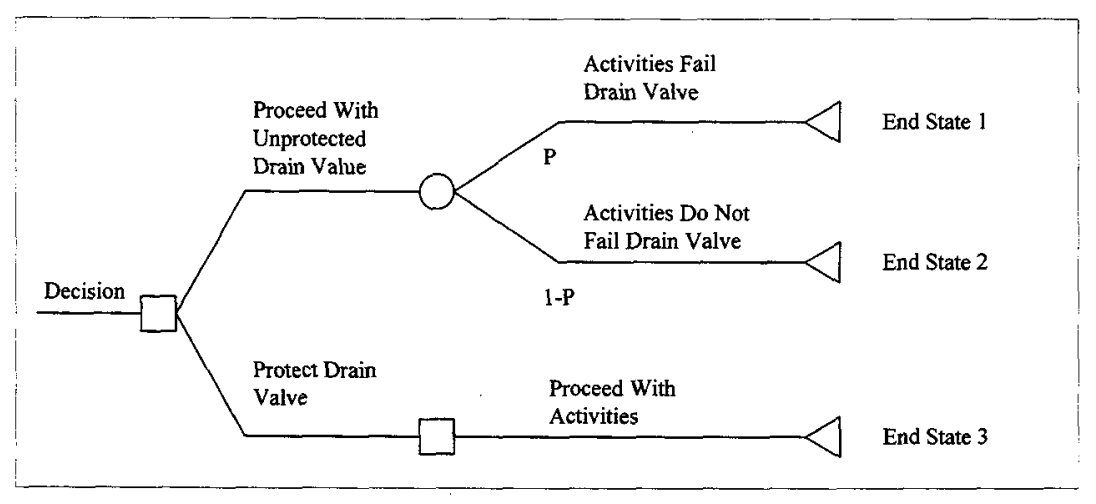

Figure 2. Simplified Decision Tree.

The objective then is to define the complete set of events that could lead to drain valve failure, $\left\{\mathrm{E}_{\mathrm{j}}\right\}$, and to quantify the net probability of drain valve failure ( $\mathrm{P}$ in Figure 2$)$. The risk will be expressed as the probability of drain valve failure and will be determined by a risk curve with the area under the risk curve equal to the net probability of drain valve failure.

The process that will be used to evaluate the probability of drain valve failure is depicted in Figure 3. Uncertainty associated with each variable in the risk assessment will be represented by a probability density function. As noted earlier, engineering judgement and technical information are used to develop the variable probability density functions, but the bounds of the probability density function are based on physical limitations. The uncertainty associated with each variable is propagated through an appropriate risk assessment model using Monte Carlo convolution techniques. The results are a probability distribution; in this case a distribution in the probability of drain valve failure. The risk curve is the CCDF of the probability density function. For this analysis the risk curve expresses the likelihood that the probability of drain valve failure will exceed a specified value (i.e., a small likelihood that the drain valve failure will be larger than $\mathrm{x}$ ). The area under the risk curve represents the net probability of drain valve failure.

A major step in the risk assessment is to develop a model that will be used to quantify the probability of drain valve failure and through which variable uncertainties can be propagated. Development of the appropriate model $[y=f(a, b, c, \ldots$.$) in Figure 3]$ will be presented in a later section. 


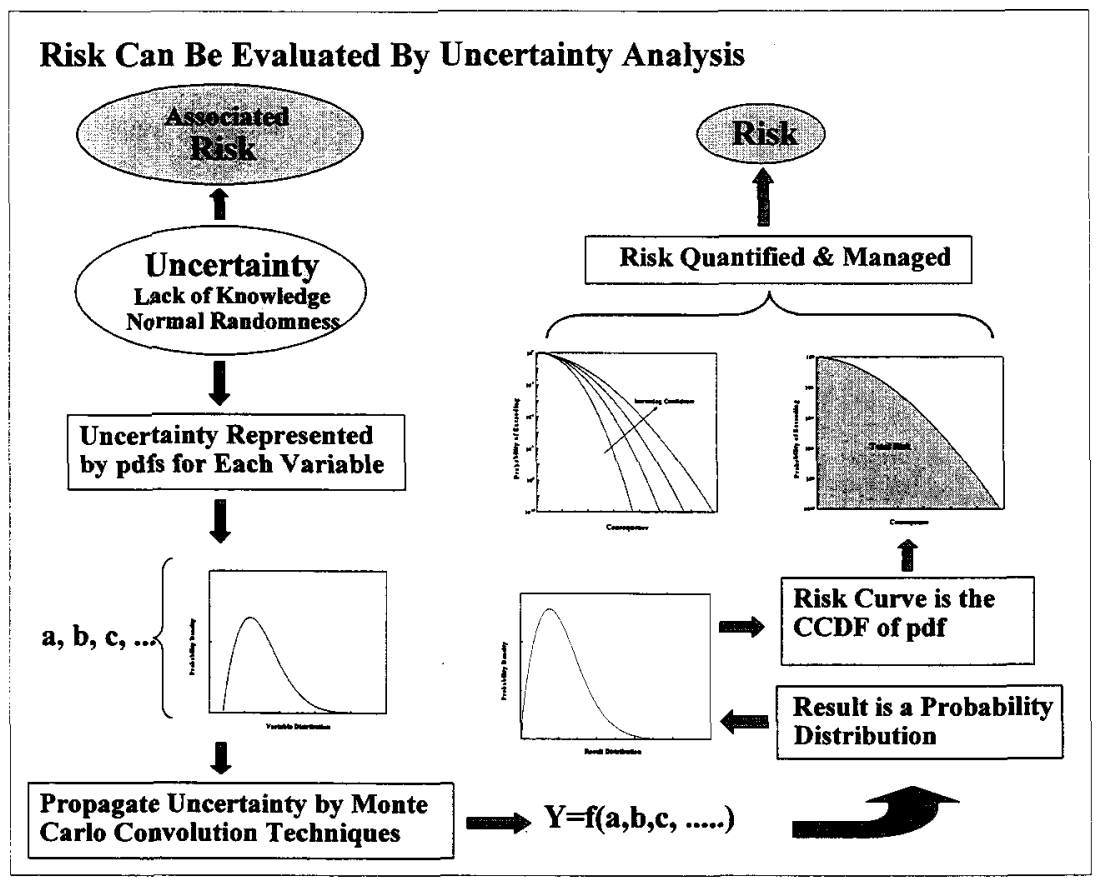

Figure 3. Schematic of Risk-Based Uncertainty Analysis.

\subsection{DESCRIPTION OF K-WEST BASIN SLOP}

A plan view of the K-West Basin SLOP is shown in Figure 4, and a partial elevation view is shown in Figure 5. Figure 4 shows the eight vertical rails that are permanently attached to the concrete walls of the SLOP that will be used to position the IPSS. The IPSS is shown in Figure 4 and partially shown in Figure 5 with its four leg structures. Each leg is supported by a leveling foot. The IPSS base plate is 1.5 -in thick, and the side plates are 0.5 -in thick. Figures 4 and 5 also show the location of the 4-in drain valve in the sump which has been filled with concrete. 


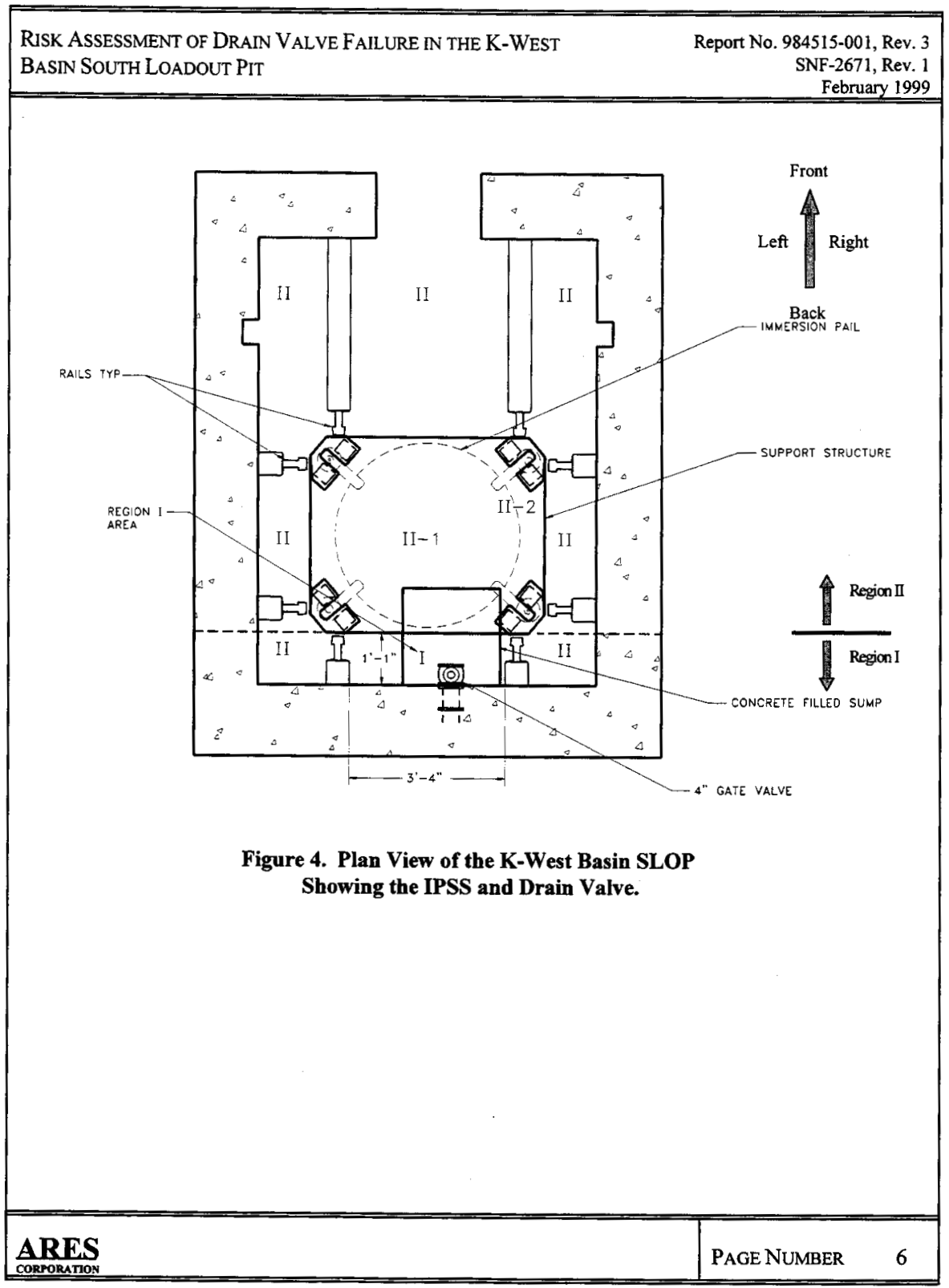




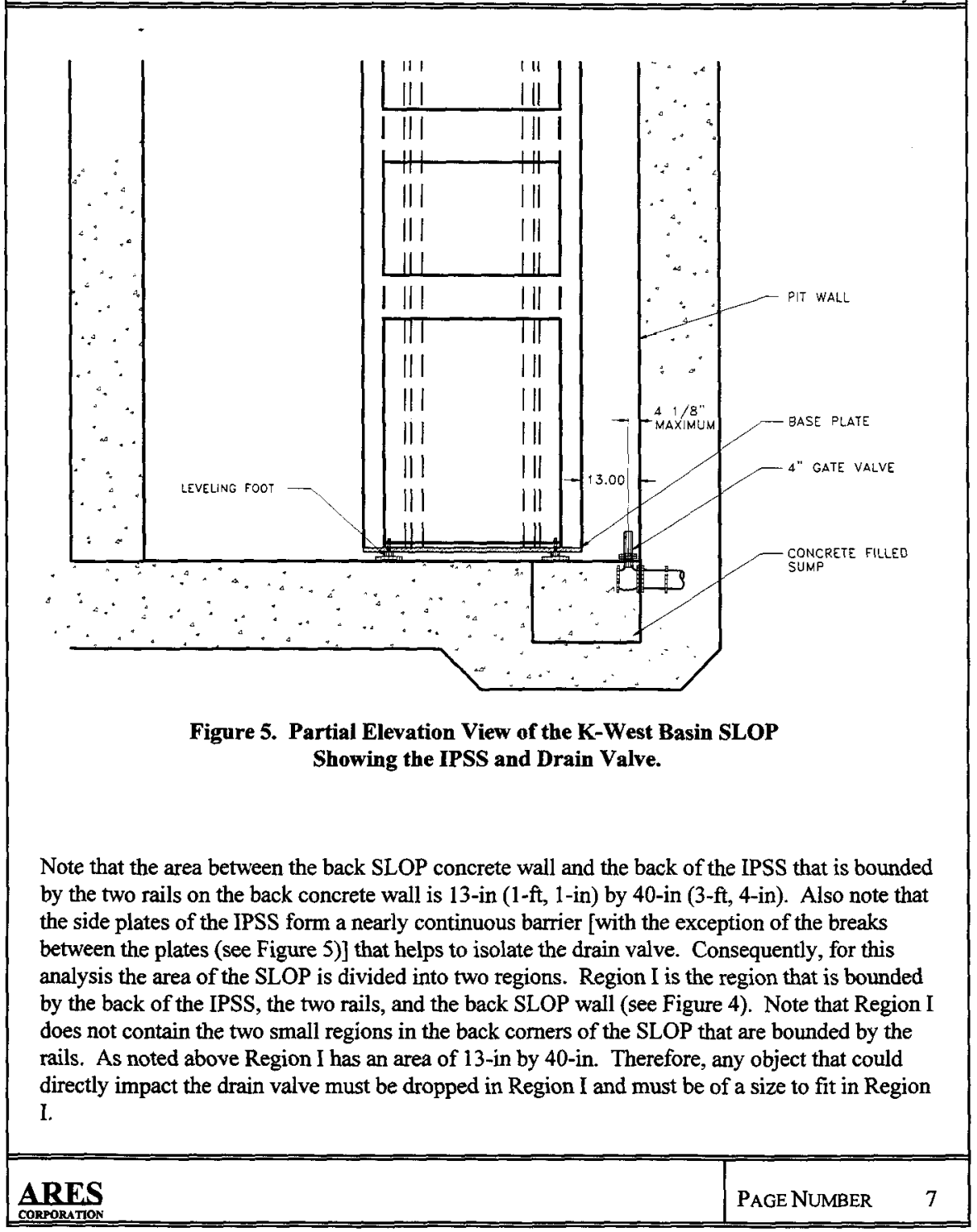


Region II is defined to be the region of the SLOP that does not include Region I. Thus, Region II is the rest of the SLOP, including the IPSS. There are four small regions contained in Region II; these are the areas bounded by the rails and the IPSS side plates.

\subsection{EVALUATION PROCESS}

The events that could lead to drain valve failure are: 1) energy directly imparted to the drain valve from an object dropped into the SLOP, 2) excessive energy imparted to the IPSS which in turn imparts energy to the drain valve, or 3) energy imparted to the concrete that is transmitted via the concrete to the drain valve. These three events are depicted in the logic diagram and schematic in Figure 6. Dropping an object into the SLOP will be addressed for both Region I and Region II. Imparting energy to the drain valve via the IPSS or the concrete will be addressed in connection with dropping an object in Region II.
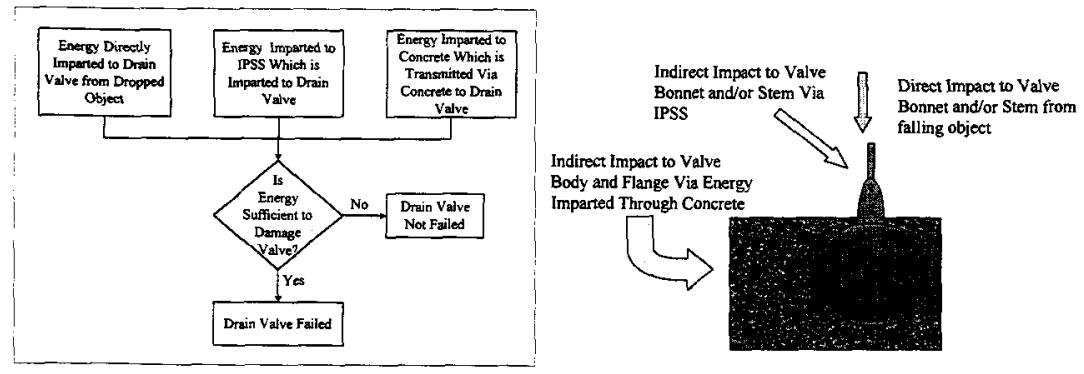

Figure 6. Logic Diagram and Schematic Representing Events That Could Lead to Drain Valve Failure.

\section{Region I}

A flow diagram that outlines the events for an object that is dropped within the footprint of Region I is shown in Figure 7. If the object is not small enough to fit within the footprint of Region I (13-in by 40 -in) then the object will not be able to strike or impart energy directly to the drain valve. 


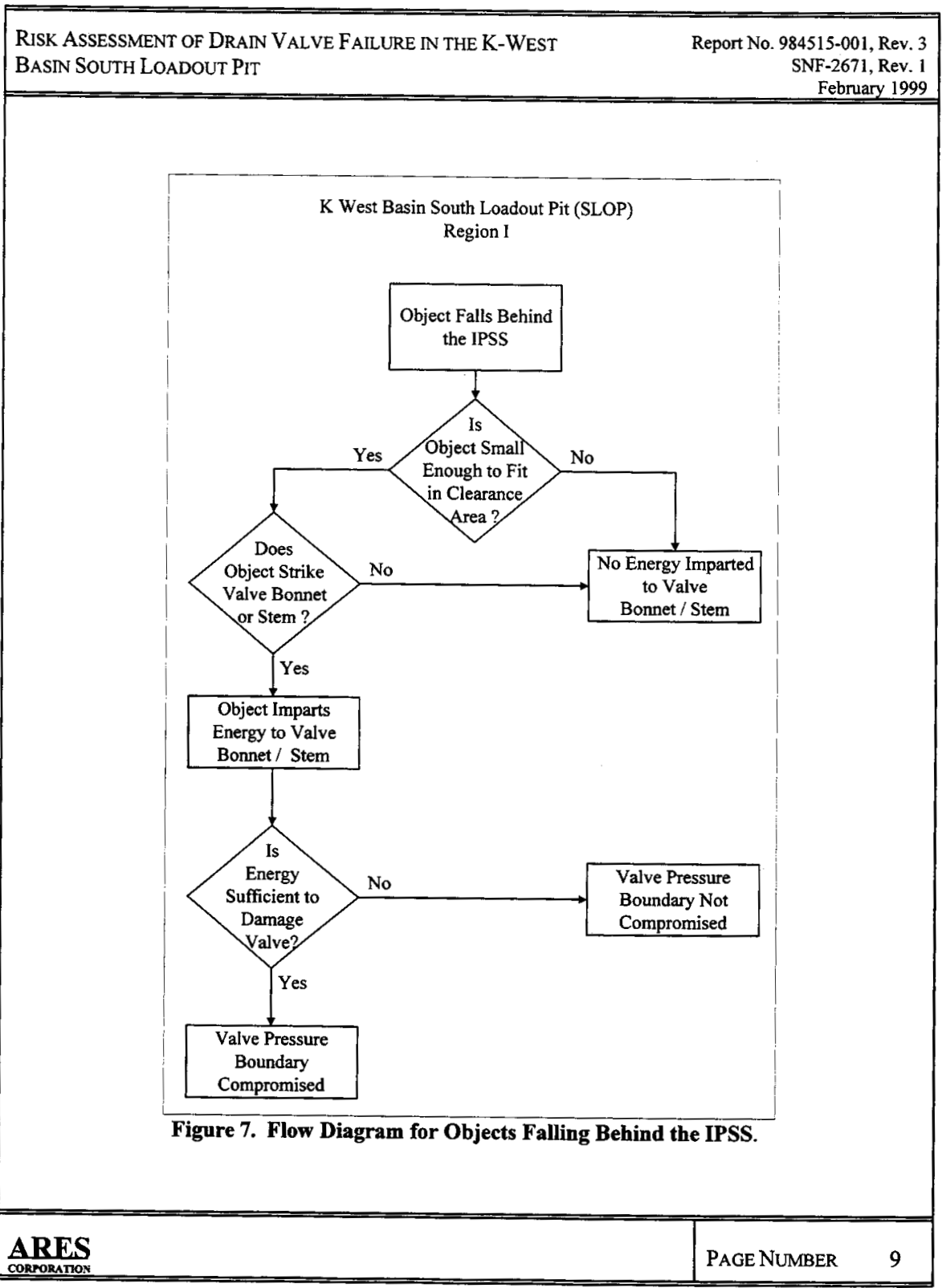


If the object fits within the footprint of Region I but does not strike the drain valve bonnet or stem, then no energy would be imparted to the drain valve. On the other hand, if the object strikes the drain valve bonnet or stem, but does not impart sufficient energy to damage the drain valve, then the drain valve pressure boundary would not be compromised. An event tree that mirrors the events of the flow diagram in Figure 7 is shown in Figure 8. Only event sequence Number 4 would lead to drain valve failure (pressure boundary being compromised).

Because of the physical restraints imposed on the size of objects that could be dropped in Region I, large, heavy objects were excluded from the Region I analysis. Thus, the analysis in Region I focuses on smaller, lighter objects that may be dropped and directly impact the drain valve.

\begin{tabular}{|c|c|c|c|c|c|c|}
\hline $\begin{array}{l}\text { Object Falls } \\
\text { Behind Support } \\
\text { Structure }\end{array}$ & $\begin{array}{l}\text { Object Fits in } \\
\text { Clearance Area }\end{array}$ & $\begin{array}{l}\text { Object Strikes } \\
\text { Valve Bonnet or } \\
\text { Stem }\end{array}$ & $\begin{array}{l}\text { Imparted Energy } \\
\text { is Sufficient to } \\
\text { Damage Valve }\end{array}$ & $\begin{array}{l}\text { Valve Pressure } \\
\text { Boundary is } \\
\text { Compromised }\end{array}$ & No. & Probability \\
\hline \multirow[t]{5}{*}{$P_{\text {or }}$} & No & & & No & 1 & $P_{O F}\left(1-P_{1}\right)$ \\
\hline & $\begin{array}{l}1-P_{1} \\
\text { Yes }\end{array}$ & No & & No & 2 & $\mathrm{P}_{\mathrm{OF}} \mathrm{P}_{1}\left(1-\mathrm{P}_{2}\right)$ \\
\hline & $P_{1}$ & $\begin{array}{l}1+\mathrm{P}_{2} \\
\text { Yes }\end{array}$ & No & No & 3 & $P_{O F} P_{1} P_{2}\left(1-P_{3}\right)$ \\
\hline & & $\mathrm{P}_{2}$ & $\begin{array}{l}1-P_{3} \\
\text { Yes }\end{array}$ & Yes & 4 & $\mathrm{P}_{\mathrm{OF}} \mathbf{P}_{1} \mathbf{P}_{2} \mathbf{P}_{3}$ \\
\hline & & & $P_{3}$ & & & \\
\hline
\end{tabular}

Figure 8. Event Tree for Objects Falling Behind the IPSS.

\section{Region II}

In Region II there are several situations or areas for which any impact on the drain valve can be neglected. First, only small objects could be dropped in the six small Region II areas bounded by the rails and the IPSS. Because these areas are a sufficient distance from the drain valve and the drain valve is protected by the IPSS, the only mechanism for transporting energy to the drain valve from these areas is via damage to the concrete. However, these regions are some distance away (greater than two to three feet), and small objects impacting the concrete in these areas would not produce sufficient energy to damage the drain valve. 
Second, large objects that may be dropped in front of the IPSS may damage the concrete but would not have a direct impact on the drain valve. Because of the distance from the front of the IPSS to the drain valve the energy that may be imparted to the concrete from the falling object would not be transmitted to the drain valve (see Appendix A).

Thus, the only situations that need to be evaluated in Region II is dropping large, heavy objects into the IPSS or onto the IPSS. Therefore, this analysis for Region II will only consider dropping the cask with a loaded MCO either into or on the IPSS. A flow diagram that outlines the events for a heavy object that is dropped within the footprint around the IPSS (Region II) is shown in Figure 9.

If a heavy object falls in the footprint around the IPSS, it may fall inside the IPSS or on the IPSS. If the object falls inside the IPSS the resulting situation depends on the position of the immersion pail. When the cask and MCO are outside the cask loading system the immersion pail is pinned at the top of the IPSS. Thus a cask drop at this stage would impact the immersion pail and would likely shear the pins. The cask and immersion pail would then drop and impact the IPSS base plate, causing the entire assembly to transfer energy to the concrete.

If the drop occurs while lifting the immersion pail with the loaded cask and MCO, there would not be any energy lost to shearing the pins. The cask, MCO and immersion pail would impact the IPSS base plate, and the entire assembly would impact the concrete.

In both situations, the energy imparted to the concrete from the falling assembly would crack the concrete. The energy could be transmitted via the concrete to the valve flange and body in the concrete grouted sump. If the energy transmitted to the valve body and flange was sufficient to damage the drain valve, then the drain valve pressure boundary could be compromised.

If the object falls on the IPSS, the energy imparted to the IPSS may be sufficient to fail the IPSS. If the energy is sufficient to fail the IPSS then it is assumed that the IPSS transmits some energy directly to the drain valve bonnet and stem. If the energy transmitted by the IPSS directly to the drain valve bonnet and stem is sufficient, then the drain valve pressure boundary could be compromised.

The energy imparted to the IPSS may also be transferred to the concrete to cause concrete cracking. This energy could then be transmitted via the concrete to the valve flange and body in the concrete grouted sump. This situation is very similar to events where an object falls inside the IPSS. 


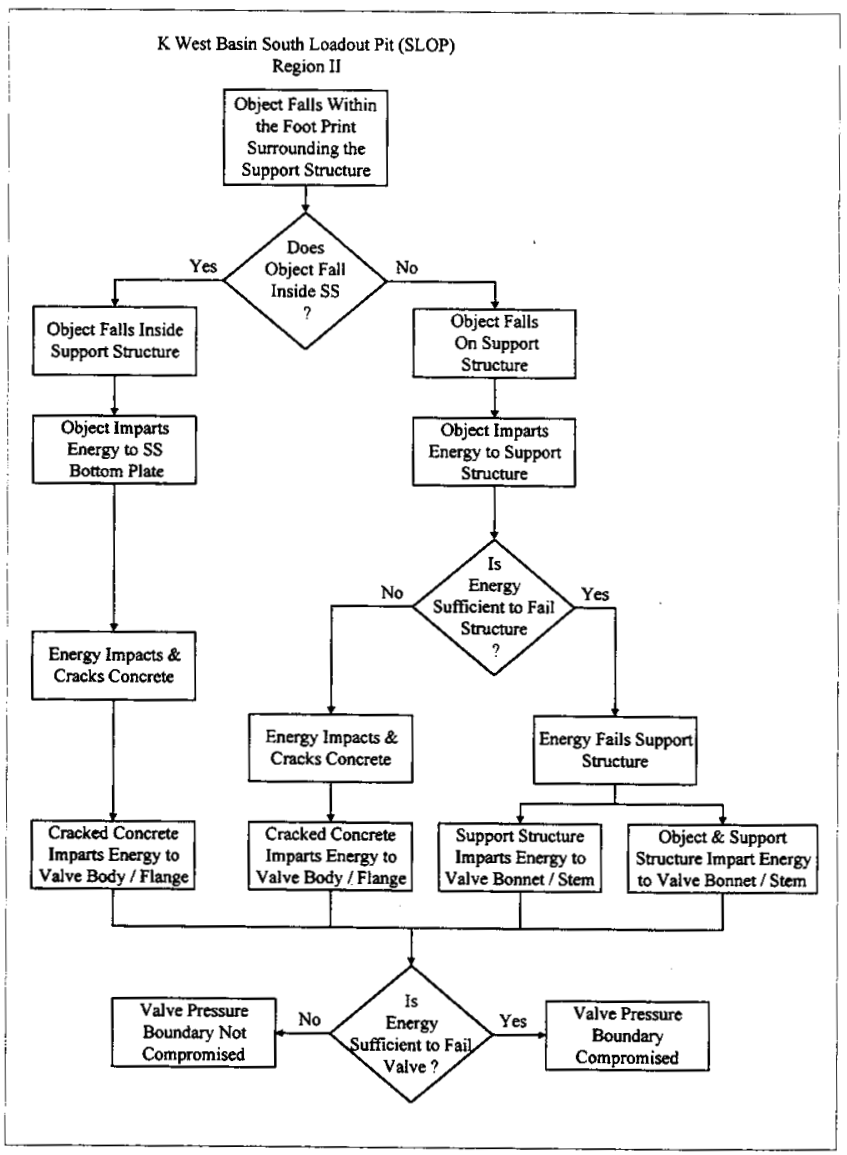

Figure 9. Flow Diagram for Objects Falling Within the Footprint Around the Support Structure. 
An event tree that mirrors the events of the flow diagram in Figure 9 is shown in Figure 10. There are two major branches for this event tree; one where the object falls inside the IPSS and one where the object falls on the IPSS. Events where objects fall onto the IPSS and cause concrete cracking have been combined with events where objects fall inside the IPSS causing concrete cracking. Of the two major branches of Figure 10, only event sequence Number 4 and 8 would lead to drain valve failure (pressure boundary being compromised).

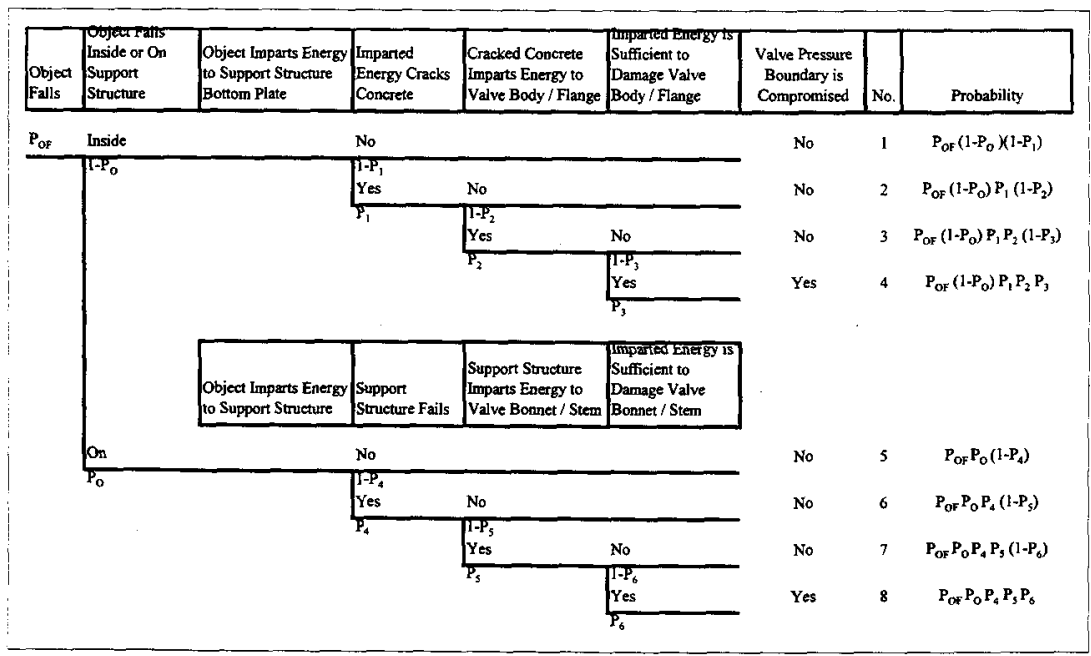

Figure 10. Event Tree for Objects Falling Within the Footprint Around the IPSS.

To complete the uncertainty analysis, the event trees in Figures 8 and 10 need to be solved with appropriate uncertainty distributions for each branch point probability. These uncertainty distributions are discussed and described in Appendix D. 


\subsection{RESULTS}

Appendix D presents the analysis for Region II and the solution of the event tree described in Figure 10. The results are presented in terms of risk curves for the probability of drain valve failure per lift for a cask dropped inside the IPSS and on the IPSS. The frequency per year of drain valve failure is obtained by considering the number of transfer bay crane lifts per year as follows:

$$
200 \mathrm{MCOs} \times \frac{4 \text { lifts }}{\mathrm{MCO}} \times \frac{1}{2 \text { year }}=400 \frac{\text { lifts }}{\text { year }} .
$$

The results of the analysis are presented in Figure 11 (see Appendix D for details) as the probability of exceeding a frequency of drain valve failure per year for a cask dropped inside the IPSS and on the IPSS. Further interpretation of the results provided by Figure 11 will be provided later. 


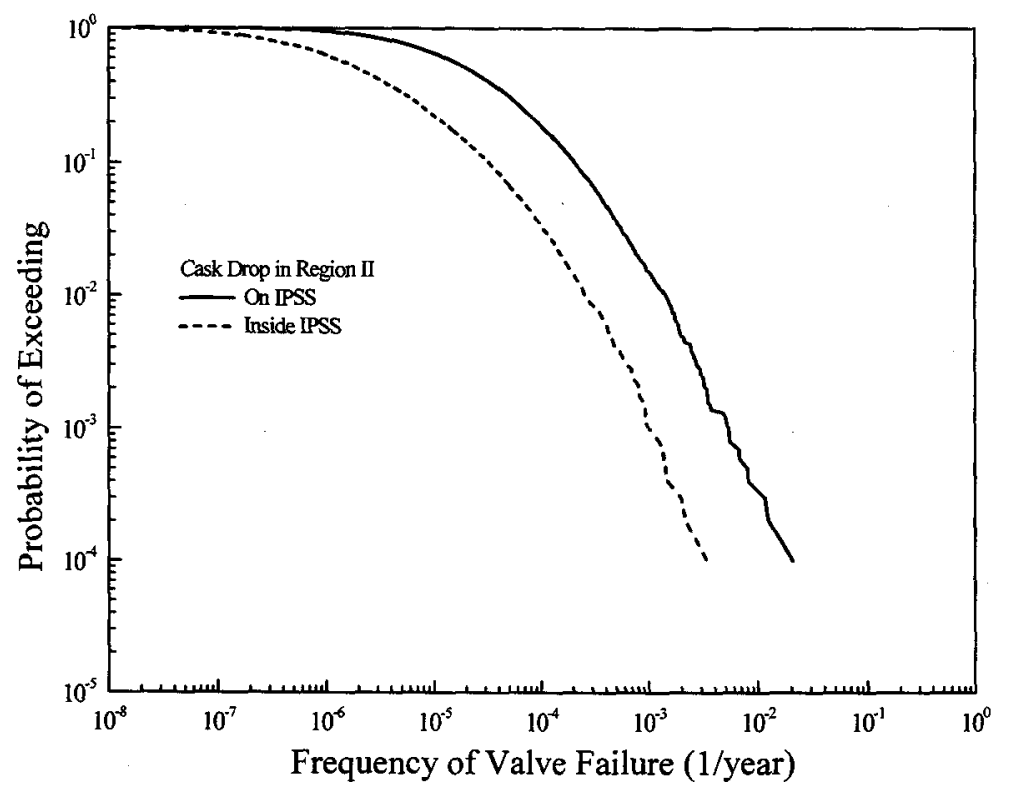

Figure 11. Risk Curves for the Frequency of Drain Valve Failure Per Year for a Cask Dropped Inside the IPSS and on the IPSS.

The analysis for Region I and the solution of the event tree described in Figure 8 is also presented in Appendix $\mathrm{D}$ for two groups of objects. Appendix $\mathrm{C}$ developed the probability of valve damage as a function of the weight of the falling object. From the information presented in Appendix C, the analysis for Region I was divided into two groups of object weights. The first group was for objects with weight less than $50 \mathrm{lb}$ for which the probability of valve damage if the object impacted the valve bonnet or stem was treated as a lognormal distribution around a median value of 0.5 . The second group was for objects with weight larger than $50 \mathrm{lb}$ for which the probability of valve damage if the object impacted the valve bonnet or stem was taken to be approaching 1. 
The analysis for Region I was also performed in terms of the drain valve failure per lift. The possible number of lifts that may be made in a year for the small $(0 \leq \mathrm{W} \leq 50 \mathrm{lb})$ and heavier objects $(50 \leq \mathrm{W})$ is hard to estimate. Therefore, two approaches were taken. The first assumed that there would be as many lifts for the small or heavier objects in Region I as there were for the lifts using the transfer bay crane (i.e., 400 lifts/year). The second approach was to treat the number of lifts as a distribution that ranged from 1 to 400 with a median value of 100 lifts per year. The first approach would provide valve failure frequencies per year that would be comparable to values for a cask drop in Region II. However, it seems that this approach may tend to over estimate the number of lifts per year. The second approach allows for the number of lifts per year to be varied, and, therefore, may be more realistic. Using the second approach, the risk curves for the frequency of drain valve failure per year for objects dropped in Region I are presented in Figure 12.

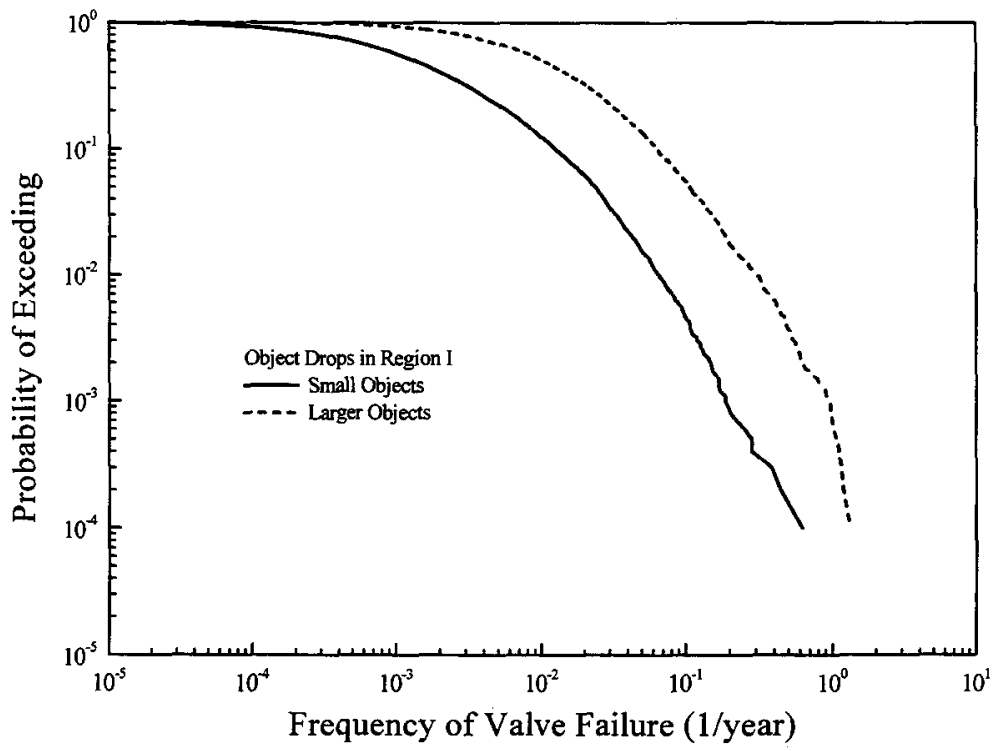

Figure 12. Risk Curves for the Frequency of Drain Valve Failure Per Year for Objects Dropped in Region I. 
The results of the risk curves shown in Figures 11 and 12 are summarized in Table 1. Also shown in Table 1 for comparison is the risk of $\mathrm{K}$ Basin being damage from a seismic event (see Appendix $\mathrm{E}$ for details). The risk curves for each of the regions identified in Table 1 are presented in Figure 13.

Table 1. Summary of the Drain Valve Failure Frequencies Per Year.

\begin{tabular}{|c|c|c|c|c|}
\hline \multirow[b]{2}{*}{ Region } & \multicolumn{4}{|c|}{ Valve Failure Frequency Per Year } \\
\hline & $\begin{array}{c}10^{\mathrm{t}} \\
\text { Percentile }\end{array}$ & Percentile & $\begin{array}{l}90^{\text {t }} \\
\text { Percentile }\end{array}$ & $\begin{array}{c}\text { Net Tota } \\
\text { Risk }\end{array}$ \\
\hline Region I - Small Objects & $1.3 \times 10^{-4}$ & $1.3 \times 10^{-3}$ & $1.3 \times 10^{-2}$ & $5.5 \times 10^{-3}$ \\
\hline Region I - Larger Objects & $1.4 \times 10^{-3}$ & $1.0 \times 10^{-2}$ & $6.4 \times 10^{-2}$ & $2.8 \times 10^{-2}$ \\
\hline Region II - Inside IPSS & $1.3 \times 10^{-7}$ & $2.0 \times 10^{-6}$ & $3.3 \times 10^{-5}$ & $1.7 \times 10^{-5}$ \\
\hline Region II - On IPSS & $1.8 \times 10^{-6}$ & $2.1 \times 10^{-5}$ & $2.1 \times 10^{-4}$ & $1.0 \times 10^{-4}$ \\
\hline Seismic Damage of Basin & $7.7 \times 10^{-6}$ & $6.0 \times 10^{-5}$ & $4.7 \times 10^{-4}$ & $2.1 \times 10^{-4}$ \\
\hline
\end{tabular}

The risk of a drain valve failure in the $\mathrm{K}$ Basin SLOP is reasonably small for a cask drop either inside or on the IPSS (a 90 percent confidence that the valve failure frequency would be less than $2 \times 10^{-4}$ per year to $3 \times 10^{-5}$ per year) and is the same order of magnitude as the risk of having water drain from the $\mathrm{K}$ Basin following a seismic event. However, the risk of a drain valve failure for an object dropped in Region I is much larger; a 90 percent confidence that the valve failure frequency would be less than 1 to $6 \times 10^{-2}$ per year. 


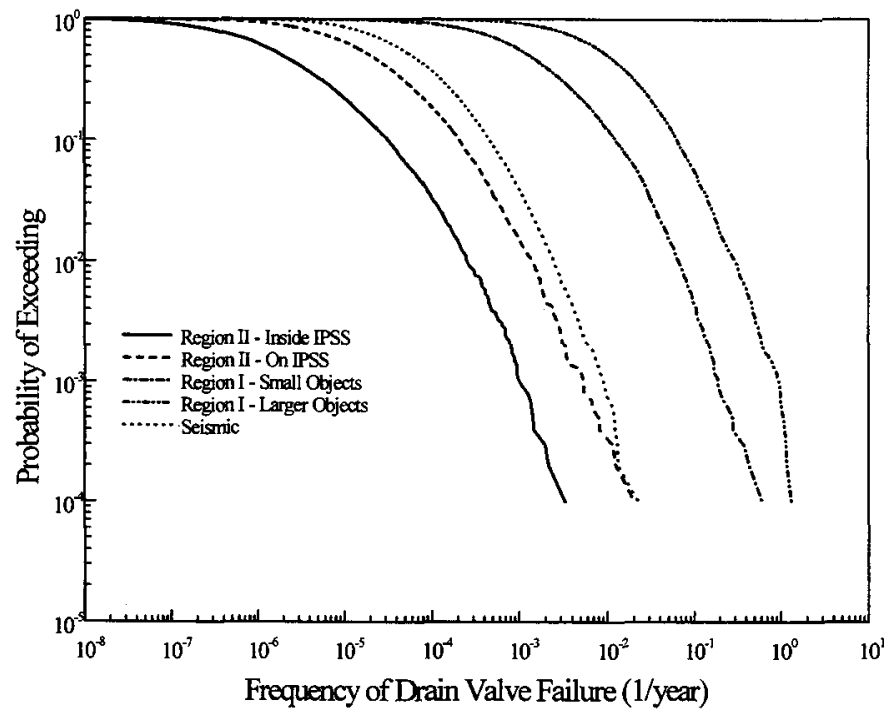

Figure 13. Risk Curves for the Frequency of Drain Valve Failure Per Year for the Situations Presented in Table 1.

\subsection{DEFENSE IN DEPTH MEASURE}

An impact limiter has been designed to limit the impact to the four-inch drain valve from any objects that may be dropped in Region I behind the IPSS. The impact limiter is designed to: 1) withstand the impact of a $550 \mathrm{lb}$ object falling $45 \mathrm{ft}$ without failing and impacting the drain valve, and 2) withstand a $100 \mathrm{lb}$ object falling $45 \mathrm{ft}$ with an impact area of one or two sq in, respectively, without piercing the top of the impact limiter. Therefore, the impact limiter will withstand an impact energy of $24,750 \mathrm{ft} \mathrm{lb}$, or a piercing impact energy density of 2,250 to 4,500

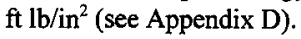


Recall in Table 1 that small objects are objects whose weight is from zero to fifty pounds, while large objects are objects whose weight is larger than fifty pounds. Standard industrial practices limit hand lifting to objects whose weight is less than or equal to $50 \mathrm{lb}$. Objects whose weight is larger than $50 \mathrm{lb}$ are handled by lifting devices. For small objects $(0 \leq \mathrm{W} \leq 50 \mathrm{lbs})$ the impact limiter will prevent any drain valve damage since the failure probability at an impact energy of $2,250 \mathrm{ft} \mathrm{lb}$ is approaching zero (see Appendix D). For larger objects whose weight is up to 550 $\mathrm{lb}$ (impact energy $=24,750 \mathrm{ft} \mathrm{lb}$ ) the impact limiter failure probability is also essentially zero (smaller than three to four orders of magnitude, $10^{-3}$ to $10^{-4}$, see Appendix D). The cask handling fixture is the largest object that will be used in the SLOP above Region I. This fixture weighs approximately $550 \mathrm{lb}$. Therefore, for most objects that may be used above the four-inch drain valve located in the SLOP, the impact limiter would prevent any drain valve damage should an object be dropped in Region I. With the impact limiter the frequency of drain valve failure per year is considerably reduced as illustrated in Table 2 . Thus, with the impact limiter there is a 90 percent confidence that the drain valve failure is less than $1 \times 10^{-6}$ per year.

Table 2. Summary of the Drain Valve Failure Frequencies Per Year for Objects Falling in Region $I$.

\begin{tabular}{|c|c|c|c|c|}
\hline \multirow[b]{2}{*}{ Region I } & \multicolumn{4}{|c|}{ Valve Failure Frequency Per Year } \\
\hline & Percentile $^{10^{\text {th }}}$ & $\begin{array}{l}50^{\mathrm{th}} \\
\text { Percentile }\end{array}$ & $\begin{array}{l}90^{\mathrm{m}} \\
\text { Percentile }\end{array}$ & $\begin{array}{l}\text { Net Total } \\
\text { Risk }\end{array}$ \\
\hline Small Objects & $1.3 \times 10^{-4}$ & $1.3 \times 10^{-3}$ & $1.3 \times 10^{-2}$ & $5.5 \times 10^{-3}$ \\
\hline With Impact Limiter & $<1 \times 10^{-8}$ & $<1 \times 10^{-8}$ & $<1 \times 10^{-8}$ & $<1 \times 10^{-8}$ \\
\hline Larger Objects & $1.4 \times 10^{-3}$ & $1.0 \times 10^{-2}$ & $6.4 \times 10^{-2}$ & $2.8 \times 10^{-2}$ \\
\hline With Impact Limiter & $<1 \times 10^{-7}$ & $<1 \times 10^{-6}$ & $<6 \times 10^{-6}$ & $<3 \times 10^{-6}$ \\
\hline
\end{tabular}

\subsection{CONCLUSIONS AND RECOMMENDATIONS}

The risk of having a drain valve failure from a cask drop into or on the IPSS is approximately the same order of magnitude as the corresponding risk from a seismic event damaging the $\mathrm{K}$ Basins. On the other hand, the risk of small objects falling into Region I and damaging the drain valve is several orders of magnitude larger. As discussed in Appendix $C$ and D, failure of the valve is defined as the conditions that might result in the release of water from the basin. Such failures 
do not imply that large leakage rates will result should the drain valve pressure boundary be compromised.

The risk of drain valve failure from a cask drop into or on the IPSS is reasonably small with a 90 percent confidence that the valve failure frequency per year is less than $2 \times 10^{-4}$ per year to $3 \times 10^{-5}$ per year. The total failure frequency for these events is from $1 \times 10^{-4}$ to $2 \times 10^{-5}$ per year.

The largest risk comes from the potential for dropping objects ( $\mathrm{W} \geq 50 \mathrm{lb}$ ) in Region I behind the IPSS. However, the impact limiter will reduce this risk by greater than four orders of magnitude (see Table 2). There is another reasonable and cost effective solution to reducing this risk. If a grating or plate were placed at the top of the SLOP above the area bounded by the back of the IPSS and the wall of the SLOP (Region I), then the probability that an object could fall in the clearance area $\left(\mathrm{P}_{1}\right.$ in the event tree of Figure 8$)$ would be much smaller, approaching zero. The actual reduction in probability would be determined by the configuration of the grating or plate. Even a grating that reduces the probability of objects falling in the clearance area by $10^{3}$ results in a significant reduction in the overall risk of damaging the drain valve (a risk of less than $1 \mathrm{x}$ $10^{-7}$, or a reduction in risk of three orders of magnitude). Therefore, any grating or plate that substantially reduces the likelihood of objects falling into Region I would greatly reduce the overall risk.

\subsection{REFERENCES}

ASTM 1997, Annual Book of ASTM Standards, Vol. 2.01.

Beer, F. P, and Johnston, E. R, 1981, Mechanics of Material, McGraw-Hill, New York.

Chenault, D. M., 1997a, Cask Drops Onto the K-Basins Immersion Pail Support structure, HNF-1789, Rev. 0, DE\&S Hanford, Inc., Richland, Washington.

Chenault, D. M., 1997b, Cask and Pail Drop Onto The K Basin Immersion Pail Support Structure Bottom Plate, HNF-1897, Rev. 0, DE\&S Hanford, Inc., Richland, Washington.

Hanford 1997, Engineering Change Notice 645560.

Kanjilal, S. K., 1997, Seismic Qualification of 105-K Basin Superstructure Using 0.12g Earthquake Ground Acceleration, HNF-SD-SNF-SA-004, Rev. 0, Fluor Daniel Northwest, Richland, Washington. 
Kaplan, S. and Garrick, J. B., On The Quantitative Definition of Risk, Risk Analysis, Vol. 1, No. 1, pp. 11-27.

Kee, A. T., 1997, SNF Cask Drop Analysis For K-Basin Loadout Pits, HNF-SD-SNF-ANAL020, Rev. 0, prepared by MCE Engineering for DE\&S Hanford, Inc., Richland, Washington.

Kennedy, R. P., et al., 1980, Probabilistic Seismic Study of an Existing Nuclear Power Plant, Nuclear Engineering and Design, Vol. 59.

Kennedy, R. P., and Short, S. A., 1994, Basis For Seismic Provisions of DOE-STD-1020, UCRL-CR-11 1478 (BNL-524218) Lawrence Livermore National Laboratory, University of California, Livermore, California.

Lindeburg, M.R., 1997, Mechanical Engineering Reference Manual, Professional Publications, Belmont, California.

NRC 1980, Control Of Heavy Loads At Nuclear Power Plants, NUREG-0612, U.S.

Nuclear Regulatory Commission, Washington, D.C.

NRC 1985, Handbook of Nuclear Power Plant Seismic Fragilities, NUREG/CR-3558,

U.S. Nuclear Regulatory Commission, Washington, D. C.

Rasmussen, R. W., 1997, Cask Immersion Pail Support Structure Drop Analysis and Installation Recommendation, Letter to R. J. Lodwick, 97-RWR-008, DE\&S Hanford, Inc., Richland, Washington.

Rodgers, L. A., 1996, Functions And Requirements For K Basins Transfer Bay Cranes, Project $A-5$ and $A-6$, WHC-SD-SNF-FRD-023, Rev. 0, Westinghouse Hanford Company, Richland, Washington.

Schifferl, D. L., 1998, K-Basins Drain Valve Corrosion Evaluation, HNF-2159, Rev. 0, DE\&S Hanford, Inc., Richland, Washington.

Tallman, A. M., 1996, Probabilistic Seismic Hazard Analysis, DOE Hanford Site, Washington, WHC-SD-W236A-TI-002, Rev. 1, Westinghouse Hanford Company, Richland, Washington. 
RISK ASSESSMENT OF DRAIN VALVE FAILURE IN THE K-WEST

Report No. 984515-001, Rev. 3

BASIN SOUTH LOADOUT PIT SNF-2671, Rev. 1

February 1999

Van Vlack, L. H., 1985, Elements of Material Science and Engineering, Addison-Welsey Publishing, Reading, Massachusetts.

Winkel, B. V., 1991, 105-KE /105-KW Irradiated Fuel Storage Basins Seismic Qualification, WHC-SD-NR-SA-024, Rev. 0, Westinghouse Hanford Company, Richland, Washington. 


\section{Appendix A}

Summary of K-West Basin South Loadout Pit Drop Analyses 


\section{A.1 INTRODUCTION}

Several drop analyses have been completed for the K Basin SLOP. These drop analyses are briefly summarized below to highlight some of the pertinent information that is useful for the risk-based uncertainty analysis. Provided first, however, is a summary of a corrosion evaluation that was completed for the $\mathrm{K}$ Basin drain valves.

\section{A.2 EVALUATION OF CORROSION (Schifferl 1998)}

In the K-West Basin, the drain valves were closed and the sumps were filled with concrete to seal them and prevent leakage. The basin and exposed portions of the valves were coated with an epoxy paint that is still adherent. Visual observations suggest the coating appears to be intact and shows no staining, blistering or spalling. Based on the inspections, no visible corrosion could be detected. The packing gland and bonnet attachment bolts and nuts do not show active corrosion in either basin. The absence of such indications suggest that very little corrosion has occurred in either basin since the valves were coated. The corrosion rate is estimated to be 1.0 to $1.9 \mathrm{mpy}$ ( 0.0010 to 0.0019 in per year). The total corrosion during the last 40 plus years is estimated to be 67 mils for K-West Basin. The results suggest that there is no corrosion leak scenario that would perforate or seriously impair the integrity of any part of the valves. Graphitic corrosion, which could result in loss of structural integrity such that a low level impact might cause brittle fracture of the valve bonnet or body is not a probable failure mechanism.

\section{A.3 FIRST CASK DROP ANALYSIS (Kee 1997)}

This analysis evaluated a postulated SNF cask drop onto the floor of the SLOP in either the KEast or K-West Basin. The cask $(60,000 \mathrm{lb})$ drops $30 \mathrm{ft}$ into the basins. The effects of buoyance are neglected. Average "g" loads ranged from 33 to 165 "g's". The concrete failed allowing a leak path into the subgrade.

\section{A.4 LOWER IMMERSION PAIL SUPPORT STRUCTURE DROP ANALYSIS (Rasmussen 1997)}

The lower frame assembly of the immersion pail support structure (IPSS) $(7,175 \mathrm{lb})$ was modeled considering a drop during a lift over the loadout pit resulting in a $7 \mathrm{ft}$ free fall into the $\mathrm{K}$ Basin water ( $21.23 \mathrm{ft} / \mathrm{sec}$ impact velocity) and a subsequent fall of $21 \mathrm{ft}$ to the bottom of the basin (19.3 $\mathrm{ft} / \mathrm{sec}$ terminal velocity). A drag coefficient of 1.05 was used in the analysis. 


\section{A.5 DROP OF IMMERSION PAIL THROUGH WATER (Rasmussen 1997)}

In this analysis, the immersion pail $(10,825 \mathrm{lb})$ is assumed to be dropped through water $(15.33 \mathrm{ft})$ impacting the bottom at $21.54 \mathrm{ft} / \mathrm{sec}$. The maximum deflection of the support structure center of gravity was 0.93 in at approximately 7 milliseconds. The maximum deflection of the foot was 0.32 in at approximately 9 milliseconds. The support structure deceleration is $114 \mathrm{~g}$. The $0.6 \%$ strain corresponding to concrete crushing extends to approximately $5 \mathrm{in}$, while the $0.3 \%$ strain corresponding to concrete compression cracking extends to approximately $6.75 \mathrm{in}$. The corresponding horizontal $0.6 \%$ strain and $0.3 \%$ strain extend to approximately 4 in to 5 in, respectively.

\section{A.6 LOADED CASK DROP IN AIR ONTO SIDE OF IMMERSION PAIL SUPPORT STRUCTURE (Chenault 1997a)}

In this analysis a fully loaded cask with a loaded MCO $(60,000 \mathrm{lb})$ is assumed to be dropped 2.08 $\mathrm{ft}$ onto one side of the IPSS. The effects of the buoyant force of water were neglected. The final velocity was $11.57 \mathrm{ft} / \mathrm{sec}$. Damage to the concrete directly under the IPSS was evaluated. The plastic strain for concrete compression cracking damage $(0.3 \%$ strain) indicated a crush and cracking to a depth of $5.75 \mathrm{in}$. The cask deceleration was $17.4 \mathrm{~g}$. The maximum deflection of the support structure $\mathrm{CG}$ is 1.27 in at approximately 24 milliseconds. The maximum deflection of the support structure foot is 0.55 in at approximately 25 milliseconds. The cask deceleration is $17.4 \mathrm{~g}$. A $0.6 \%$ strain or greater corresponds to concrete crushing while $0.3 \%$ strain corresponds to concrete compression cracking. The $0.6 \%$ strain extends to approximately 3.9 in to 4 -in, while the $0.3 \%$ strain extends to approximately 5.75 in. In the horizontal direction, the $0.6 \%$ strain extends to approximately 2.2 to 2.3 in while the $0.3 \%$ strain extends to approximately 4.0 in to 4.5 in.

\section{A.7 LOADED CASK DROP IN AIR INTO IMMERSION PAIL (Chenault 1997a)}

In this analysis a fully loaded cask $(60,000 \mathrm{lb})$ is assumed to be dropped $14.15 \mathrm{ft}$ into the immersion pail pinned in place at the top of the support structure. The effects of the buoyant force of water was neglected. The final velocity was $30.19 \mathrm{ft} / \mathrm{sec}$. Buckling of the support structure beams was constrained by the 0.5 -in steel plates. The cask deceleration was $25.4 \mathrm{~g}$ with some plastic damage to the bottom and side walls of the pail. The plastic strain for concrete compression cracking damage ( $0.3 \%$ strain) indicated a crush and cracking to a depth of 6.5 in. The simplified model did not allow any local buckling or cross section changes to the support structure which would reduce the energy and damage inflicted on the concrete slab. The 
maximum deflection of the cask is 6.7 in at approximately 37 milliseconds. The maximum deflection of the bottom of the immersion pail is 7.21 in at approximately 37 milliseconds. The cask deceleration is $25.4 \mathrm{~g}$. The $0.6 \%$ strain extends to approximately 4.0 to 4.2 -in, while the $0.3 \%$ strain extends to approximately $6.5 \mathrm{in}$. In the horizontal direction, the $0.6 \%$ strain extends to approximately 3.5 in while the $0.3 \%$ strain extends to approximately 4.5 in.

\section{A.8 LOADED CASK AND IMMERSION PAIL DROP INTO SUPPORT STRUCTURE BOTTOM PLATE (Chenault 1997b)}

A fully loaded cask and the immersion pail $(66,000 \mathrm{lb})$ is assumed to drop $13.42 \mathrm{ft}$ through water to impact the IPSS bottom 1.5-in steel plate. The immersion pail was assumed to provide a buoyance force of $6,000 \mathrm{lb}$. A drag coefficient of 0.87 was assumed for the pail. The impact velocity was $27.02 \mathrm{ft} / \mathrm{sec}$. The cask deceleration was $24.7 \mathrm{~g}$ after the bottom of the immersion pail contacted the bottom plate. The maximum deflection of the cask was 4.08 in at approximately 23 milliseconds. The maximum deflection of the immersion pail bottom was 4.42 in at approximately 23 milliseconds. The plastic strain for concrete compression cracking damage ( $0.3 \%$ strain) for the bottom plate impact indicated a crush and cracking to a depth of 3.0 in in the vertical direction and approximately 0.8 in in the horizontal direction. Other less damage may extend out to 4.5 in in the horizontal direction.

\section{A.9 SUMMARY OF DROP ANALYSIS RESULTS}

Table A.1 summarizes the pertinent results of the drop analyses described above. 
Table A.1. Summary of Drop Analysis Results.

\begin{tabular}{|c|c|c|c|c|c|c|c|c|}
\hline \multirow[b]{3}{*}{ Drop Description } & \multirow{3}{*}{$\begin{array}{l}\text { Object } \\
\text { Weight } \\
\text { (1b) }\end{array}$} & \multirow{3}{*}{$\begin{array}{l}\text { Fall } \\
\text { Height } \\
\text { (ft) }\end{array}$} & \multirow{3}{*}{$\begin{array}{l}\text { Impact } \\
\text { Velocity } \\
\text { (ft/sec) }\end{array}$} & \multirow{3}{*}{$\begin{array}{l}\text { Object } \\
\text { Deceleration } \\
\text { (g) }\end{array}$} & \multicolumn{4}{|c|}{ Concrete Strain Distance (in) } \\
\hline & & & & & \multicolumn{2}{|c|}{$0.6 \%$ Strain } & \multicolumn{2}{|c|}{$0.3 \%$ Strain } \\
\hline & & & & & v & $\mathbf{H}$ & v & $\mathbf{H}$ \\
\hline $\begin{array}{l}\text { Drop of Immersion Pail } \\
\text { Through Water }\end{array}$ & 10,825 & 15.33 & 21.5 & 114 & 5.0 & 4.0 & 6.8 & 5.0 \\
\hline $\begin{array}{l}\text { Drop of Loaded Cask } \\
\text { Onto Side of IPSS }\end{array}$ & 60,000 & 2.08 & 11.6 & 17.4 & 3.9 & 5.8 & 2.3 & 4.5 \\
\hline $\begin{array}{l}\text { Drop of Loaded Cask Into } \\
\text { Immersion Pail }\end{array}$ & 60,000 & 14.15 & 30.2 & 25.4 & 4.2 & 3.5 & 6.5 & 4.5 \\
\hline $\begin{array}{l}\text { Drop of Loaded Cask \& } \\
\text { Immersion Pail Into } \\
\text { Bottom Plate }\end{array}$ & 66,000 & 13.42 & 27.0 & 24.7 & & & 3.0 & 1.0 \\
\hline
\end{tabular}


RISK ASSESSMENT OF DRAIN VALVE FAILURE IN THE K-WEST

BASIN SOUTH LOADOUT PIT

Report No. 984515-001, Rev. 3

SNF-2671, Rev. 1

February 1999

Appendix B

Risk of a Load Drop Per Crane Lift 


\section{B.1 INTRODUCTION}

The risk of dropping an object while the object is being hoisted using the K Basin SLOP transfer bay crane is developed using the methodology discussed in Appendix B of the Nuclear Regulatory Commission document, Control Of Heavy Loads At Nuclear Power Plants, NUREG0612, (NRC 1980). Modifications are made to the fault trees in order to better portray the actual components associated with the SLOP transfer bay crane. The fault tree analysis is not intended to be all inclusive, but, rather to be representative such that probability distributions can be developed to represent significant features of the SLOP transfer bay cranes. The failure rates for components and for operator error are taken from NUREG-0612.

\section{B.2 SIGNIFICANT SAFETY FEATURES OF THE TRANSFER BAY CRANE}

Following is a list of safety features installed as part of the transfer bay crane that improve the crane's reliability and significantly decrease the risk of dropping an object while using the crane. The following list is not intended to be all inclusive, but lists those features which provide significant protection is using the crane to list objects above the SLOP.

\section{Safety Features:}

Emergency brakes on both the crane motor and the drum,

Misreeving detectors,

Limit switches, redundant and independent,

Load cells for overload protection, and

Operator key over ride.

It should be noted that the operator key over ride is a safety feature and is not a devise that may be used to bypass a safety feature. The SLOP transfer bay crane is rated at 32 ton capacity and is load tested to 40 ton. The heaviest object that will be lifted by the SLOP transfer bay crane is a loaded cask containing a MCO loaded with five baskets of SNF. The combined weight of the cask, $\mathrm{MCO}$ and fuel is 30 ton. Consequently, if proper procedures are followed it will be impossible in the SLOP to lift an object that is heavier than the crane rating, and for which the crane has been load tested. Thus, a crane failure due to lifting an object that is beyond the crane rating and load test is not considered further in this analysis. 


\section{B.3 PROBABILITY OF A LOAD DROP}

The probability of a load drop while the crane is lifting an object is evaluated by first considering those events or failures that could possibly lead to a load drop. The events are shown in Figure B.1. The events include a failure of the crane bridge, a failure of the crane cable, a failure of the crane hook, a failure of the crane lower block sheaves, a failure of the spreader block, or a failure of the cask lifting trunnions. Once the cask and MCO have been loaded and secured in the immersion pail in the IPSS, the entire assembly will be lowered to the bottom of the IPSS for fuel loading. Thus, a failure of the immersion pail rigging is also included in Figure B.2 to account for this phase of the cask moving operation.

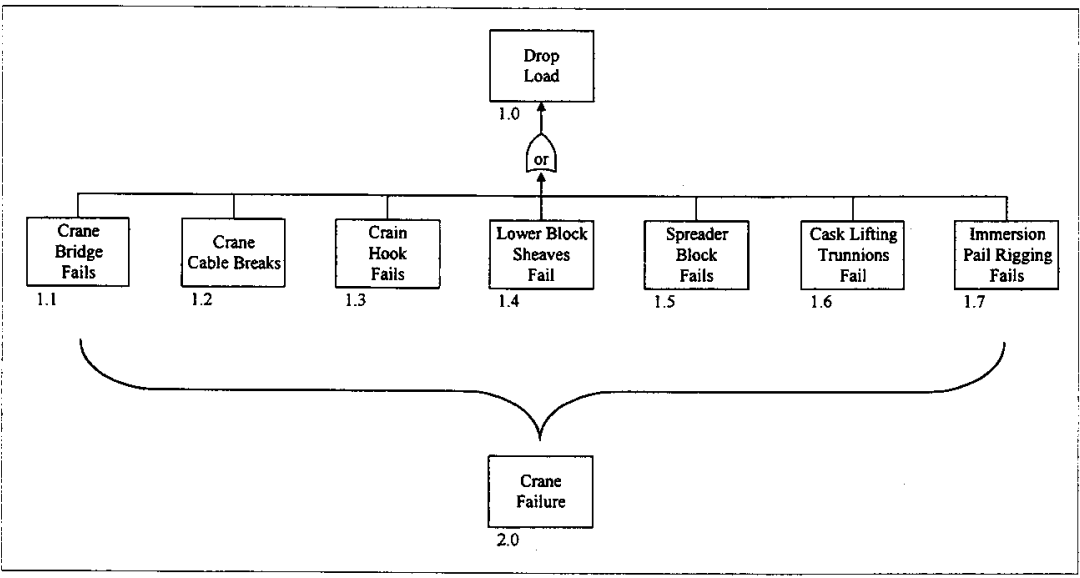

Figure B.1 Generic Fault Tree for Load Drop Using the SLOP Transfer Bay Crane.

Any one of the events shown in Figure B.1, if they occurred, could lead to dropping the load while using the crane. For this generic analysis, crane failure is defined as any event occurring that is listed in the fault tree. The events that could possibly lead to crane failure are shown in Figure B.2. Again, Figure B.2 is not intended to be all inclusive but is intended to consider common failures that have been experienced using cranes and for which the safety features listed above were installed. 
As noted earlier a crane failure due to lifting too heavy a load is not included in Figure B.2 because the weight of the heaviest object (i.e., fully loaded cask with an $\mathrm{MCO}$ ) in the SLOP is less than the crane load rating. Also, failures due to components that do not have redundant backups or component with random failures are not included. When considered, their failure rate (NRC 1980) is nearly the same as the other items shown in Figure B.2. Further, since the fault tree in Figure B.2 ends in an "or gate", the failure probabilities are combined using the Boolean addition operator, which because of the small overlap in the probabilities can be approximated by a linear sum of the probabilities. Hence, adding additional failure mechanisms into the Fault Tree in Figure B.2 with smaller or equivalent failure probabilities will not change the results significantly. 


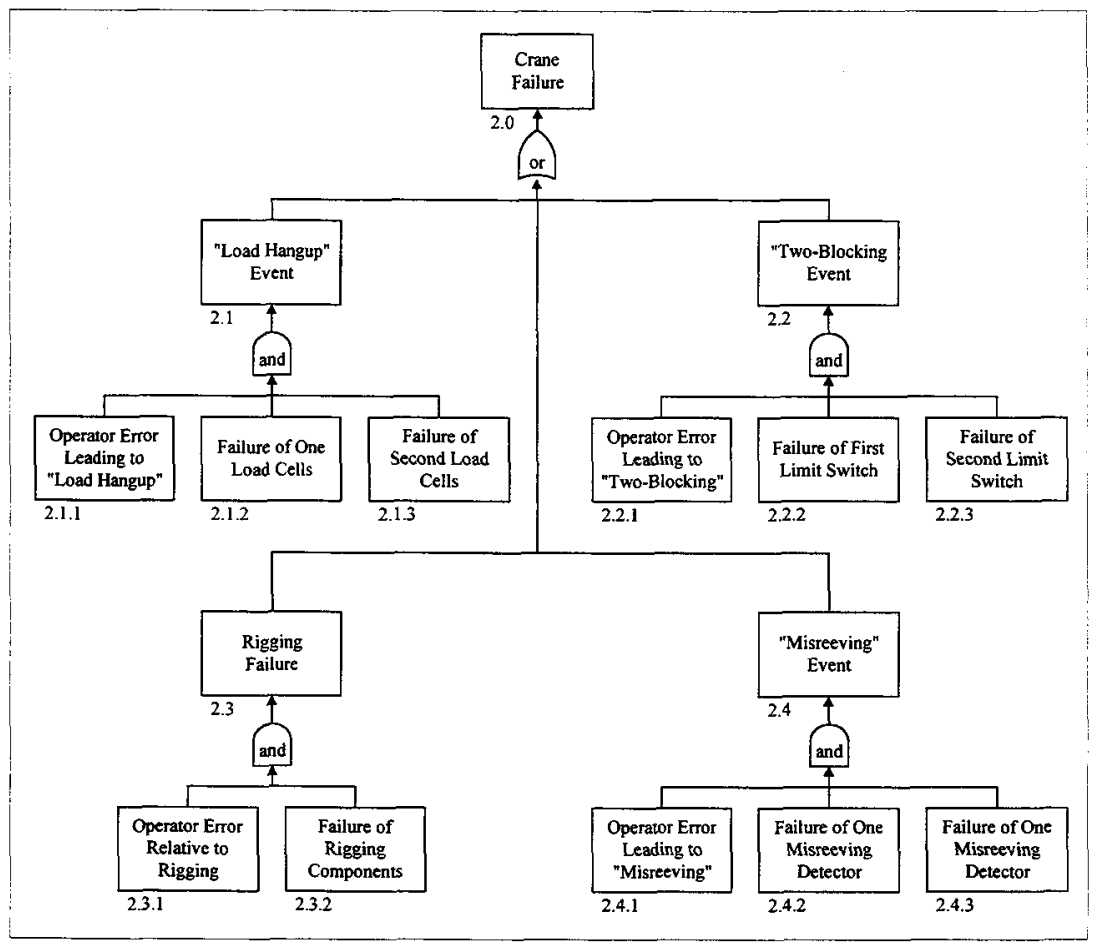

Figure B.2. Generic Fault Tree for Crane Failure Using the SLOP Transfer Bay Crane.

The point-value solution to the Fault Tree in Figure B.2 is nearly equivalent to the solution given in NUREG-0612 for NUREG-0612 Figure B.3, Sheet 2 (B) (page B-19). The difference is that a misreeving event has been added in Figure B.2 above. Also, the rigging event is included in this figure tied to the other events with an "or gate" rather than being combined later (also via an "or gate") as is done in NUREG-0612. 
In NUREG-0612, the U.S. Navy crane experience is referenced. In U.S. Navy applications, the cranes range from large shipyard cranes and on-board cranes used for cargo or weapons handling, to smaller cranes, hoist, and chainfalls. NUREG-0612 considers the U.S. Navy crane lifts and crane load drops to estimate the probability of a crane load drop per lift. The number of load drops cited in NUREG-0612 range from 37 to 74 with the total number of lifts ranging from 2.5 $\times 10^{5}$ to $1.5 \times 10^{6}$ lifts. This results in a probability of load drop per lift ranging from $2.5 \times 10^{-5}$ to $3 \times 10^{-4}$ load drops per lift. The importance of this information is that the data includes experience using small cranes, hoists, and chainfalls as well as extremely large cranes. This information will be used as a bench mark later in the analysis.

Using the failure data provided in NUREG-0612, the point value solution of the Fault Tree in Figure B.2 ranges from $1 \times 10^{-7}$ drops per lift to $1 \times 10^{-5}$ drops per lift (Note that in NUREG-0612 the solution is in events per reactor operating year with an average of 200 lifts per reactor year). Although operator error is listed in NUREG-0612 as being in the range of $10^{-2}$ per event (as is commonly accepted), they evaluate smaller probabilities for operator enror when associated with specific events, such as "Load-Hangup" events or "Two-Blocking" events. In this analysis a compromise was taken between the more specific results presented in NUREG-0612 and the conventional range of operator error as $10^{-2}$. The values presented in NUREG-0612 for the failure rate per demand of two independent protective devices were used in this analysis.

Reasonable probability distributions were developed for each of the representative branches of the Fault Tree in Figure B.2 starting with the values provided in NUREG-0612. These values. were used as the median values for the probability distributions, but the probability distributions were defined with wide, realistic ranges. As noted above a compromise was used relative to the failure rates for operator error. Also, for failure rates of two independent protective devices, the lower value provided in NUREG-0612 was used.

A lognormal PDF was used to represent the failure probabilities in the Fault Tree. A lognormal PDF was used because it is the only probability distribution that can adequately represent variables that range over decades. The lognormal PDFs were defined by the lognormal mean and the lognormal standard deviation and were bounded between reasonable, physical bounds. The appropriate PDFs for the Fault Tree in Figure B.2 are listed in Table B.1.

The Fault Tree in Figure B.2 was solved twice. The first solution was for the (SLOP) transfer bay crane (as depicted in Figure B.2) and the second solution was for lifting objects with either the auxiliary hoist, a chainfall, or other available hoists. For the second analysis, the same operator training was assumed, that is, the same failure rates for operator error were used for both solutions. However, it was assumed in the second solution that the hoist or chainfall had no specific safety features, and particularly had no redundant safety features. 
Table B.1. Lognormal PDF Parameters for Each Event in the Fault Tree of Figure B.2.

\begin{tabular}{|c|c|c|c|c|c|}
\hline Event & $\begin{array}{l}\text { Minimum } \\
\text { Value }\end{array}$ & Median Value & $\begin{array}{l}\text { Maximum } \\
\text { High }\end{array}$ & Ln Mean & Ln Sigma \\
\hline 2.1 .1 & $1 \times 10^{-5}$ & $1 \times 10^{-3}$ & 1 & -6.91 & 1.2 \\
\hline 2.1 .2 & $1 \times 10^{-5}$ & $1 \times 10^{-2}$ & 1 & -4.61 & 1.2 \\
\hline 2.1 .3 & $1 \times 10^{-5}$ & $1 \times 10^{-1}$ & 1 & -2.30 & 1.2 \\
\hline 2.2 .1 & $1 \times 10^{-5}$ & $1 \times 10^{-3}$ & 1 & -6.91 & 1.2 \\
\hline 2.2 .2 & $1 \times 10^{-5}$ & $1 \times 10^{-2}$ & 1 & -4.61 & 1.2 \\
\hline 2.2 .3 & $1 \times 10^{-5}$ & $1 \times 10^{-1}$ & 1 & -2.30 & 1.2 \\
\hline 2.3 .1 & $1 \times 10^{-5}$ & $1 \times 10^{-3}$ & 1 & -6.91 & 1.2 \\
\hline 2.3 .2 & $1 \times 10^{-8}$ & $1 \times 10^{-5}$ & 1 & -11.51 & 1.2 \\
\hline 2.4 .1 & $1 \times 10^{-5}$ & $1 \times 10^{-3}$ & 1 & -6.91 & 1.2 \\
\hline 2.4 .2 & $1 \times 10^{-5}$ & $1 \times 10^{-2}$ & 1 & -4.61 & 1.2 \\
\hline 2.4 .3 & $1 \times 10^{-5}$ & $1 \times 10^{-1}$ & 1 & -2.30 & 1.2 \\
\hline
\end{tabular}

\section{B.4 RESULTS}

The risk curves for the probability of load drop per lift for both the SLOP transfer bay crane and other auxiliary hoists are shown in Figure B.3. The risk curves represent the probability of exceeding a specific probability of load drop per lift, and the area under the risk curves represent the total risk. A summary of the results presented in Figure B.3 are listed in Table B.2. For example, from the data in Table B.2 for the SLOP transfer bay crane, there is a 90 percent confidence that the probability of load drop per lift will not be larger than $4.3 \times 10^{-5}$ drops per lift, and the net total risk is $1.9 \times 10^{-5}$ load drops per lift. On the other hand for the auxiliary hoists, there is a 90 percent confidence that the probability of load drop per lift will not be larger than $2.7 \times 10^{-3}$ drops per lift, and the net total risk is $1.3 \times 10^{-3}$ load drops per lift. Recall that for the U.S. Navy data (which included extremely large cranes as well as small cranes, hoists, and chainfalls) the probability of load drop per lift ranged from $2.5 \times 10^{-5}$ to $3 \times 10^{-4}$ load drops per lift. Thus, the results of this analysis for the SLOP transfer bay crane are bracketed by the data available from the U.S. Navy as quoted in NUREG-0612.

The important point is this analysis provides a distribution of load drops per lift for both the SLOP transfer bay crane and auxiliary hoists which is in reasonable agreement with other analyses and available data. These distributions will be used in the uncertainty analysis of the failure of the SLOP drain valve. 


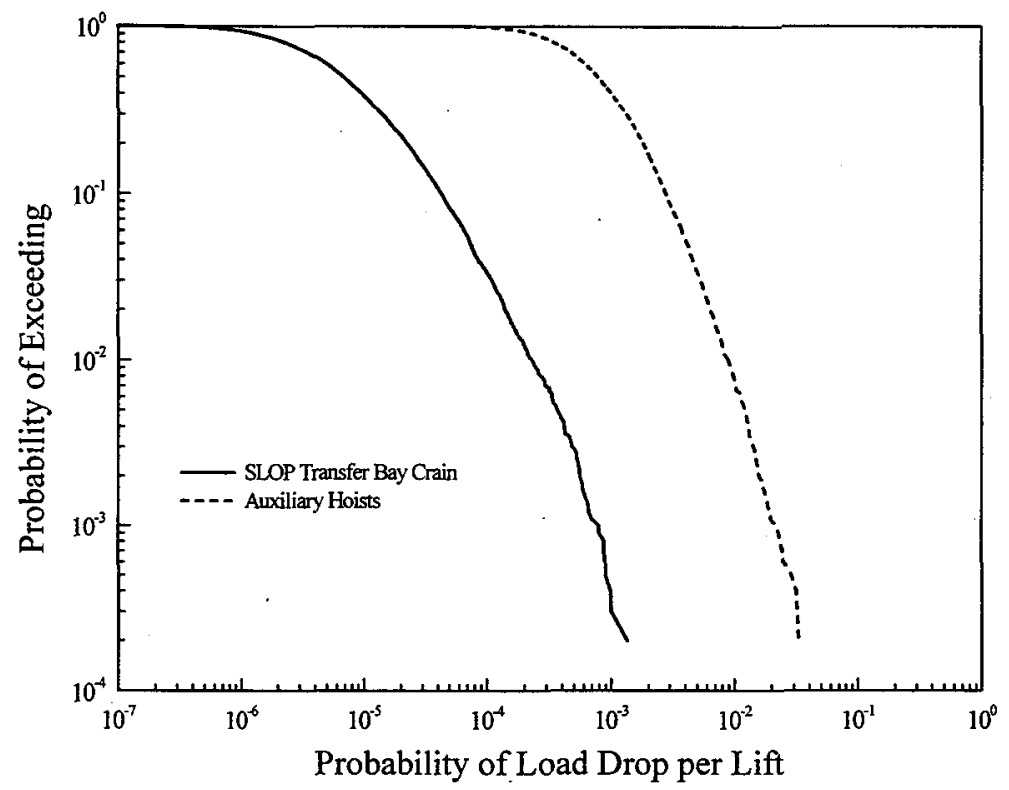

Figure B.3 Risk Curves for the Probability of Load Drop per Lift.

Table B.2. Summary of Results for the Probability of Load Drop per Lift.

\begin{tabular}{|l|c|c|c|c|c|}
\hline & $\begin{array}{c}10^{\mathrm{t}} \\
\text { Percentile }\end{array}$ & $\begin{array}{c}50^{\mathrm{t}} \\
\text { Percentile }\end{array}$ & $\begin{array}{c}90^{\mathrm{t}} \\
\text { Percentile }\end{array}$ & $\begin{array}{c}\text { Net Total } \\
\text { Risk }\end{array}$ & $\begin{array}{c}\text { U.S. Navy } \\
\text { Data }\end{array}$ \\
\hline $\begin{array}{l}\text { SLOP Transfer Bay } \\
\text { Crane }\end{array}$ & $1.3 \times 10^{-6}$ & $6.8 \times 10^{-6}$ & $4.3 \times 10^{-5}$ & $1.9 \times 10^{-5}$ & $\begin{array}{c}2.5 \times 10^{-5} \\
\text { to } \\
3 \times 10^{-4}\end{array}$ \\
\cline { 1 - 5 } Auxiliary Hoists & $2.4 \times 10^{-4}$ & $7.9 \times 10^{-4}$ & $2.7 \times 10^{-3}$ & $1.3 \times 10^{-3}$ & \\
\hline
\end{tabular}


RISK ASSESSMENT OF DRAIN VALVE FAILURE IN THE K-WEST

Report No. 984515-001, Rev. 3

BASIN SOUTH LOADOUT PIT

SNF-2671, Rev. 1

February 1999

\section{Appendix C}

Probability of Drain Valve Failure Due to an Impact Load . 


\section{C.1 INTRODUCTION}

The probability that a falling object would damage the valve was analyzed. The object was assumed to fall first through air, then through water before striking the valve. For conservatism, valve damage was defined as any plastic deformation that the valve suffered due to impact from a falling object. Such plastic deformation does not imply catastrophic failure of the valve nor does it imply large leakage rates will result. For conservatism however, it is assumed that any plastic deformation results in the release of water from the basin.

Only objects falling behind the support structure were considered. In this region, the geometry of the pit and support structure constrain the object's trajectory to a near vertical fall. For conservatism, it is assumed that all of the falling object's kinetic energy is converted into strain energy. In addition, only the valve is assumed to absorb the kinetic energy (the falling object does not suffer any strain).

$$
\text { Kinetic Energy }{ }_{\text {object }}=\text { Strain Energy }_{\text {valve }}
$$

The damage resulting from the impact was modeled in two ways. Since the geometry of the region behind the support structure limits the falling object to a vertical trajectory, the most likely point of impact will be the valve's stem. Therefore, the stress resulting in the valve stem from an axially blow was analyzed. It is also possible that a falling object might impact the valve off-axis striking the valve's bonnet and not the valve stem. Thus, off-axis impact was also modeled.

\section{C.2 CALCULATING IMPACT VELOCITY OF FALLING OBJECT}

To determine the amount of energy that a falling object could impart to the valve, the object's kinetic energy was calculated at the time of impact. To do this, the object's velocity was determined just before impact. The object's drag and buoyancy forces were taken into account since these forces greatly effect the final velocity of the falling object.

Newton's Second Law predicts the velocity resulting from unbalanced forces acting on an object. Specific to an object falling through a viscous media (e.g., water or air), Newton's Second Law can be written as, 


$$
F_{G}+F_{D}+F_{B}=m \frac{d v}{d t}
$$

where $F_{G}$ is the gravitation force acting on the object, $F_{D}$ is the object's drag force, $F_{B}$ is the buoyancy force acting on the object, $m$ is the mass of the object, $v$ is the object's instantaneous velocity and $t$ is time.

The gravitational force and buoyancy force were assumed constant over the distance that objects could be dropped. This assumption implies that the height is small relative to changes in the gravitational constant and that the density of the fluid medium does not change appreciably over the distance that the object travels. The drag force was assumed to vary proportionately with the square of the velocity. The equations used to define the three forces were,

$$
\begin{aligned}
& F_{G}=m g \\
& F_{D}=-\frac{1}{2} C_{D} \rho A_{f} v^{2} \\
& F_{B}=-\rho g V_{\text {disp }} .
\end{aligned}
$$

where $g$ is the gravitational constant, $\rho$ is the average density of the fluid, $A_{f f}$ is the frontal area of the object, and $V_{\text {disp }}$ is the volume of fluid displaced by the object.

Substituting Equation C-2 into Equation C-1, integrating, and solving for the velocity (refer to Calculation No. 1 of Appendix F for derivation) yields,

$$
\begin{gathered}
v=\sqrt{v_{0}^{2} e^{-\frac{2 k h}{m}}-\frac{\rho g V_{\text {disp }}}{k}\left(1-e^{-\frac{2 k h}{m}}\right)+\frac{m g}{k}\left(1-e^{-\frac{2 k h}{m}}\right)} \\
\text { where } k=\frac{1}{2} C_{D} A_{t r} \rho
\end{gathered}
$$

where $v$ is the object's velocity after falling a distance $h$, and $v_{0}$ is the initial object velocity at the beginning of the fall. Since it was assumed that the falling object was dropped above the basin's 
water line, Equation C-3 was solved twice. First, the equation was solved to predict the velocity of an object falling through air to the water's surface. Then using the calculated final velocity as an initial velocity, Equation C-3 was solved for an object falling through water from a height equal to the pit's depth.

Since objects of differing sizes, shapes and weights could be dropped, many of the variables in Equation C-3 were represented by distribution functions. These distribution functions when combined in Equation C-3 yielded a range of possible velocities that an object might have at the time the object struck the valve. Table C-1 summarizes those variables of Equation C-3 that were modeled as distribution functions.

Table C-1. Summary of Distribution Functions Used in Calculation of Object Velocity.

\begin{tabular}{|c|c|c|c|c|c|c|}
\hline & Variable & $\begin{array}{l}\text { Type of } \\
\text { Distribution } \\
\text { Function }\end{array}$ & $\begin{array}{l}\text { Min. } \\
\text { Value }\end{array}$ & $\begin{array}{l}\text { Max. } \\
\text { Value }\end{array}$ & $\begin{array}{l}\text { Median } \\
\text { Value }\end{array}$ & Units \\
\hline m & Mass of the falling object & Uniform & 0.1 & 100 & 1 & $\mathrm{lb}$ \\
\hline $\mathrm{Cd}$ & Object's Drag Coefficient & Lognormal & 0.01 & 10 & 1.0 & $\mathrm{n} / \mathrm{a}$ \\
\hline$A_{\text {fr }}$ & Frontal area of object & Lognormal & 0.01 & 3.6 & 0.1 & sq ft \\
\hline SG & $\begin{array}{l}\text { Specific Gravity of object } \\
\text { (related to } V_{\text {disp }} \text { ) }\end{array}$ & Triangular & 1.0 & 11.4 & 7.8 & $\mathrm{n} / \mathrm{a}$ \\
\hline
\end{tabular}

The weight of a falling objects was ranged from 1 ounce to $100 \mathrm{lb}$. Objects weighing more than $100 \mathrm{lb}$ were not considered, since such objects always resulted in valve damage. The distribution function representing the range was assumed uniform; drops involving objects of lighter weight had the same likelihood as drops of heavier weight objects.

To accommodate objects with a wide range of possible shapes, the drag coefficient was varied from 0.1 to 10 . Cylinders typically have a drag coefficient of approximately 1.2 for the range of velocities the falling object would experience (Lindeburg 1997). Spheres typically have a drag coefficient of approximately 0.4 at such velocities (Lindeburg 1997). Previous studies have used similar drag coefficients. Chenault (1997a) used 0.87 when considering drops of the pail 
into the basin. Rasmussen (1997) used 1.05 when considering drops of the support structure. Because an object's drag coefficient increases (by as much a factor of 10) as one considers objects less than spherical in shape (Lindeburg 1997), the distribution was developed to include a very wide range of the coefficients $(0.1$ to 10$)$. Since the more likely coefficients would occur near unity, the distribution function representing the drag coefficient was modeled as a lognormal distribution with peak value at 1.0 .

The frontal area of Equation $\mathrm{C}-3$ was varied from an $1.0 \mathrm{sq}$ in to $3.6 \mathrm{sq} \mathrm{ft}$. This range accommodated objects that were very small to objects as large as the cross-sectional area of Region I. Tools were assumed the most likely object to be dropped with weights less than 100 $\mathrm{lb}$. The median value of the range was arbitrarily chosen as a tool with a length of eight inches and a width of two inches. Therefore, the distribution was modeled as a lognormal distribution centered about an area equal to $16 \mathrm{sq}$ in.

In order to solve Equation C-3, the volume of the object must be known. The volume was found from combining the object's mass with an assume value of the object's specific gravity. Rather than representing all objects with a single value of specific gravity, a distribution of assumed specific gravities was used to span the range of expected object densities. Objects whose specific gravity were less than 1.0 were not considered, as such objects are negatively buoyant and would float in water. The greatest specific gravity considered was that of lead (approximately 11.4). Since steel has a specific gravity of approximately 7.8 , the lognormal distribution modeling the range of specific gravities was centered about 7.8 .

Other variables of Equation C-3 were not modeled as varying. Fixed values were assumed for the height from which an object was dropped (h), the average density of air and water $(\rho)$, and the initial object velocity at the beginning of the fall $\mathbf{v}_{\mathbf{0}}$. The distance an object falls before reaching the water surface was taken as $5.5 \mathrm{ft}$. This distance corresponds to a worker dropping an object from chest level $(4.0 \mathrm{ft})$ while standing at a level equal to the pit's grating $(1.5 \mathrm{ft}$ above the water level). The distance that an object falls through the water was taken as $24 \mathrm{ft}$. This distance is consistent with the pit floor lying $24.3 \mathrm{ft}$ below the water level (H-1-20912), and the valve protruding 4 in above the pit floor (H-1-20912 and ECN 645560).

The density of air was taken as $0.075 \mathrm{lbf} / \mathrm{ft}^{3}$ which corresponds to the density of air at $70^{\circ} \mathrm{F}$ and 1 atmosphere (Lindeburg 1997). The density will vary slightly with temperature and in general will be slightly less due to Hanford's elevation above sea level. However, the air density in Equation C-3 only affects the drag force as the object falls through air. This force is almost negligible for the relatively low velocities that the falling object will experience. Therefore, the density was not corrected for temperature variation or for elevation. 
The density of water was taken as $62.3 \mathrm{lbf} / \mathrm{ft}^{3}$ (Lindeburg 1997). This quantity is equivalent to water at $70^{\circ} \mathrm{F}$ and 1 atmosphere. Since water is very nearly incompressible, variations in pressure due Hanford's elevation above sea level or due to the pool's depth have negligible effects on altering the density. Furthermore, the density of water changes by less than 1 percent over the range of $50^{\circ} \mathrm{F}$ to $100^{\circ} \mathrm{F}$ (Lindeburg 1997). Therefore the density of water was not corrected for temperature or pressure variations.

Finally, the initial object velocity at the beginning of the fall $\left(\mathrm{v}_{\mathrm{o}}\right)$ was assumed to be zero. This is consistent with an object being accidentally dropped, where the object is not given any appreciable initial velocity in the downward direction.

\section{C.3 CALCULATING VALVE DAMAGE FROM AXIAL BLOW TO STEM}

With the velocity of the falling object computed, the stress resulting from an axial impact to the valve stem can be calculated. For conservatism, it is assumed that all of the falling object's kinetic energy is converted into strain energy. Confining the calculation to strain energies less than the proportionality limit, the imparted strain energy $\left(\mathrm{U}_{\mathrm{stem}}\right)$ can be written as (Beer and Johnston 1981),

$$
U_{\text {stem }}=\frac{1}{2} F \delta=\frac{F^{2} L_{s}}{2 A_{s} E_{s}}=\frac{\sigma^{2} L_{s} A_{s}}{2 E_{s}}
$$

where $\mathrm{F}$ is the force of impact, $\delta$ is the amount of deformation, $\mathrm{E}_{s}$ is the modulus of elasticity, and $L_{s}$ and $A_{s}$ are the length and cross-sectional area of the valve stem. Equating valve's strain energy with the object's kinetic energy and solving for the stress yields,

$$
\sigma=\sqrt{\frac{m v^{2} E_{s}}{L_{s} A_{s}}}
$$

where $\mathrm{m}$ is the mass of the falling object, and $\mathrm{v}$ is the velocity of the object just prior to impact.

As discussed in Section C.2, many of the equation variables were represented by distribution functions. Similar to Table $\mathrm{C}-1$, Table $\mathrm{C}-2$ provides a summary of the distribution functions 
used in calculating the probability of damage from an axial impact to the stem. When these distribution functions were combined in Equation C-5, a range of stresses was calculated that the stem might possibly sustain due to a falling object. The resulting stresses were then compared with the yield strength of the stem to determine what falling mass might damage the stem.

Table C-2. Summary of Distribution Functions Used in Calculating Axial Impact.

\begin{tabular}{|c|c|c|c|c|c|c|}
\hline & Variable & $\begin{array}{l}\text { Type of } \\
\text { Bistributio } \\
\text { n Function }\end{array}$ & $\begin{array}{l}\text { Min. } \\
\text { Value }\end{array}$ & $\begin{array}{l}\text { Max. } \\
\text { Yalue }\end{array}$ & $\begin{array}{l}\text { Median } \\
\text { Value }\end{array}$ & Units \\
\hline $\mathrm{S}_{\mathrm{s}}$ & Ultimate strength of the stem & Lognormal & $45 \times 10^{3}$ & $52 \times 10^{3}$ & $47 \times 10^{3}$ & psi \\
\hline $\mathrm{E}_{\mathrm{s}}$ & Stem's Modulus of Elasticity & Lognormal & $14 \times 10^{6}$ & $17 \times 10^{6}$ & $15 \times 10^{6}$ & psi \\
\hline $\mathrm{L}_{\mathrm{s}}$ & Length of the stem & Lognormal & 7 & 9 & 8 & in \\
\hline$A_{s}$ & Stem's cross-sectional area & Lognormal & 0.35 & 1.23 & 0.79 & sq in \\
\hline
\end{tabular}

Vendor information included in the Engineering Change Notice 645560 (Hanford 1997) provides specifics of the valve's size, shape and material. The stem is composed of cast manganese bronze which is an alloy of copper and zinc with small amounts of iron, aluminum and manganese. Cast manganese bronze conforms to designation UNS C86200 and ASTM specifications B-584 and B-763. The minimum yield strength of UNS C86200 is $45 \times 10^{3}$ psi (ASTM 1997) with the expected actual strength to be slightly larger. To account for this, the yield strength was modeled as a lognormal distribution with a minimum value of $45 \times 10^{3} \mathrm{psi}$. The lognormal distribution was constructed such that the median value and the maximum value were +5 percent and +15 percent larger than the rated yield strength, respectively.

The approximate modulus of elasticity of brass is $15 \times 10^{6} \mathrm{psi}$ (Lindeburg 1997). To account for this value being only an approximation, the modulus of elasticity was also represented by a lognormal distribution function. Since cast manganese bronze is a type of high strength yellow brass, it is conservative to assume the modulus of elasticity is equal to ordinary brass. To partially offset this conservatism, a lognormal distribution was constructed that had a minimum value equal to the brass modulus of elasticity. The maximum value of the distribution was chosen as a value 15 percent greater than that of the brass modulus. The median value of the distribution was chosen conservatively as 5 percent greater than the brass modulus. 
The length was conservatively estimated to be 8 in. Since the stem length was difficult to determine from the vendor information (Hanford 1997), the stem was modeled as a lognormal distribution centered about 8 in with a deviation of \pm 1 in. Similarly, the cross-sectional area of the stem was difficult to determine from the vendor information. The stem's radius was estimated as 0.5 in; however the radius could actually be \pm 25 percent of this estimate. Therefore, the cross-sectional area of the stem was modeled as a lognormal distribution centered about $0.784 \mathrm{sq}$ in. To account for the \pm 25 percent variation in radius, the minimum and maximum range of the area function were 0.35 and $1.23 \mathrm{sq}$ in, respectively.

\section{C.4 CALCULATING VALVE DAMAGE FROM ECCENTRIC BLOW TO BONNET}

As described in above, it is also possible that a falling object might impact the valve off-axis striking the valve's bonnet and not the valve stem. This off-axis impact would create a bending moment in the bonnet resulting in potential damage to the bonnet. Modeling the bonnet as a hollow beam, the resulting maximum bending stress can be written as (Beer and Johnston 1981),

$$
\sigma_{\max }=\frac{F_{y}}{A_{b}} \pm \frac{M r}{I_{c}}
$$

where $\sigma_{\max }$ is the maximum bending stress, $F_{y}$ is the vertical component of the eccentric load, $A_{b}$ is the area of the bonnet, $M$ is the moment due to the eccentric load, $r$ is the outer radius of the bonnet, and $I_{c}$ centroidal moment of the bonnet's cross-section.

Careful review of Hanford (1997) indicates that the bonnet is very nearly circular in crosssection. While the internal structure of the bonnet helps to strengthen the bonnet, the internal structure was ignored in calculating the bonnet's bending stress. Rather the bonnet was modeled as a hollow, cylindrical beam. The length of the beam was taken as the height of the exposed bonnet; portions of the bonnet and valve embedded within the concrete were not considered (this consideration is conservative, as the additional length and mass would serve to lessen the potential for damage). The curved nature of the bonnet's top was ignored except in calculating the amount of force an object imparts to the bonnet (i.e, $F_{y}$ of Equation C-6]). Due to the curving nature of the bonnet's top, the vertical impact force strikes the bonnet at an angle that is less than normal to the bonnet's surface. Thus for impacts near the outer edge of the curved bonnet, very little of the force is transmitted to the bonnet. 
As before, it was assumed that all of the falling object's kinetic energy was converted into strain energy. The strain energy that results from the off-axis impact can be written as (Beer and Johnston 1981),

$$
\mathrm{U}_{\mathrm{b}}=\frac{\mathrm{F}_{\mathrm{y}}^{2} \mathrm{~h}}{2 \mathrm{~A}_{\mathrm{b}} \mathrm{E}_{\mathrm{b}}}+\frac{\mathrm{M}^{2} \mathrm{~h}}{2 \mathrm{E}_{\mathrm{b}} \mathrm{I}_{\mathrm{c}}}
$$

where $U_{b}$ is the impacted strain energy, $h$ is the length of the bonnet, and $E_{b}$ is the modulus of elasticity of the bonnet.

Equating Equation C-7 to the kinetic energy of the falling object allows the maximum bending stress to calculated from Equation C-6 (refer to Appendix F, Calculation No. 2). As before, various equation variables were represented by distribution functions. Refer to Table C-3 for a summary. When these distribution functions were combined with Equations C-6 and C-7, a range of bending stresses was calculated that the bonnet might possibly sustain due to a falling object. The resulting stresses were then compared with the yield strength of the bonnet to determine what falling mass might damage the stem. 
Table C.3. Summary of Distribution Functions used in Calculating Eccentric Impact.

\begin{tabular}{|c|c|c|c|c|c|c|}
\hline & Variable & $\begin{array}{l}\text { Type of } \\
\text { Distributio } \\
\text { a Function }\end{array}$ & $\begin{array}{l}\text { Mir. } \\
\text { Yalue }\end{array}$ & $\begin{array}{l}\text { Max. } \\
\text { Value }\end{array}$ & $\begin{array}{l}\text { Median } \\
\text { Value }\end{array}$ & Units \\
\hline$S_{b}$ & Ultimate Strength of bonnet & Lognormal & $20 \times 10^{3}$ & $23 \times 10^{3}$ & $21 \times 10^{3}$ & psi \\
\hline $\mathrm{E}_{\mathrm{b}}$ & $\begin{array}{l}\text { Bonnet's Modulus of } \\
\text { Elasticity }\end{array}$ & Lognormal & $14 \times 10^{6}$ & $15 \times 10^{6}$ & $16 \times 10^{6}$ & psi \\
\hline$h_{b}$ & Length of exposed bonnet & Lognormal & 3 & 5 & 4 & in \\
\hline $\mathrm{r}_{\mathrm{i}}$ & Inner radius of bonnet & Lognormal & 2.00 & 2.25 & 2.12 & in \\
\hline$w_{t}$ & Wall thickness of bonnet & Lognormal & 0.12 & 0.25 & 0.18 & in \\
\hline e & Eccentricity of impact & Lognormal & 0.00 & 2.12 & 1.63 & in \\
\hline
\end{tabular}

Vendor information included in Hanford (1997) provides specifics of the valve's size, shape and material. The bonnet is made of gray cast iron which behaves as a brittle material and fails while in the linear stress-strain region predicted by Hooke's law (Lindeburg 1997). Since very little, if any, plastic deformation occurs prior to failure, the ultimate strength of the material will be used to predict the material's proportionality limit. Van Vlack (1985) specifies the ultimate strength of gray cast iron as a function the material type (Pearlitic, Martensitic, Bainitic, and Ferritic). Since the type of gray cast iron used is unknown, the ultimate strength of Ferritic $\left(20 \times 10^{3} \mathrm{psi}\right)$ was used. Since this is a minimum rating, the actual strength will be slightly larger. To account for this rating, the ultimate strength was modeled as lognormal distribution with a minimum value of $20 \times 10^{3} \mathrm{psi}$. The lognormal distribution was constructed such that the median value and the maximum value were +5 percent and +15 percent larger than the rated strength, respectively.

The modulus of elasticity of the gray cast iron is approximately $15 \times 10^{6} \mathrm{psi}$ (Lindeburg 1997). To account for this value being only an approximation, the modulus of elasticity was also represented by a lognormal distribution function. The distribution was constructed with a range equal to \pm 10 percent of the estimated modulus of elasticity.

The length of the exposed bonnet was estimated to be approximately 4.0 in. Since the actual amount is unknown, the length was modeled as a lognormal distribution centered about 4 in with 
a deviation of \pm 1 in. The inner radius of the bonnet was assumed to be at least $2.0 \mathrm{in}$. This is consistent with the bonnet housing the valve gate when the valve is in the open position. From Hanford (1997), the bonnet's inner radius is slightly larger than the valve gate. To account for this, the radius was modeled as a lognormal distribution function centered between a minimum value of 2.0 in and a maximum value of 2.25 in.

As discussed in Schifferl (1998) the bonnet was manufactured with a minimum wall thickness of 0.25 in. Corrosion during the last 43 years likely will have reduced the minimum thickness to something less. Schifferl (1998) estimated corrosion to have reduced the external surface by 0.067 in while reducing the interior surface by a negligible amount. Since the actual amount of corrosion is unknown, the wall thickness was modeled as a lognormal distribution centered about 0.18 in (corresponding to a loss of 0.067 in of wall thickness). The distribution function was ranged from 0.17 in (corresponding to a twice the estimated corrosion rate) to 0.25 in (no corrosion).

The point on the bonnet at which an object strikes the valve greatly affects the amount of bending stress developed within the bonnet. Forces applied near the bonnet's outer edge will generate the greatest bending stress. However, the curved nature of the bonnet's top counters this effect since impacts very near the bonnet's outer edge deliver very little force to the valve (i.e., angle is small between the line of impact and the bonnet's surface normal). To capture the effects of varying points of impact, the eccentricity of the applied load was varied as a lognormal distribution. Since the point of impact could occur anywhere within the circular cross-section of the bonnet, the distribution function was ranged between the center of the bonnet to the bonnet's outer edge. To maintain a uniform probability through the cross-section, the median value of the function was centered about a radius equal to 71 percent of the bonnet's outer radius.

\section{C.5 RESULTS OF THE CALCULATIONS}

Using the equations, variables and distributions discussed in Sections C.2 through C.4, the probability of valve damage was calculated. The analysis was performed by propagating the distribution functions through Equations C-3, C-5, C-6 and C-7 using a Monte Carlo technique. The calculated stress resulting from each Monte Carlo simulation was then compared with the yield strength of the material. Simulations that resulted in stress greater than the material's yield strength were classified as having failed the valve. The set of all solutions was then sorted by mass of the falling object, and a probability function developed. 
The probability of an object damaging the valve is depicted in Figure C-1. The likelihood of deforming the stem and the likelihood of deforming the bonnet are presented. The figure indicates that damaging the bonnet is more likely than damaging the stem. This is due to the differences in the material types and the amount of material composing the stem and bonnet. In addition, a stem failure is inherently less likely to occur than a bonnet failure since the stem's failure is dominated by the axial mode of failure and not the bending mode of failure.

Figure C-1 also indicates that objects weighing more than $100 \mathrm{lb}$ will almost certainly damage the valve (the probability is very nearly 1.0 ). Figure $\mathrm{C}-1$ also indicates that objects weighing between 25 and $100 \mathrm{lb}$ will most likely damage the valve (the probability is between 0.9 and 1.0). For objects weighing less than $25 \mathrm{lb}$, the likelihood of damaging the valve quickly tapers to zero. However, even objects weighing only $5 \mathrm{lb}$ or $10 \mathrm{lb}$ still have some discernable likelihood of damaging the valve.

Several factors explain the valve's inability to sustain blows by lighter weight objects. Despite drag and buoyancy forces, a falling object will achieve an appreciable velocity after falling approximately $30 \mathrm{ft}$ to the pit floor. This implies that appreciable energy is transmitted to the valve at the time of impact. In the case of the bonnet, the gray cast iron material composing the bonnet has a very low ultimate strength. While the valve is designed to contain sizeable internal pressures, the material is brittle and is subject to fracture. In the case of the valve stem, the cross-sectional area of the stem is very small. While the stem material is stronger than the bonnet material, the small cross-sectional area of the stem concentrates the strain into a small volume of material.

Even though small objects may damage the valve, such damage does not necessarily result in large leakage rates. If the impact energy is small, the resulting damage may be cracks in the valve's bonnet or may be damage to the valve's seat. Such damage would result in a only a slow leakage rate, as the damaged valve would still offer a significant flow restriction. 


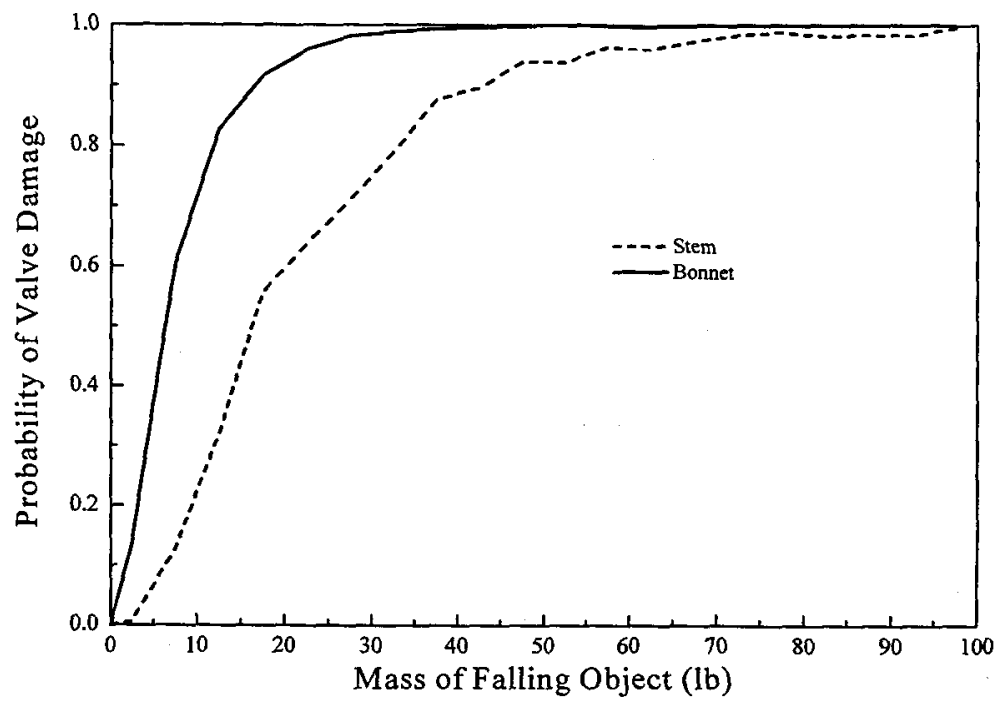

Figure C-1. Probability of Valve Damage for Dropping Objects of Varying Mass. 
RISK ASSESSMENT OF DRAIN VALVE FAILURE IN THE K-WEST

Report No. 984515-001, Rev. 3

BASIN SOUTH LOADOUT PIT

SNF-2671, Rev. 1

February 1999

Appendix D

Analysis and Results 


\section{D.1 INTRODUCTION}

This appendix provides the analysis of the probability of drain valve failure by solving the two event trees in Figure D.1, "Event Tree for Objects Falling Behind the IPSS", and Figure D.2, "Event Tree for Objects Falling Within the Footprint Around the IPSS". Also provided is the rational for the median and realistic lower and upper bounds of the probability density distributions that were used to represent the uncertainly of the event tree branch-point probabilities. The results for the probability of drain valve failure in Region I, behind the IPSS, and in Region II, within the footprint around the IPSS, are also provided. Refer to the main document for descriptions of Region I and Region II.

\begin{tabular}{|c|c|c|c|c|c|c|}
\hline $\begin{array}{l}\text { Object Falls } \\
\text { Behind Support } \\
\text { Structure }\end{array}$ & $\begin{array}{l}\text { Object Fits in } \\
\text { Clearance Area }\end{array}$ & \begin{tabular}{|l} 
Object Strikes \\
Valve Bonnet or \\
Stem
\end{tabular} & $\begin{array}{l}\text { Imparted Energy } \\
\text { is Sufficient to } \\
\text { Damage Valve }\end{array}$ & $\begin{array}{l}\text { Valve Pressure } \\
\text { Boundary is } \\
\text { Compromised }\end{array}$ & No. & Probability \\
\hline \multirow[t]{5}{*}{$\mathrm{P}_{\mathrm{OF}}$} & No & & & No & 1 & $P_{O F}\left(1-P_{1}\right)$ \\
\hline & $\begin{array}{l}1-P_{1} \\
\text { Yes }\end{array}$ & No & & No & 2 & $P_{\text {OF }} P_{1}\left(1-P_{2}\right)$ \\
\hline & $\overline{P_{1}}$ & $\begin{array}{l}1-\mathrm{P}_{2} \\
\text { Yes }\end{array}$ & No & No & 3 & $P_{O F} P_{1} P_{2}\left(1-P_{3}\right)$ \\
\hline & & $\mathrm{P}_{2}$ & $\begin{array}{l}1-P_{3} \\
\text { Yes }\end{array}$ & Yes & 4 & $\mathrm{P}_{\mathrm{OF}} \mathrm{P}_{1} \mathrm{P}_{2} \mathrm{P}_{3}$ \\
\hline & & & $\mathrm{P}_{3}$ & & & \\
\hline
\end{tabular}

Figure D.1 Event Tree for Objects Falling Behind the IPSS. 


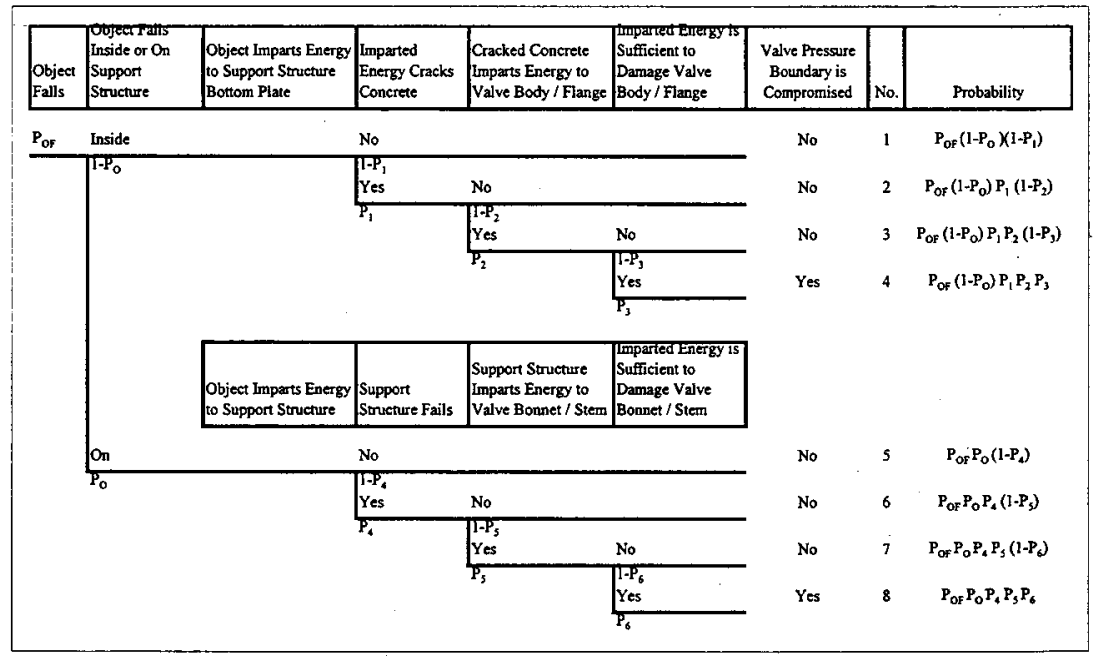

Figure D.2. Event Tree for Objects Falling Within the Footprint Around the IPSS.

\section{D.2 SOLUTION OF THE EVENT TREE FOR REGION II}

The transfer bay crane will lift a cask including-MCO from the transfer truck, transport the assembly to the SLOP, and lower the assembly into the immersion pail in the IPSS. After the cask has been assembled to the immersion pail, the entire assembly is lowered to the bottom of the IPSS. Following the loading of the MCO with fuel baskets, the process is reversed.

If a crane drop were to occur while the cask assembly is directly over the immersion pail and being lowered into the immersion pail, or while the entire assembly (cask, $\mathrm{MCO}$, and immersion pail) is being lowered to the bottom of the IPSS, the drop would be inside of the IPSS. If a crane drop were to occur while the cask assembly is being moved toward or away from the IPSS and the cask assembly is not directly over the immersion pail, the drop would impact the IPSS. If the lateral motion of the cask assembly were far enough away from the IPSS, then the drop impact would most likely be taken by the concrete floor. These three possible situations are shown schematically in Figure D.3, where Case 1 is the cask assembly directly over the immersion pail, 
Case 2 is the cask assembly area intersecting part of the IPSS, and Case 3 is the cask assembly area mostly intersecting the concrete floor.

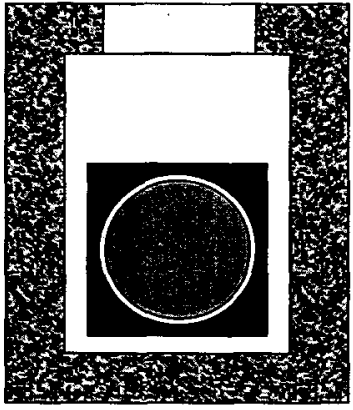

Case 1

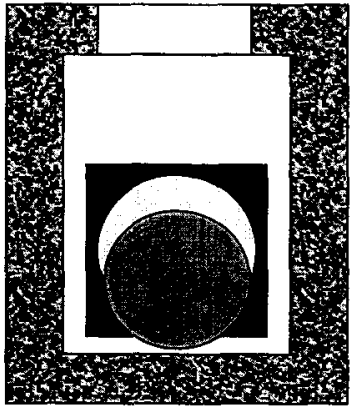

Case 2

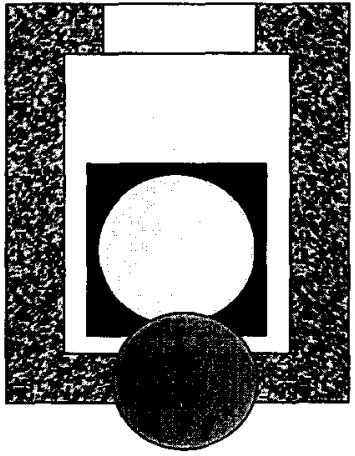

Case 3

Figure D.3. Schematic of Three Possible Situations of the Cask Assembly Area in the SLOP.

Because of the movement associated with the cask assembly, the majority of the time involved when the cask assembly is being lifted with the transfer bay crane is when the cask assembly area completely coincides with the immersion pail area (Case 1). The lateral motion of the cask assembly toward or away from the SLOP when the cask assembly area intersects both the immersion pail area and the IPSS area (Case 2) is a much shorter period of time. Therefore, there is a larger probability that a crane drop would occur when the cask assembly area completely coincides with the immersion pail area (Case 1). Thus, the conditional probability that the cask falls on the IPSS given that the crane drops the casks is taken to be a lognormal distribution ranging from zero to one with a median value of 0.2 . For this analysis Case 3 , when most of the cask assembly area intersects the concrete floor, is not considered since a crane drop in this situation would not likely be able to impact the drain valve.

If the cask and $\mathrm{MCO}$, or the cask, $\mathrm{MCO}$, and immersion pail were to be dropped into the IPSS, impacting the IPSS bottom plate, the concrete below the bottom plate would be damaged. The amount of damage can be inferred from one of the drop analyses summarized in Appendix A. Appendix A, Section A.8, summarizes a drop of a fully loaded cask and immersion pail which 
impact the bottom of the IPSS. The concrete was strained with a $0.3 \%$ strain to 3 -in in the vertical direction and 1.0-in in the horizontal direction. An evaluation of Table A.1 shows that for the four drop analyses summarized in the table the lateral distance of the $0.3 \%$ strain was approximately 4 -in to 5 -in, while the lateral distance of the $0.6 \%$ strain was approximately 4 -in to 6-in. Therefore, it is highly unlikely that the concrete damage will extend from the edge of the immersion pail bottom plate 13-in to the drain valve or from the IPSS foot 21-in to the drain valve. It is even more unlikely that the amount of energy contained in the strained concrete will be able to damage the drain valve body and flange. Thus, the conditional probability that the energy transmitted through the cracked concrete imparts energy to the valve and the conditional probability that any imparted energy is sufficient to damage the drain valve body and flange are represented by lognormal distributions ranging from $1 \times 10^{-6}$ to one with median values of 0.1 and 0.01 , respectively.

If the fully loaded cask were dropped onto the IPSS, the energy imparted to the IPSS would be absorbed by the structure's buckling or by plastic deformation. The absorbed energy could results in kinetic energy that may displace some of the pieces of the structure. The IPSS is held in place and secured by eight rails; two on each of the four corners. This IPSS support limits the ways in which the IPSS can buckle and deform given an impact at its top surface. However, it is quite likely that the IPSS will fail if impacted by the dropped cask, but the manner in which IPSS fails is unknown. However, given that the IPSS is damaged, the likelihood that the damaged structure or pieces of the damaged structure impact the drain valve is reasonably small. It is assumed that any energy imparted to the drain valve by the energy imparted to the IPSS or unattached pieces of the IPSS would be sufficient to damage the drain valve.

Based on the above discussion, the conditional probability that the impact of the dropped cask will fail the IPSS is represented by a lognormal distribution ranging from $1 \times 10^{-3}$ to one with a median value of 0.5 . The probability that the damaged IPSS impacts the drain valve bonnet given that the IPSS fails is also represented by a lognormal distribution ranging from $1 \times 10^{-4}$ to one with a median value of 0.1 . The probability that the energy imparted to the drain valve is sufficient to damage the drain valve bonnet is represented by a lognormal distribution ranging from 0.01 to one with a median value of 0.8 .

The probability distributions discussed above are summarized in Table D.1. The probability distribution for a load drop per lift for the transfer bay crane was determined from the information presented in Figure B.3 of Appendix B; the lognormal distribution representing this probability distribution is also provided in Table D.1. The branch-point probabilities in Table D.1 are also correlated with the branch-point probabilities identified in the event tree in Figure D.2. 
Table D.1. Summary of the Parameters for the Branch-Point Probabilities for Region II.

\begin{tabular}{|l|c|c|c|c|c|c|c|}
\hline Conditional Probability & & Value & Median & Value & Max & Value & Ln \\
Mean & Sigma & Ln \\
\hline Probability of Load Drop per Lift & $\mathrm{P}_{\mathrm{OF}}$ & $1 \times 10^{-8}$ & $7.1 \times 10^{-6}$ & 1 & -11.86 & 1.35 \\
\hline Object Falls On Support Structure & $\mathrm{P}_{\mathrm{o}}$ & 0 & 0.2 & 1 & -1.61 & 0.5 \\
\hline Imparted Energy Cracks Concrete & $\mathrm{P}_{1}$ & & 1 & & & \\
\hline Cracked Concrete Imparts Energy to Valve & $\mathrm{P}_{2}$ & $1 \times 10^{-6}$ & 0.1 & 1 & -2.30 & 1.2 \\
\hline Energy is Sufficient to Damage Valve & $\mathrm{P}_{3}$ & $1 \times 10^{-6}$ & 0.01 & 1 & -4.61 & 1.2 \\
\hline Support Structure Fails, & $\mathrm{P}_{4}$ & $1 \times 10^{-3}$ & 0.5 & 1 & -0.69 & 0.2 \\
\hline Support Structure Impacts Valve Bonnet & $\mathrm{P}_{5}$ & $1 \times 10^{-4}$ & 0.1 & 1 & -2.30 & 1.2 \\
\hline Energy is Sufficient to Damage Valve & $\mathrm{P}_{6}$ & $1 \times 10^{-2}$ & 0.8 & 1 & -0.22 & 0.2 \\
\hline
\end{tabular}

\section{D.3 RESULTS OF THE ANALYSIS FOR THE EVENT TREE FOR REGION II}

Using the probability distributions defined by the values given in Table D.1 and the probability distribution for a load drop per lift determined in Appendix B, the event tree defined by Figure D.2 was evaluated. There are two branches of the event tree in Figure D.2 for which the drain valve pressure boundary would be compromised. These branches are Branch 4 (cask falls inside the IPSS) and Branch 8 (cask falls on the IPSS). For Branch 4, the probability of drain valve failure is given by;

$$
P_{\text {inside }}=P_{O F}\left(1-P_{O}\right) P_{1} P_{2} P_{3} \text {, }
$$

which is a convolution of the appropriate lognormal PDFs defined by the parameters given in Table D.1.

For Branch 5, the probability of drain valve failure is given by;

$$
\mathrm{P}_{\text {on }}=\mathrm{P}_{\mathrm{OF}} \mathrm{P}_{\mathrm{O}} \mathrm{P}_{4} \mathrm{P}_{5} \mathrm{P}_{6} \text {, }
$$

which is also a convolution of the appropriate lognormal PDFs defined by the parameters given in Table D.1. 
The results for the convolution analysis of Equations D-1 and D-2 is a risk curve which gives the probability of exceeding a specific probability of drain valve failure in failures per lift. These results are given in Figure D.4 for a cask drop inside of the IPSS (Branch 4) and for a cask drop on the IPSS (Branch 8).

There are approximately $400 \mathrm{MCO}$ that will be used to remove SNF from the K Basins, with approximately $200 \mathrm{MCO}$ per basin. Each cask and MCO assembly will be lifted four times during the cask's voyage through one $\mathrm{K}$ Basin as follows:

1. The first lift is when the cask and MCO assembly is lifted from the loading truck and brought directly over the immersion pail and lowered into the immersion pail.

2. The second lift is when the cask, $\mathrm{MCO}$, and immersion pail are lowered to the bottom of the IPSS.

3. The third lift is when the cask, $\mathrm{MCO}$, and immersion pail are lifted from the bottom of the IPSS to the immersion pail holding assembly.

4. The fourth lift is when the cask and MCO assembly is lifted from the immersion pail to directly above the immersion pail and then taken to the loading truck.

The schedule for removal of SNF from each of the K Basins is 18 months, with a 6-month overlap between each basin. Thus, the time of fuel removal from each basin will be taken as two years. Consequently, the number of transfer bay crane lifts per year is given by;

$$
=200 \mathrm{MCOs} \times \frac{4 \text { lifts }}{\mathrm{MCO}} \times \frac{1}{2 \text { year }}=400 \frac{\text { lifts }}{\text { year }} .
$$




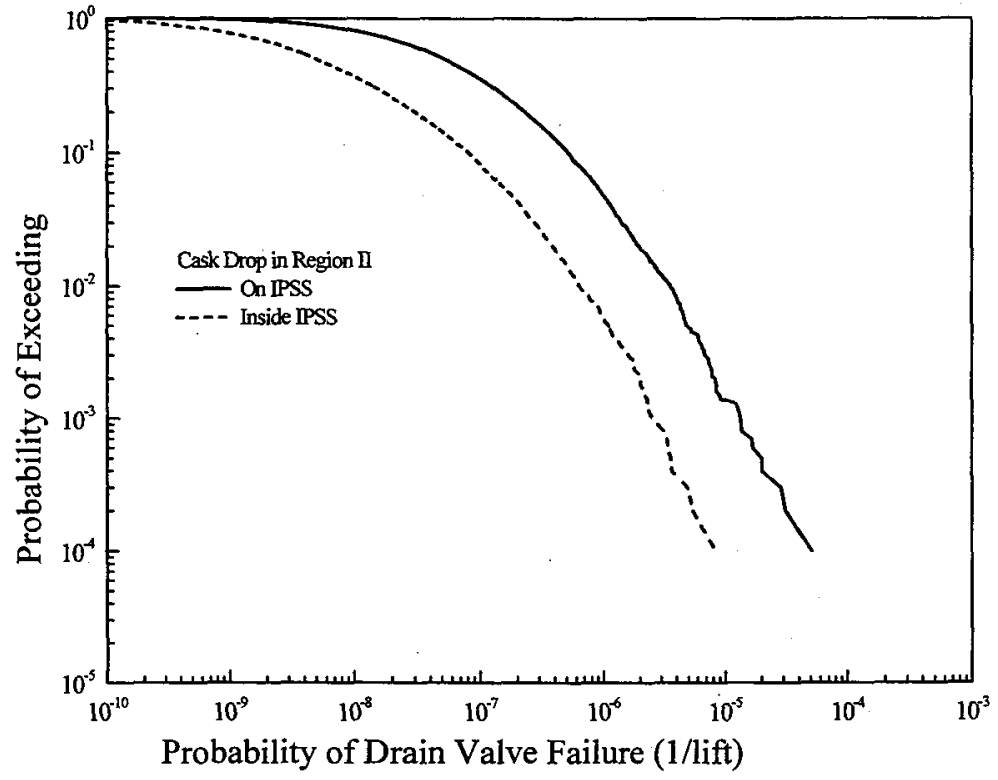

Figure D.4. Risk Curves for the Probability of Drain Valve Failure per Lift for a Cask Dropped Inside the IPSS and on the IPSS.

The frequency of drain valve failure per year is determined by combining the probability of drain valve failure per lift given in Figure D.4 with the number of transfer bay crane lifts per year (Equation D-3). The results are shown in Figure D.5 for a cask drop inside the IPSS and on the IPSS. The risk curves in Figure D.5 give the probability of exceeding a specific frequency of drain valve failure in failures per year. Again, these results are for a cask drop inside of the IPSS (Branch 4) and for a cask drop on the IPSS (Branch 8). 


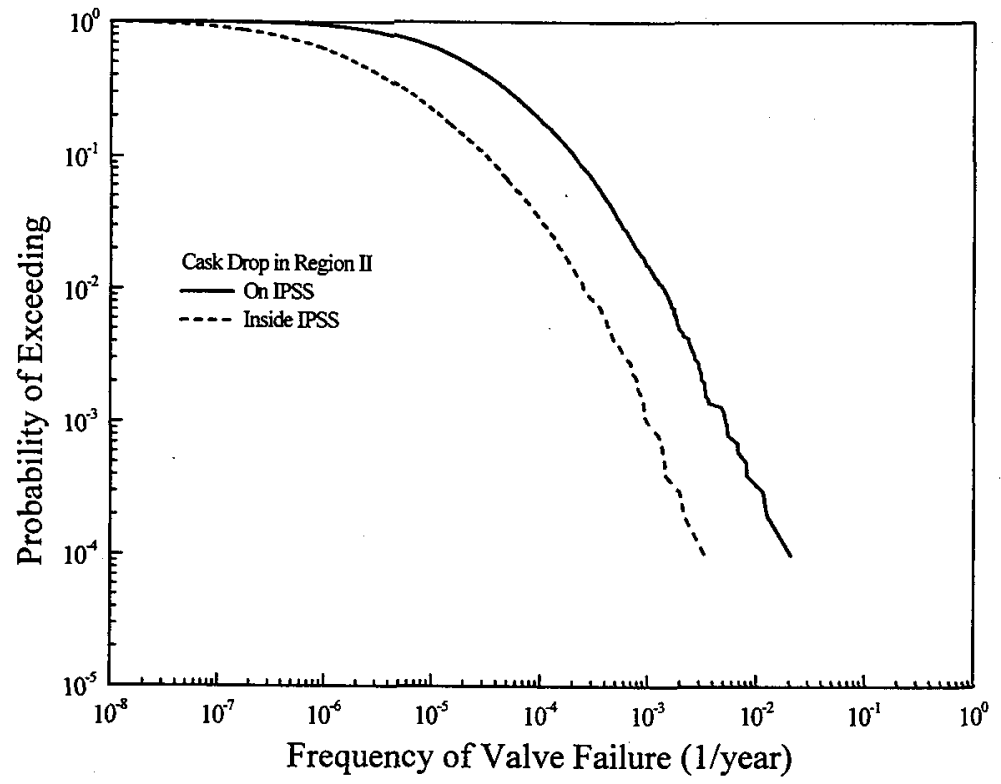

Figure D.5. Risk Curves for the Frequency of Drain Valve Failure per Year for a Cask Dropped Inside the IPSS and on the IPSS.

\section{D.4 SOLUTION OF THE EVENT TREE FOR REGION I}

There is one branch of the event tree in Figure D.1 for which the drain valve pressure boundary would be compromised (Branch 4). For Branch 4 the probability of drain valve failure is given by;

$$
\mathrm{P}=\mathrm{P}_{\mathrm{OF}} \mathrm{P}_{1} \mathrm{P}_{2} \mathrm{P}_{3},
$$

which is a convolution of the appropriate lognormal PDFs. There are two situations associated with the event tree in Figure D. 1 that must be considered. The first is for objects that may be 
lifted by a hoist or chain fall, and the second is for objects that may be lifted by a person. Using the information presented in Figure B.3 of Appendix B, a probability distribution was developed for the load drop per lift $\left(\mathrm{P}_{\mathrm{OF}}\right)$ for loads lifted with a hoist. The lognormal distribution representing this probability distribution is provided in Table D.2. The probability of a load drop per lift $\left(\mathrm{P}_{\mathrm{OF}}\right)$ for small objects that may be lifted by a person was represented by the same probability distribution that was used for a load drop per lift using a hoist. The justification is that the probability distribution covers an applicable and reasonable range of potential load drops per lift including up to one load drop per lift.

The analysis in Appendix $\mathrm{C}$ provided the probability of valve damage as a function of the mass of the falling object. For objects with mass larger than $50 \mathrm{lb}$ the probability of drain valve damage was nearly 1.0. Consequently the analysis for Region I was divided into two groups for the object weight. The first group was for objects with weight less than $50 \mathrm{lb}$ for which the probability of valve damage was treated as a lognormal distribution around the median value of 0.5 with a range from 0.001 to 1 . The second group was for objects with weight larger than $50 \mathrm{lb}$ for which the probability of valve damage was taken to be 1 . As discussed in Appendix C, valve damage is defined as the valve having suffered plastic deformation from the falling object's impact. Such plastic deformation does not imply catastrophic failure of the valve nor does it imply that large leakage rates will result. For conservatism however, it is assumed that any plastic deformation results in the release of water from the basin.

For the smaller objects $(0 \leq \mathrm{W} \leq 50 \mathrm{lb})$ it was assumed that the object would fit in the area over the drain valve so that the probability that an object fits in the area over the drain valve given that the object is dropped in Region I was taken to be 1.0. It is less likely that small objects would strike the drain valve bonnet or stem if they fell in Region I. Thus, the probability that an object strikes the valve bonnet or stem was treated as a lognormal distribution around the median value of 0.1 with a range from 0.001 to 1 .

All larger and heaver objects $(50 \leq \mathrm{W})$ may not fit in the area over the drain valve, so the probability that an object fits in the area over the drain valve given that the object is dropped in Region I was taken as a lognormal distribution around the median value of 0.5 with a range from 0.001 to 1 . It is more likely that a larger object will strike the drain valve bonnet or stem if they fall in Region I. Therefore, the probability that an object strikes the valve bonnet or stem was treated as a lognormal distribution around the median value of 0.5 with a range from 0.001 to 1 .

Each of the PDFs used to represent the uncertainty of the branch-point probabilities for the event tree in Figure are listed in Table D.2 for both small objects $(0 \leq \mathrm{W} \leq 50 \mathrm{lb})$ and heaver objects $(50 \leq \mathrm{W})$. 
RisK ASSESSMENT OF DRAN VALVE FaILURE IN THE K-WEST

Report No. 984515-001, Rev. 3

Basin SOUTH LOADOUT PIT

SNF-2671, Rev. 1

February 1999

Table D.2. Summary of the Parameters for the Branch-Point Probabilities for Region I.

\begin{tabular}{|c|c|c|c|c|c|c|}
\hline Conditional Probability & 4 & $\begin{array}{l}\text { Min } \\
\text { Value }\end{array}$ & $\begin{array}{l}\text { Median } \\
\text { Value }\end{array}$ & $\begin{array}{l}\text { Max } \\
\text { Value }\end{array}$ & Mean & Sigma \\
\hline Object Falls in Region I & $\mathrm{P}_{\mathrm{OF}}$ & $1 \times 10^{-6}$ & $7.8 \times 10^{-4}$ & 1 & -7.16 & 0.98 \\
\hline \multicolumn{7}{|l|}{ Small Objects } \\
\hline Object Fits in Area & $P_{1}$ & & 1.0 & & & \\
\hline Object Strikes Valve Bonnet or Stem & $\mathbf{P}_{2}$ & $1 \times 10^{-3}$ & 0.1 & 1 & -2.30 & 1.2 \\
\hline Energy is Sufficient to Damage Valve & $\mathbf{P}_{3}$ & $1 \times 10^{-3}$ & 0.5 & 1 & -0.96 & 0.7 \\
\hline \multicolumn{7}{|l|}{ Larger Objects } \\
\hline Object Fits in Area & $P_{1}$ & $1 \times 10^{-1}$ & 0.5 & 1 & -0.69 & 0.5 \\
\hline Object Strikes Valve Bonnet or Stem & $\mathbf{P}_{2}$ & $1 \times 10^{-3}$ & 0.5 & 1 & -0.69 & 1.2 \\
\hline Energy is Sufficient to Damage Valve & $\mathrm{P}_{3}$ & & 1.0 & & & \\
\hline
\end{tabular}

\section{D.5 RESULTS OF THE ANALYSIS FOR THE EVENT TREE FOR REGION I}

Using the probability distributions defined by the values given in Table D.2 and the probability distribution for a load drop per lift determined in Appendix B for a chain hoist, the event tree defined by Figure D.1 was evaluated. The appropriate risk curves for the probability of exceeding a drain valve failure per lift for both small $(0 \leq \mathrm{W} \leq 50 \mathrm{lb})$ and heaver objects $(50 \leq \mathrm{W})$ are provided in Figure D.6. 


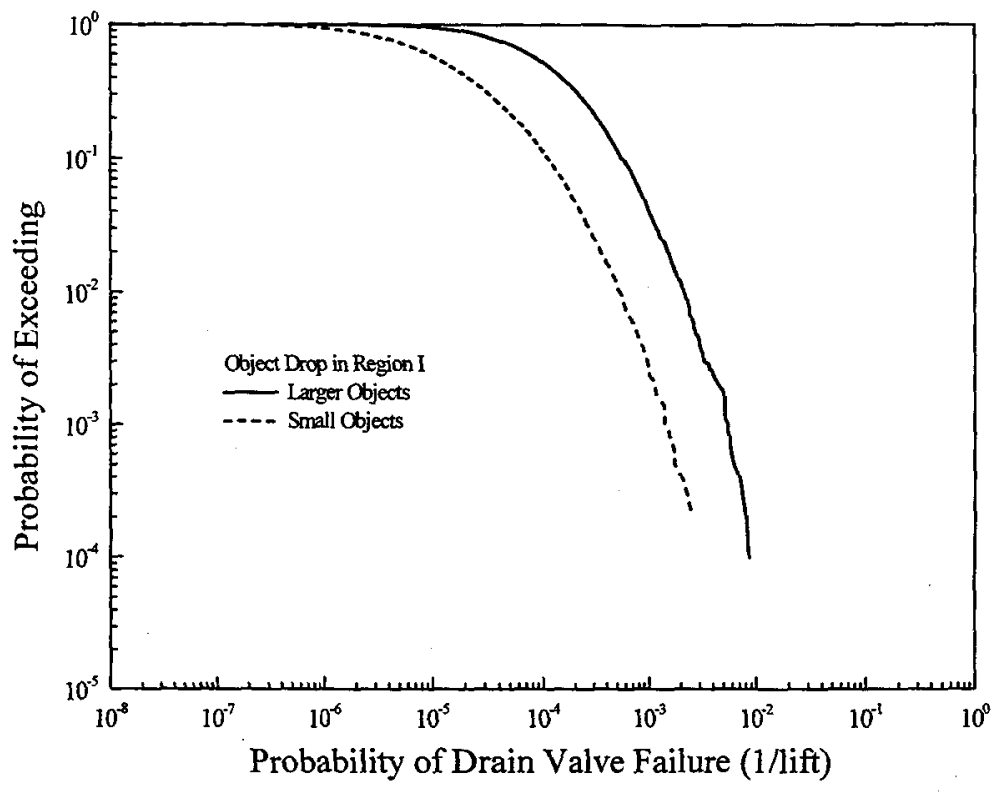

Figure D.6 Risk Curves for the Probability of Drain Valve Failure per Lift for Objects Dropped Inside Region I.

The possible number of lifts that may be made in a year for the small $(0 \leq \mathrm{W} \leq 50 \mathrm{lb})$ and heavier objects $(50 \leq W)$ is hard to estimate. Therefore, two approaches were taken. The first assumed that there would be as many lifts for the small or heavier objects as there were for the lifts using the transfer bay crane (i.e., 400 lifts/year). The second approach was to treat the number of lifts as a distribution that ranged from 1 to 400 with a median value of 100 lifts per year. The first approach would provide valve failure frequencies per year that would be comparable to values for a cask drop in Region II. However, it seems that this approach would tend to over estimate the number of lifts per year. It seems that during the process of getting ready to start fuel move from the $\mathrm{K}$ Basins there may be a relative large number of lifts on the back side of the IPSS. 
However, as the fuel removal moves into normal operations there may be less lifts on the back side of the IPSS. The second approach allows for a variable number of lifts per year, and may, therefore, be more realistic. Figure D.7 shows the risk curves for the frequency of drain valve failure per year for objects dropped in Region I using the second approach where the number of lifts was taken as a variable with uncertainty.

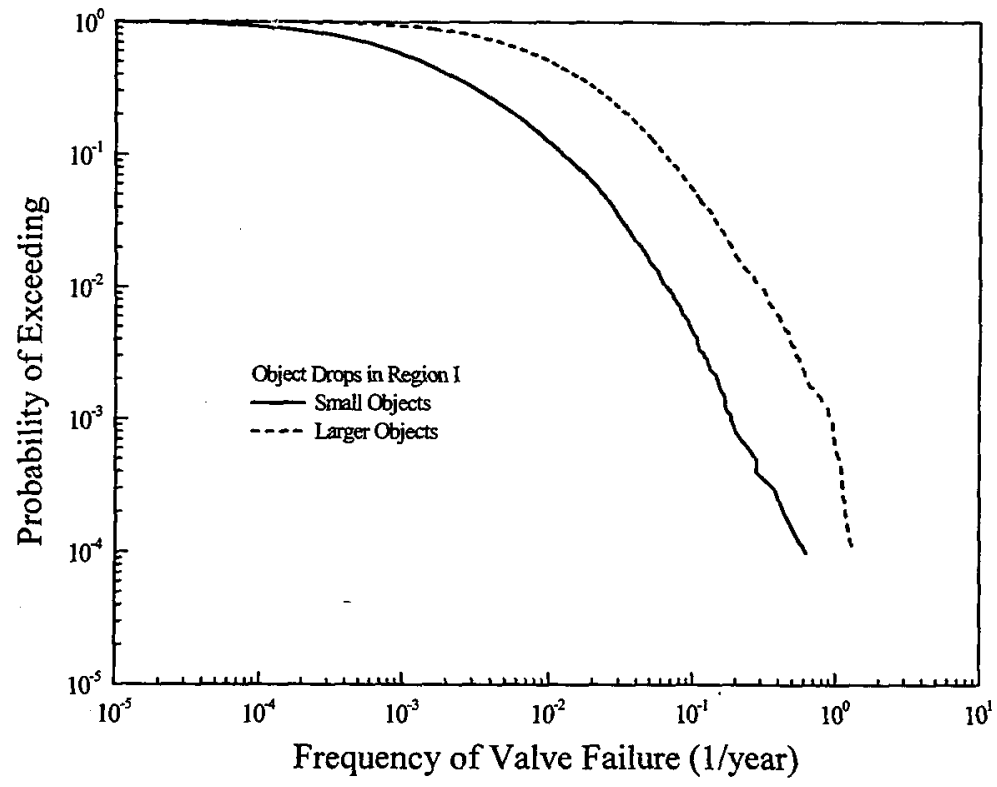

Figure D.7. Risk Curves for the Frequency of Drain Valve Failure per Year for Objects Dropped in Region I.

The results in Figure D.7 are summarized in Table D.3. Also shown in Table D.3 for comparison is the risk of $\mathrm{K}$ Basin damage from a seismic event (See Appendix E) where the basin would be damaged allowing basin water to be released. 
Table D.3. Summary of the Drain Valve Failure Frequencies per Year.

\begin{tabular}{|l|c|c|c|c|}
\hline \multirow{2}{*}{ Region } & \multicolumn{3}{|c|}{ Valve Failure Frequency per Year } \\
\hline Region I - Small Objects & $1.3 \times 10^{-4}$ & $1.3 \times 10^{-3}$ & $1.3 \times 10^{-2}$ & $5.5 \times 10^{-3}$ \\
\hline Region I - Larger Objects & $1.4 \times 10^{-3}$ & $1.0 \times 10^{-2}$ & $6.4 \times 10^{-2}$ & $2.8 \times 10^{-2}$ \\
\hline Region II - Inside IPSS & $1.3 \times 10^{-7}$ & $2.0 \times 10^{-6}$ & $3.3 \times 10^{-5}$ & $1.7 \times 10^{-5}$ \\
\hline Region II - On IPSS & $1.8 \times 10^{-6}$ & $2.1 \times 10^{-5}$ & $2.1 \times 10^{-4}$ & $1.0 \times 10^{-4}$ \\
\hline Seismic Damage of Basin & $7.7 \times 10^{-6}$ & $6.0 \times 10^{-5}$ & $4.7 \times 10^{-4}$ & $2.1 \times 10^{-4}$ \\
\hline
\end{tabular}

The risk of a drain valve failure in the K Basin SLOP is reasonably small for a cask drop either inside or on the IPSS (a 90 percent confidence that the valve failure frequency would be less than $3 \times 10^{-5}$ per year to $2 \times 10^{-4}$ per year) which is the same order of magnitude as the risk of having water drain from the $K$ Basins following a seismic event. However, the risk of a drain valve failure for an object dropped in Region I is much larger (a 90 percent confidence that the valve failure frequency would be less than 1 to $6 \times 10^{-2}$ per year). The risk curves for each of the situations presented in Table D. 3 are provided in Figure D.8. 


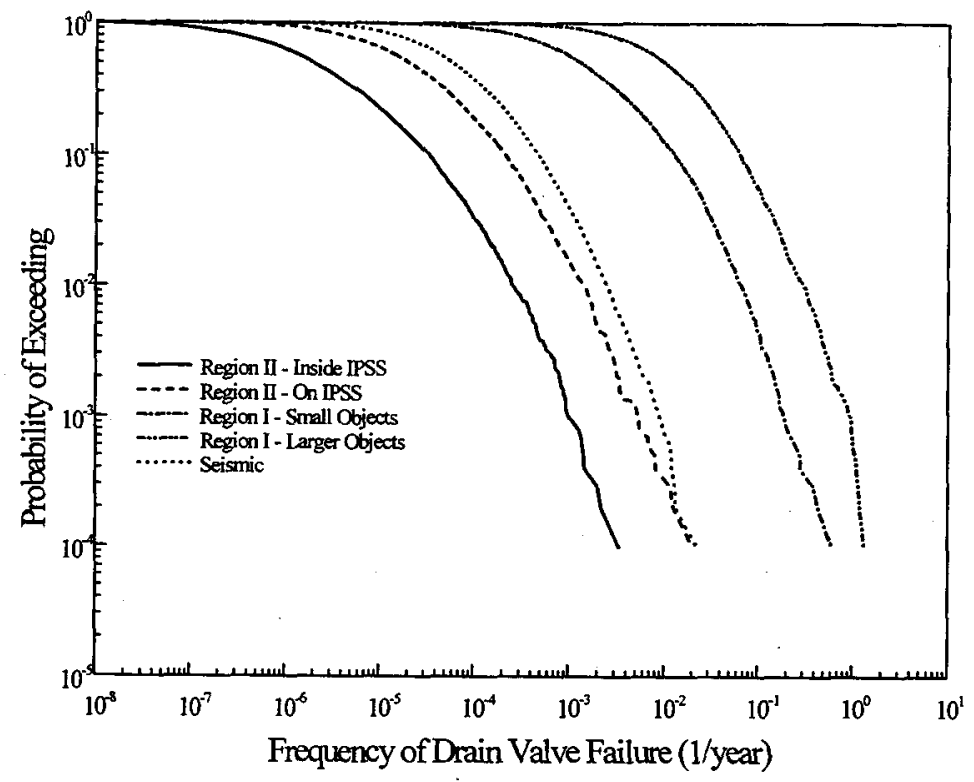

Figure D.8. Risk Curves for the Frequency of Drain Valve Failure per Year for the Situations Presented in Table D.3.

\section{D.6 DEFENSE IN DEPTH MEASURES}

An impact limiter has been designed to limit the impact to the four-inch drain valve from any objects that may be dropped in Region I behind the IPSS. The impact limiter is designed to: 1) withstand the impact of a 550 pound object falling $45 \mathrm{ft}$ without failing and impacting the drain valve, and 2) withstand a 100 pound object falling $45 \mathrm{ft}$ with an impact area of one or two square inches, respectively, without piercing the top of the impact limiter. Therefore, the impact limiter will withstand an impact energy of $24,750 \mathrm{ft} l \mathrm{lb}(550 \mathrm{lb} \times 45 \mathrm{ft})$, or a piercing impact energy 
density of 2,250 to $4,500 \mathrm{ft} \mathrm{lb} / \mathrm{in}^{2}\left(100 \mathrm{lb} \times 45 \mathrm{ft} / 1 \mathrm{in}^{2}\right.$ or $\left.100 \mathrm{lb} \times 45 \mathrm{ft} / 2 \mathrm{in}^{2}\right)$. A schematic showing the impact limiter directly over the four-inch drain valve located in the SLOP is shown in Figure D.9.

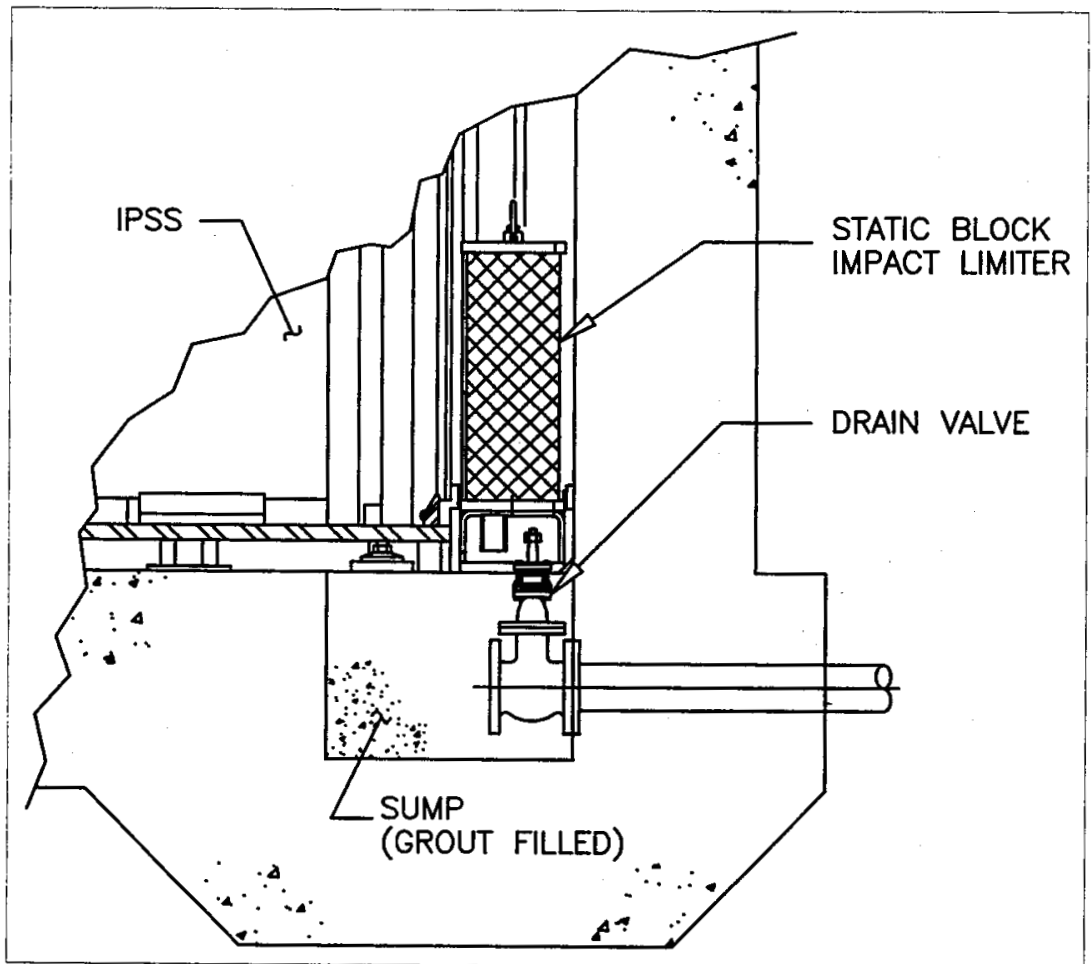

Figure D.9 Static Block Impact Limiter For SLOP. 
Assuming that the impact limiter is designed with a safety factor of 1.5 the failure probability at 10 percent should be larger than or equal to the safety factor times the impact energy.

Mathematically, this design requirement is written as;

$\operatorname{Pr}$ [Impact Energy at $10 \%$ Prob. Of Failure $\geq \mathrm{SF} *$ Impact Energy] $=0.10$.

The impact limiter would have a probability of failure approaching zero at an impact of $24,750 \mathrm{ft}$ $\mathrm{lb}(550 \mathrm{lb} \mathrm{x} 45 \mathrm{ft})$. That is, the impact limiter is designed to withstand the impact of an object weighing $550 \mathrm{lb}$ dropped from a height of $45 \mathrm{ft}$. With a safety factor of 1.5 , the impact limiter should withstand an impact energy of $37,125 \mathrm{ft} \mathrm{lb}(1.5 \times 24,750 \mathrm{ft} \mathrm{lb})$ with a failure probability of 0.10 . Using these two physical limitations one can construct the failure probability curves for the impact limiter. This is done by identifying a cumulative distribution function for which the probability is 0.10 at an impact energy of $37,125 \mathrm{ft} \mathrm{lb}$ and the probability is nearly zero at an impact energy of $24,750 \mathrm{ft} \mathrm{lb}$. A failure probability curve that satisfies the above conditions is shown in Figure D.10. The upper and lower distribution curves shown in Figure D.10 represent uncertainty variations about the median distribution by assuming that the uncertainty is lognormally distributed with a logarithmic standard deviation.

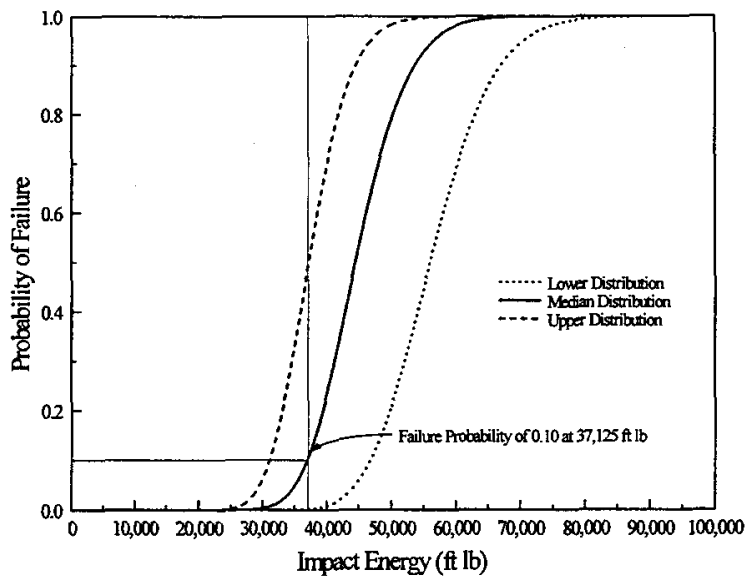

Figure D.10. Possible Failure Probability curves for the Impact Limiter. 
Recall that in Table D.3 small objects are objects whose weight is from zero to $50 \mathrm{lb}$, while large objects are objects whose weight is larger than $50 \mathrm{lb}$. Standard industrial practices limit hand lifting to objects whose weight is less than or equal to $50 \mathrm{lb}$. Objects whose weight is larger than $50 \mathrm{lb}$ are handled by qualified lifting devices. For small objects $(0 \leq \mathrm{W} \leq 50 \mathrm{lb})$ the impact limiter will prevent any drain valve damage $(50 \mathrm{lb} \times 45 \mathrm{ft}=2,250 \mathrm{ft} \mathrm{lb}$ ) since from Figure D.10 the failure probability at an impact energy of $2,250 \mathrm{ft} \mathrm{lb}$ is approaching zero. For larger objects whose weight is up to $550 \mathrm{lb}$ (impact energy $=550 \mathrm{lb} \mathrm{x} 45 \mathrm{ft}=24,750 \mathrm{ft} \mathrm{lb}$ ) the impact limiter failure probability is also essentially zero (less than 0.002 or smaller than three to four orders of magnitude, $10^{-3}$ to $10^{-4}$ ). The cask handling fixture is the largest object that will be used in the SLOP above Region I. This fixture weighs approximately $550 \mathrm{lb}$. Therefore, for most objects that may be used above the four-inch drain valve located in the SLOP, the impact limiter would prevent any drain valve damage should an object be dropped in Region I. With the impact limiter the frequency of drain valve failure per year is considerably reduced as illustrated in Table D.4. Thus, with the impact limiter there is a 90 percent confidence that the frequency of drain valve failure will be less than $1 \times 10^{-6}$ per year.

\section{Table D.4. Summary of the Drain Valve Failure Frequencies per Year for Objects Falling in Region I.}

\begin{tabular}{|c|c|c|c|c|}
\hline \multirow[b]{2}{*}{ Region 1} & \multicolumn{4}{|c|}{ Valve Failure Frequency per Year } \\
\hline & $\begin{array}{c}10^{\mathrm{th}} \\
\text { Percentile }\end{array}$ & $\begin{array}{c}50^{\mathrm{th}} \\
\text { Percentile }\end{array}$ & $\begin{array}{l}90^{\mathrm{t}} \\
\text { Percentile }\end{array}$ & $\begin{array}{l}\text { Net Total } \\
\text { Risk }\end{array}$ \\
\hline Small Objects & $1.3 \times 10^{-4}$ & $1.3 \times 10^{-3}$ & $1.3 \times 10^{-2}$ & $5.5 \times 10^{-3}$ \\
\hline With Impact Limiter & $<1 \times 10^{-8}$ & $<1 \times 10^{-8}$ & $<1 \times 10^{-8}$ & $<1 \times 10^{-8}$ \\
\hline Larger Objects & $1.4 \times 10^{-3}$ & $1.0 \times 10^{-2}$ & $6.4 \times 10^{-2}$ & $2.8 \times 10^{-2}$ \\
\hline With Impact Limiter & $<1 \times 10^{-7}$ & $<1 \times 10^{-6}$ & $<6 \times 10^{-6}$ & $<3 \times 10^{-6}$ \\
\hline
\end{tabular}


RISK ASSESSMENT OF DRAIN VALVE FAILURE IN THE K-WEST

Report No. 984515-001, Rev. 3

BASIN SOUTH LOADOUT PIT SNF-2671, Rev. 1

February 1999

Appendix E

K Basin Seismic Risk 


\section{E.1 INTRODUCTION}

Drain valve failure is defined as the loss of the drain valve pressure boundary integrity such that water may be released from the $\mathrm{K}$ Basin via the drain system. The risk of drain valve failure is thus equated to the risk of releasing water from the $K$ Basin via the drain system assuming that the drain lines are open. This risk can be compared to other events that may result in the loss of water from the $\mathrm{K}$ Basin. One such risk is from a seismic event where the seismic event damages the structural concrete of the $\mathrm{K}$ Basin allowing water to be released. This appendix evaluates the risk due to a seismic event in terms of the risk curve for the frequency of $\mathrm{K}$ Basin structural damage given that a seismic event occurs.

\section{E.2 EVALUATION OF THE RISK OF A SEISMIC EVENT}

The risk due to a seismic event is determined using the process pictorially represented in Figure E.1. The results of the analysis is the conditional probability of a structural failure given that a seismic event has occurred. Each contribution presented in Figure E.1 is discussed below.

\section{Seismic Hazard Curve}

Frequency of Exceeding

a PGA Given a Seismic

Event Occurs.

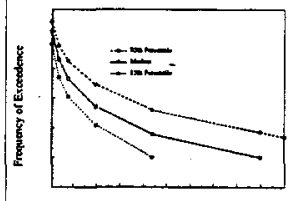

Prat Groand Acodorivo
Fragility Curve

Probability of Structural

Failure as a Function of the PGA.

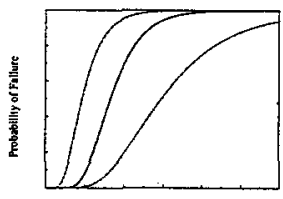

Pesik Growad Aectaraion
Frequency of Failure Conditional Frequency of Structural Failure Given a Seismic Event.

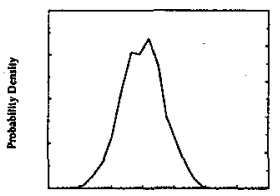

Failure Frequensy (1)yen)

$$
\left.\int_{\mathrm{PGA}}\left[\begin{array}{c}
\text { Derivative of the } \\
\text { Seismic Hazard Curve }
\end{array}\right] *(\text { Fragility Curve })=\mathrm{Fr}\left[\begin{array}{cc}
\text { Structural } \\
\text { Failure }
\end{array}\right) \begin{array}{c}
\text { Seismic } \\
\text { Event }
\end{array}\right]
$$

Figure E.1. Pictorial Representation of the Analysis Process. 
The seismic hazard curves for a site express the frequency (in events per year) that the PGA for the event will be larger than or equal to a specific value (exceedance frequency) given that a seismic event has occurred. Thus, the seismic hazard curves are the complementary CCDF of the PDF that represents the distribution of potential values of the PGA. Note that for the seismic hazard curves to be expressed in terms of an exceedance frequency the PDF is normalized to the average number of seismic events per year rather than normalized to unity.

Let $\phi$ (a) represent the CCDF of the PGA, or the seismic hazard curve. The probability that the $P G A$ is between $a$ and $a+d a$ is given by;

$$
-\frac{d \phi(a)}{d a}=g(a),
$$

which is the PDF of the distribution of the PGA.

The fragility curve of a structure, $F(a)$, characterizes the ability of the structure to resist a seismic event. The fragility curve expresses the probability of structural failure as a function of the PGA. The fragility curve of a structure also has uncertainty which is represented by a distribution of the failure probability about a median value, and a family of curves distributed about the median value.

The integral of the derivative of the seismic hazard curve and the fragility curve represents the conditional probability of structural failure given a seismic event occurs. Mathematically the integral is expressed by;

$$
\theta=\int_{\text {all } a}\left[-\frac{d \phi(a)}{d a}\right] F(a) d a .
$$

If the uncertainty in the seismic hazard curve and the fragility curve are considered, then the conditional probability of structural failure given a seismic event occurs is a distribution of values given by;

$$
\theta_{i j}=\int_{a l l ~ a}\left[-\frac{d \phi_{i}(a)}{d a}\right] F_{j}(a) d a
$$

where the uncertainty in the seismic hazard curve and the fragility curve is represented by a family of curves noted by the indices $i$ and $\mathbf{j}$. 
The seismic hazard curves for the Hanford $100 \mathrm{~K}$ Area have been determined (Tallman 1996) and are provided in Figure E.1. The uncertainty in the seismic hazard curves is expressed by the curves for the median $\left(50^{\text {th }}\right.$ percentile) and the $5^{\text {th }}$ and $95^{\text {th }}$ percentiles.

Figure E.2 shows the seismic hazard curves for the Hanford $100 \mathrm{~K}$ Area as well as the normalized lognormal PDFs that were created to represent the data. The normalized lognormal PDFs are used to facilitate the analysis using Equation E-3.

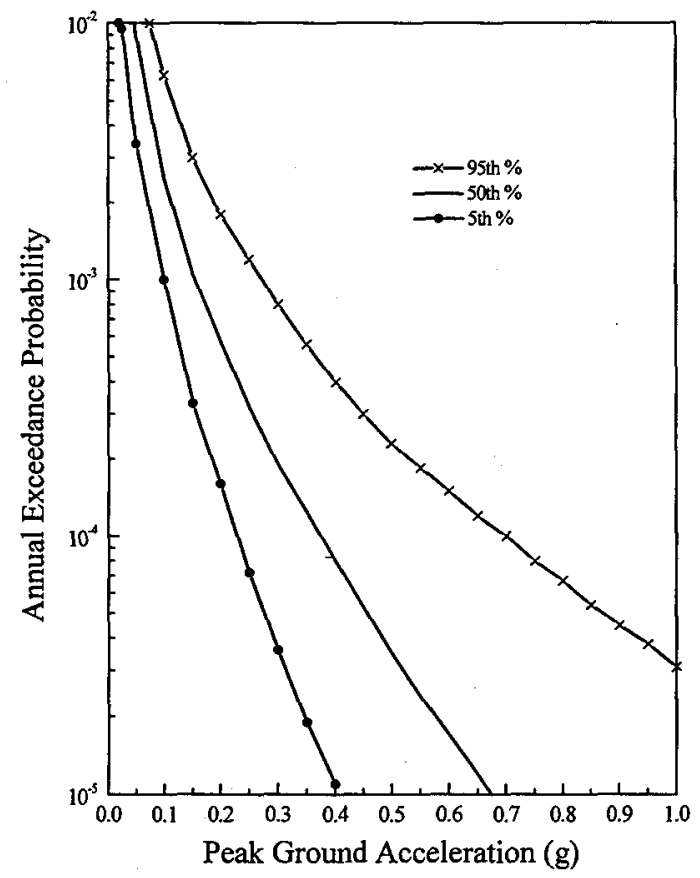

Figure E.1 Seismic Hazard Curves for the Hanford Site $100 \mathrm{~K}$ Area Shown on a Semi-Log Scale. 


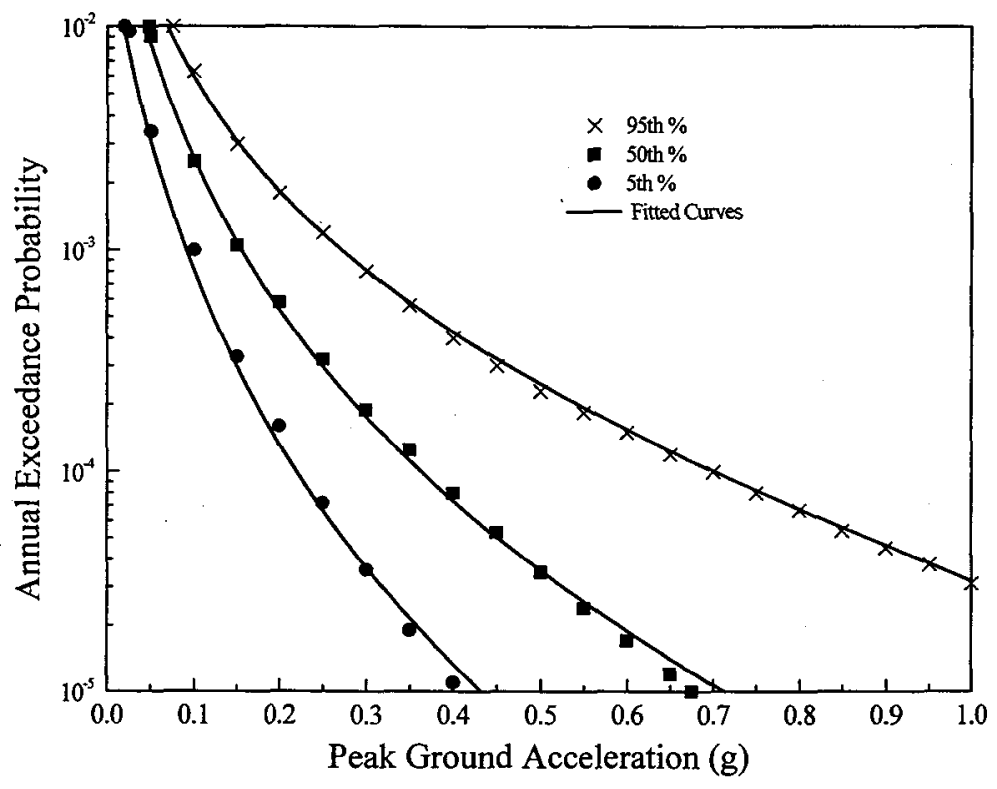

Figure E.2. Seismic Hazard Curves for the Hanford $100 \mathrm{~K}$ Area and the Associated Normalized Lognormal PDFs That Were Used to Represent the Data.

A fragility curve is expressed in terms of the structures median PGA capacity ( $\AA$ ) and two random variables that represent the inherent variability about the median ground acceleration capacity and the uncertainty in the median value. It is usually assumed that the random variables are lognormally distributed with logarithmic standard deviation defined by $\beta_{\mathrm{R}}$ and $\beta_{\mathrm{U}}$ (Kennedy 1980). Thus, $\beta_{R}$ represents the inherent randomness about the median PGA, and $\beta_{U}$ represents the uncertainty in the median value. The values of $\beta_{R}$ and $\beta_{U}$ are determined by considering various safety factors of a structure. 
The evaluation criteria given in DOE-STD-1020 (discussed by Kennedy and Short 1994) is aimed at achieving a safety factor of 1.5 at a structure failure capacity of 0.10 (10 percent). That is, the PGA at a probability of structure failure of 0.10 should be larger than or equal to the safety factor times the PGA of the DBE. Mathematically, this goal is written as;

$$
\begin{gathered}
\mathrm{PGA}_{10 \%} \geq \mathrm{SF} * \mathrm{DBE} \text {, or } \\
\operatorname{Pr}\left[\mathrm{PGA}_{10 \%} \geq \mathrm{SF} * \mathrm{DBE}\right]=0.10 .
\end{gathered}
$$

For the $\mathrm{K}$ Basin concrete structure the DBE has a PGA of 0.20 g (SAR 1998). Winkel (Winkel 1991 ) lists the demand and capacity for various areas of the $\mathrm{K}$ Basin concrete structure and the average safety factor (ratio of demand to capacity) is approximately 3.5. Thus, a more conservative safety factor of 1.5 is used for the concrete structure in agreement with the evaluation criteria suggested in DOE-STD-1020 (Kennedy and Short 1994). Thus, with a safety factor of 1.5 and a PGA for the DBE of $0.20 \mathrm{~g}$, the PGA at a probability of structure failure of 0.10 is $P A_{10 \%} \geq 1.5 * 0.20 \mathrm{~g}=0.30 \mathrm{~g}$. Taking the inverse of the probability of structure failure at 0.10 at a PGA of $0.30 \mathrm{~g}$ gives a median PGA capacity of $0.43 \mathrm{~g}(\AA)$. That is, one finds the cumulative distribution function for which the probability of structural failure is 0.10 at a PGA of $0.30 \mathrm{~g}$.

While there is not sufficient information to determine $\beta_{R}$ and $\beta_{\mathrm{V}}$, there is sufficient information to consider some possible values. It is assumed that the $\mathrm{K}$ Basin concrete structure is not very resilient to a seismic event (as suggested by the low PGA) such that the inherent randomness about the median PGA would be quite small. Therefore, a value of $\beta_{R}=0.28$ was selected. On the other hand, the uncertainty in the median value of the PGA should be reasonably large. Therefore, a value of $\beta_{U}=0.40$ was selected. These values of $\beta_{R}$ and $\beta_{U}$ are reasonable and are typical of values used for structures which are not very resilient to a seismic event. They are also representative of the range of values suggested by the U.S. Nuclear Regulatory Commission (NRC) for developing fragility curves (NRC 1985).

However, it should be noted that because of the steep slope of the seismic hazard curves in Figure E-1 near a PGA of $0.12 \mathrm{~g}$ to $0.43 \mathrm{~g}$, the slope of the seismic hazard curves dominate the integral in Equation E-3. Thus, the structural failure frequency is not very sensitive to the uncertainty associated with the fragility curves, and reasonable variations in the fragility curves will be dominated by the slope of the seismic hazard curves. The chosen values of $\beta_{\mathrm{R}}$ and $\beta_{\mathrm{U}}$ are reasonable and could vary by as much as 50 percent and not significantly change the value of the integral in Equation E-3. The intent is to obtain a reasonable fragility curve that would represent 
some of the known features of the $\mathrm{K}$ Basin concrete structure. Using the values of $\AA=0.43 \mathrm{~g}, \beta_{\mathrm{R}}$ $=0.28$, and $\beta_{U}=0.40$ produces the fragility curves presented in Figure E.3. Note that as expected, Figure E.3 shows that there is a very low probability of structural failure at the PGA of the DBE $(0.20 \mathrm{~g})$. That is, the structure is designed to withstand the PGA of the DBE with a safety margin.

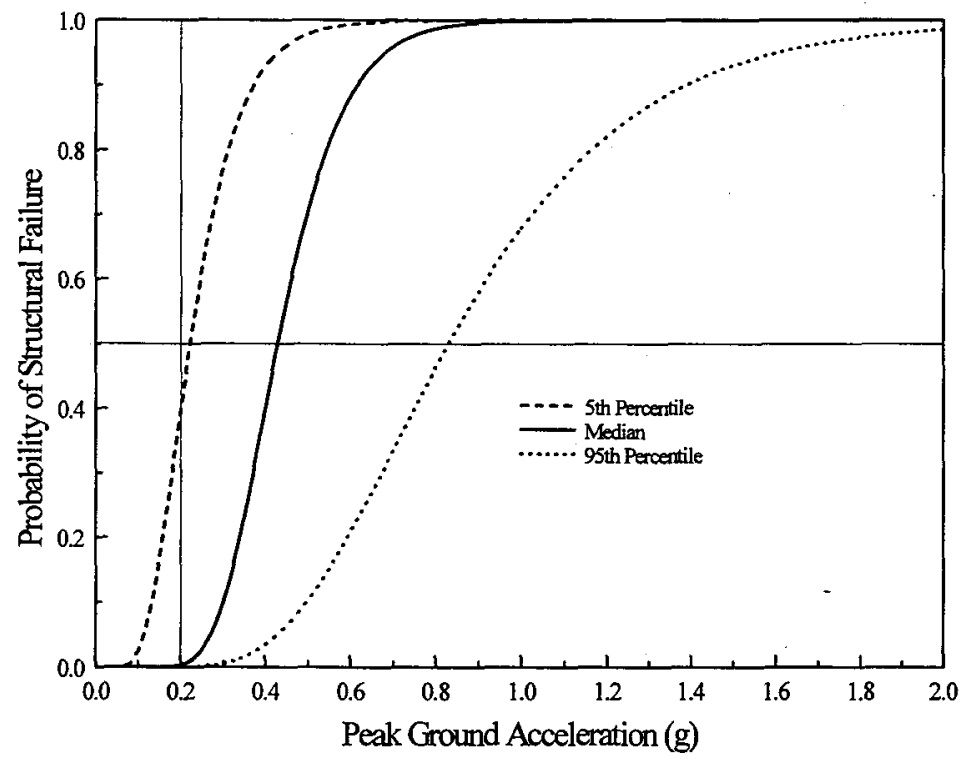

Figure E.3. Possible Fragility Curves for the K Basin Concrete Structure.

Using Equation E-3 and the family of curves represented by the seismic hazard curves and the fragility curves, the conditional probability of structural failure given that a seismic event occurs is calculated. The CCDF of the conditional probability provides the risk curve for the frequency 
of structural failure given that a seismic event occurs. The results are presented in Figure E.4. Figure E.4 provides the probability of exceeding a structural failure frequency (1/year). Figure E.4 provides the risk from a seismic event where the seismic event damages the structural concrete of the $\mathrm{K}$ Basin allowing water to be released. This risk curve can then be compared to the risk curve for drain valve failure where the drain valve pressure boundary integrity is compromised such that water may be released from the $\mathrm{K}$ Basin via the drain system.

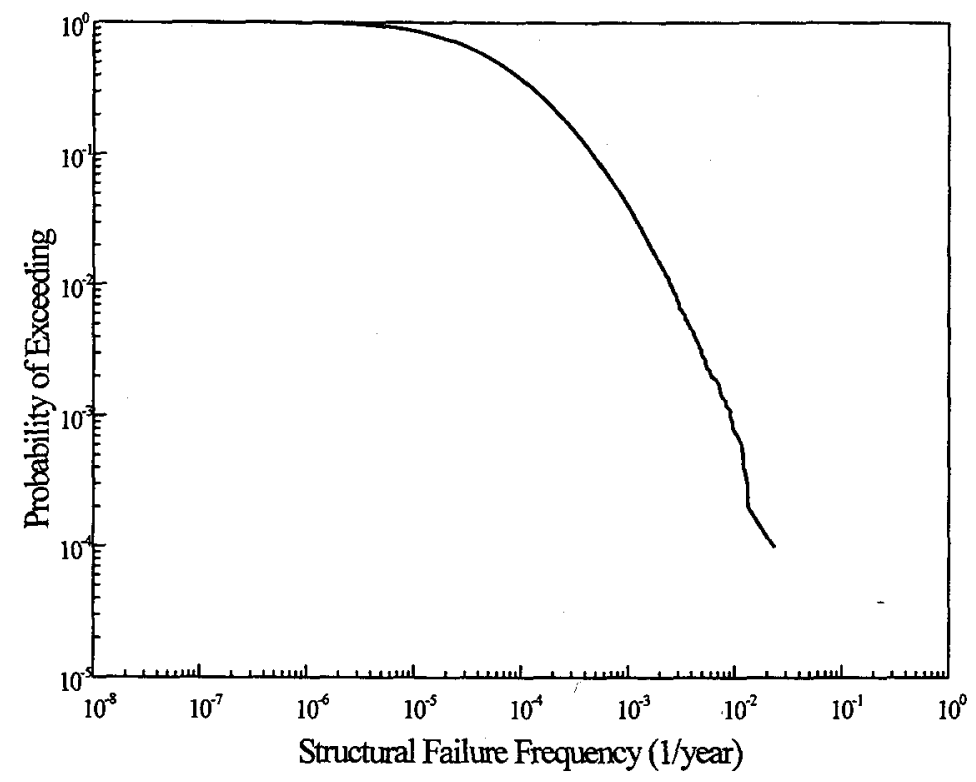

Figure E.4. Risk Curve for the Frequency of Structural Failure of the K Basin Concrete Structure Given that a Seismic Event Occurs. 


\section{Appendix F}

Validation of Analysis Models

PAGENUMBR




\section{F.1 INTRODUCTION}

This appendix provides documentation that: 1) the report has been independently reviewed; 2) equations used in the stress analysis were correctly derived; and 3) the stress analysis model was numerically correct.

\section{F.2 CHANGES IN REVISION 3}

This revision of the report (Revision 3) was modified from Revision 2 to include a discussion of the impact limiter that is installed over the four-inch drain valve in the SLOP. A new section was added to Appendix D (Section D.6) to discuss the impact limiter (defense in depth measures) and the added protection that the impact limiter provides to the four-inch drain valve $\left(10^{-3}\right.$ to $\left.10^{-4}\right)$ for objects that may be dropped in Region I. Appendix E was modified to include a safety factor of structure failure capacity for the $\mathrm{K}$ Basin concrete structure which illustrates that if a seismic event were to occur whose PGA was less than or equal to the PGA of the Basin's DBE the concrete structure would not $f$ ail. The fragility curves for the $\mathrm{K}$ Basin concrete structure were re-evaluated considering this safety factor. A new section (Section 6.0) was added to the main report to discuss the added protection that the defense in depth measure (impact limiter) provides.

\section{F.3 INDEPENDENT REVIEW}

The report (Revision 2) was originally peer reviewed by a two senior ARES Corporation employees who had not participated in the analysis. One individual provided an overall technical review of the process and conclusions, while the second individual reviewed specific aspects of the model to ascertain that the model and calculations were error free. A Peer Review Checklist was used to coordinate the efforts of these individuals. Comments resulting from this independent review were documented using a Review Comment Record (RCR). Where appropriate, the report was modified in light of the review comments. Documentation of this process is attached and consists of: 1) the Peer Review Checklist used in conducting the independent review, and 2) the RCR denoting the disposition of review findings. 


\section{F.4 DERIVATION OF STRESS EQUATIONS}

Numerous equations were presented in Appendix C. Where possible, published equations were used and the appropriate references given in Appendix $C$. In some instances, however, derivations were required to obtain the necessary equations. In these cases, the derivation steps were documented and the final equation independently verified as correctly derived. These derivations are attached, and are denoted as Calculation No. 1,2, and 3. Each page of the derivation has been signed indicating that the resulting equation has been derived properly.

\section{F.5 VALIDATION OF STRESS MODEL}

The results of the stress model (developed in Appendix C) were validated by comparing the model's output with hand calculations for several sets of parameters. The hand calculations were prepared by a senior ARES Corporation employee who had not participated in the analysis. These hand calculations, denoted as Calculation No. 4, 5 and 6, are attached as evidence of this validation process. 
RISK ASSESSMENT OF DRAIN VALVE FALLURE IN THE K-WEST

BASIN SOUTH LOADOUT PIT

Report No. 984515-001, Rev. 3

SNF-2671, Rev. 1

February 1999

Attachment F-1

Peer Review Checklist 


\section{CHECKLIST FOR PEER REVIEW}

Document Reviewed: RISK ASSESSMAENT OF DRAIN VALVE FAILURE IN THE K-WEST BASIN SCUTH LOADOUT PIT- DRAFT Scope of Review: Repert No. 984515-001, RayO, Apil 1, 1998: SECTIONS 10 through

\section{Yes No NA Revinuer} 7,0 , APPENBICES A through' $E$.

[ ] [ ] [ ]* N/A Previous reviews complete and cover analysis, up to scope of this review, with no gaps.

[X] [ ] [ ] A Problem completely defined.

[X] [ ] [ ] A Accident scenarios developed in a clear and logical manner.

(] [ ] [ ] A Necessary assumptions explicitly stated and supported.

W] [ ] [ ] B Computer codes, verification and validation, and data files documented.

[X] [ ] [ ] A Data used in calculations explicitly stated in document.

[X] [ ] [ ] B Data checked for consistency with original source information as applicable.

Q] [ ] [ ] B Mathematical derivations checked including dimensional consistency of results.

[X] [ ] [ ] A Models appropriate and used within range of validity or use outside range of established validity justified.

\] [ ] [ ] B Hand calculations checked for errors. Spreadsheet results should be treated exactly the same as hand calculations.

[X] [ ] [ ] B Software input correct and consistent with document reviewed.

[D] [ ] [ ] B Software output consistent with input and with results reported in document reviewed.

[X] [ ] [ ] A Limits/criteria/guidelines applied to analysis results are appropriate and referenced. Limits/criteria/guidelines checked against references.

[X] [ ] [ ] A Safety margins consistent with good engineering practices.

[X [ ] [ ] A Conclusions consistent with analytical results and applicable limits.

[x] [ ] [ ] A Results and conclusions address all points required in the problem statement.

[ ] [ ] [x] $\omega / \AA$ Format consistent with appropriate NRC Regulatory Guide or other standards.

[X] [ ]* B Review calculations, comments, and/or notes are attached.

D] [ ] [ ] A/B Dqcument approved.

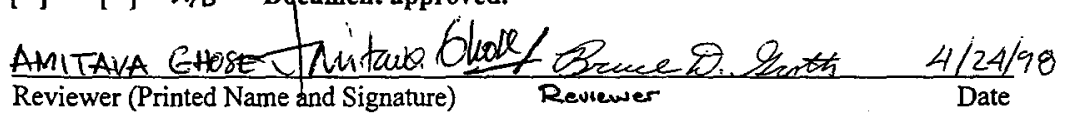

* Any calculations, comments, or notes generated as part of this review should be signed, dated, and attached to this checklist. Such material should be labeled and recorded in such a manner as to be intelligible to a technically qualified third party. 
RISK ASSESSMENT OF DRAIN VALVE FAILURE IN THE K-WEST

Report No. 984515-001, Rev. 3

BASIN SOUTH LOADOUT PIT

SNF-2671, Rev. 1

February 1999

Attachment F-2

Review Comment Record 


\section{Attachment F-3}

Derivation of Stress Analysis Equations 
REV. 1

ARES

BEST AVAILABLE COPY

CALCULATION

SHEET

Protect No:: 984515 CaLl. No:: 1 Revision No: 0 SheEt No: 1 if 2

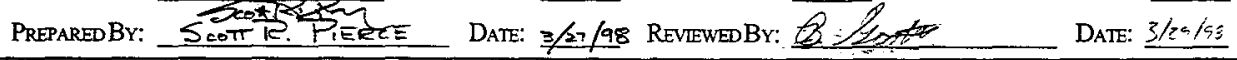

Problem : Calculate final velocity of on object Falling a distance h through a fluid.

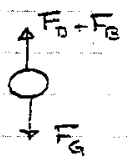

$F_{0} \equiv$ Draper Fore e

Fe E Buoyancy Fore e

$F_{0} \equiv$ Crawition: Fore

Salton: From Newton's Second Law,

$$
F_{D}+F_{B}-F_{G}=m \frac{d v}{d t^{2}}
$$

where $\quad F_{D}=\frac{1}{2} C_{D} \rho A_{F_{r}} v^{2}=k v^{2}$ where $k=\frac{1}{2} C_{D} \rho A_{F}$

$F_{B}=$ pg $V_{\text {diff }}$

$F_{G}=m g$.

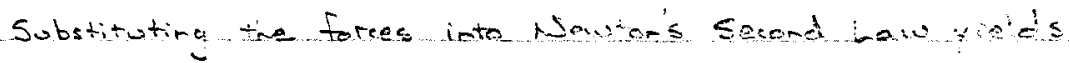

$$
k v^{2}+\rho g V_{\text {dish }}-m g=m \frac{d v}{d t}
$$

Expanding the accelerate n term,

$$
\frac{d v}{A^{2}}=\frac{d v}{d i}-\frac{d t}{c t}=v \frac{d u}{d r}
$$

Substituting the expanded term, string variables and integration yeasts.

$$
\int_{h}^{0} d h=\int_{v_{0}}^{v_{1}} \frac{m v}{k v^{2}+\rho g v_{\text {dis }}-m g} d v
$$

Solving the integral yields,

$$
-h=\frac{m}{2 k} \ln \left(\frac{k v_{1}^{2}+\rho g V_{d i s p}-m g}{k v_{0}^{2}+\rho g V_{i s p}-m g}\right)
$$

Taking the exponent of each sidle?

$$
e^{-\frac{2 k h}{m}}=\frac{k v_{1}^{2}+p g V_{d_{b p}} m g}{k v_{0}^{2}+p_{g} V_{\text {dis }} m g}
$$

$F-10$ 
REV.

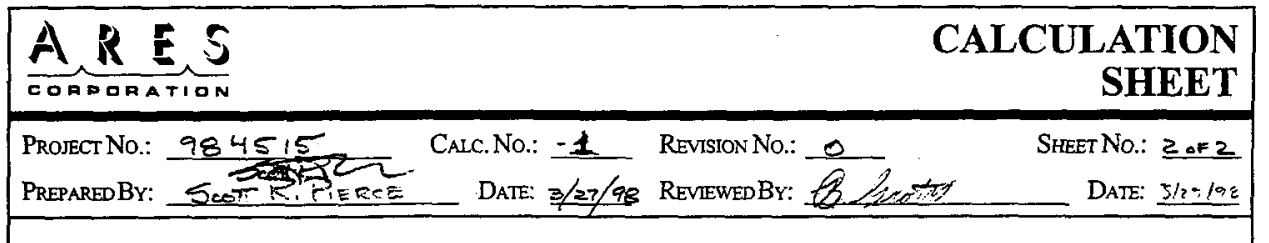

Rearranging terms,

$$
k v_{1}^{2}=k v_{0}^{2} e^{-\frac{2 k p}{m}}+\rho g V_{d i s p} e^{-\frac{2 k n}{m}}-m g e^{-\frac{2 k h}{m}}-\rho g V_{d i s p}+m g
$$

Solving for the velocity $v_{1}$,

$$
v_{1}=\sqrt{v_{0}^{2} e^{-\frac{2 k h}{m}}+\frac{\rho g}{k} V_{d i s p}\left(e^{-\frac{2 k h}{m}}-1\right)+\frac{m a}{k}\left(1-e^{-\frac{2 k i}{m}}\right)}
$$

Reordering the second term,

$$
v_{1}=\sqrt{v_{0}^{2} e^{-\frac{2 k h}{m}}-\frac{\rho g}{k} v_{\text {diff }}\left(1-e^{-\frac{2 k h}{m}}\right)+\frac{m g}{k}\left(1-e^{-\frac{2 k i k}{m}}\right)}
$$

where $v_{1}$ is the object's final velocity $v_{0}$ is the object's initial velocity $k=\frac{1}{2} C_{D} \rho A$

$C_{D}$ is the object's drag coefficient $p$ is the density of the flue $g$ is the gravitational constant $f$ is the height from which the object falls.

$m$ is the mass of the object$V_{\text {dip }}$ is the volume of the object

BEST AVAILABLE COPY

$m$

SN- 2671

REV. 1

ARES

CALCULATION

SHEET 
SNF-267]

REV. 1

ARES

CALCULATION

SHEET

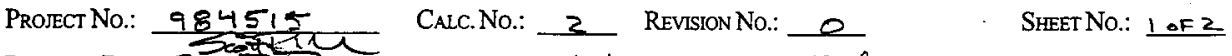

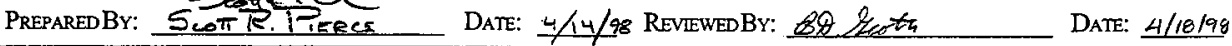

Problem: Assuming the strain Energy is known, determine the maximum stress resulting. from an eccentric force applied to a value bennet

Solution:

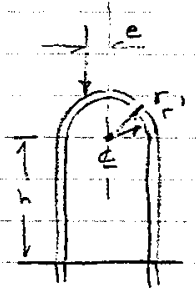

where $e$ is the distance from the centrertine to the point at which the fore is oppiled. and $r$ is the outer radius $r^{\prime}$ is tie inner radius.

From Beer and Johnston: Mechanics of Motrin, the strain ernest; end the maximum bending stress from an eccentric load can be writers

$$
\begin{aligned}
U_{S E} & =\frac{F_{y}^{2} h}{2 A E}+\frac{M^{2} h}{2 E I_{C}} \\
\sigma_{\max } & =\frac{F_{Y}}{A}+\frac{M_{r}}{I_{c}}
\end{aligned}
$$

where $F y$ is the normal force resulting from the eccentric load h.. the height - of the bonne-

$A$ the cross - sectional area of the bonnet.

$E$ the modulus of elasticity of the son mo-

$M$ the bending moment resulting from the eccentric oo d

Ic the centroid al moment of inertia

Writing out several of the terms and factoring out $F$,

$$
\begin{aligned}
& F_{y}=\left(1-\frac{x^{2}}{r^{2}}\right) F \quad \text { (see Call. No .3 for derivation) } \\
& M=\left\{\sqrt{\frac{x^{2}}{r^{2}}-\frac{x^{4}}{r^{4}}}\left(h-\sqrt{r^{2}-x^{2}}\right)-\left(1-\frac{x^{2}}{r^{2}}\right) \times\{F\right.
\end{aligned}
$$

(see CalaNo. 3 for derivation)

BEST AVAILABLE COPY

$F-12$

- 
SP -267
REV. 1

ARE, R

CALCULATION

SHEET

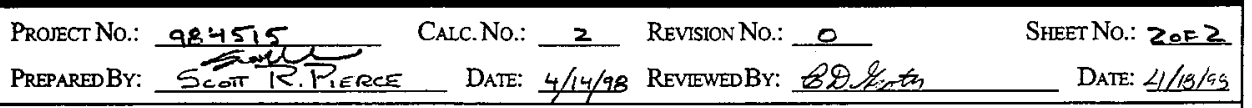

Furthermore,

$$
\begin{aligned}
& A=\pi r^{2}-\pi r^{2} \\
& I_{c}=\frac{\pi r^{4}}{4}-\frac{\pi r^{4}}{4} \quad \text { (For a hollow cylindrical beam) }
\end{aligned}
$$

- Now, rewriting the strain energy equation and maximum bending stress equation (From coot) normalized with. $F$,

$$
\begin{aligned}
& \frac{U_{S E}}{F^{2}}=\frac{\left(E_{F}\right)^{2} h}{2 A E}-\frac{\left(\frac{M}{F}\right)^{2} h}{2 E I} \\
& \frac{\sigma_{\text {max }}}{F}=\frac{\left(\frac{F_{F}}{F}\right)}{A}+\frac{\left(\frac{M}{F}\right)_{r}}{I_{C}}
\end{aligned}
$$

The amount $F$ required to yield a specified strain energy - can be Found,

$$
F=\sqrt{U_{S E} \cdot\left(\frac{U_{S E}}{\left.E^{2}\right)^{-1}}\right.}
$$

With the force derived, the maximum stress can be determined,

$$
\sigma_{\text {max }}=F\left(\frac{\sigma_{\max }}{F}\right)
$$

BEST AVAILABLE COPY

$F-13$ 
BEST AVAILABLE COPY

REV. 1

ARES

CALCULATION

SHEET

Protect No: $\frac{984515}{32}$ Call. No: 3 Revision No: 0

SHEET No:: 1 of 2

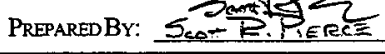

DATE: $4 / 14 / 98$ REVIEWED BY: 8.8. \&e nth

DATE: $4 / 18 / 98$

Problem: For an eccentric load applied to the top of a curved. bonnet, determine the equivalent axial force and bending moment.

Solution:
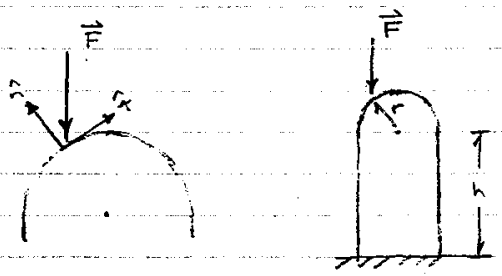

Dividing the Force $F$ into its norma and tangents components,

$$
\vec{F}=F_{r} \hat{n}+F_{T} \hat{x}
$$

Noting that on $y$ the normal component applies force to the bonnet (friction is ignored), the axial force and the bending moment resulting from Fo will be developed.

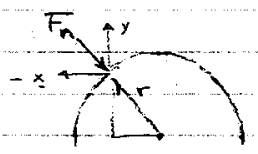

The normal force $F_{n}$ is found from the impact force as,

$$
F_{n}=\frac{y}{r} F=\frac{\sqrt{r^{2}-x^{2}}}{r} F
$$

Decomposing F into its $x$ and $y$ components $y$ ied

$$
\begin{aligned}
F_{x} & =\frac{x}{r} F_{n} & F_{y} & =\stackrel{F}{r} F_{n} \\
& =\frac{x}{r} \cdot \frac{\sqrt{r^{2}-x^{2}}}{r} F & & =\frac{\sqrt{r^{2}-x^{2}}}{r} \cdot \frac{\sqrt{r_{2}-x^{2}}}{r} \cdot F \\
& =\sqrt{\frac{x^{2}}{r^{2}}-\frac{x^{4}}{r^{4}} E} & & =\left(1-\frac{x^{2}}{r^{2}}\right) F
\end{aligned}
$$

$F-14$ 
$05-257$
REV. 1

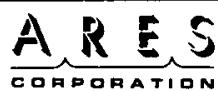

CALCULATION

SHEET

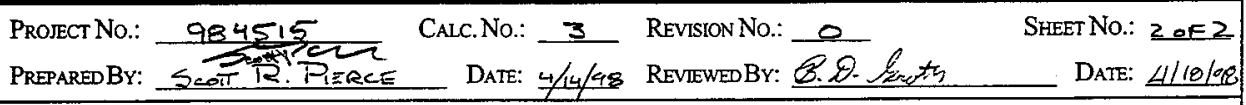

The bending moment that results from the decomposed - normal force is

$$
\begin{aligned}
M & =F_{x}(h+y)-F_{y}(x) \\
& =F_{x}\left(h+\sqrt{r^{2}-x^{2}}\right)-F_{y}(x)
\end{aligned}
$$

Substituting the equations for $F_{x}$ and $F_{y} y$ ie dis,

$$
\begin{aligned}
M & =\sqrt{\frac{x^{2}}{r^{2}}-\frac{x^{4}}{r^{4}}}\left(h+\sqrt{r^{2}-x^{2}}\right) F-\left(1-\frac{x^{2}}{r^{2}}\right) F x \\
& =\left\{\sqrt{\frac{x^{2}}{r^{2}}-\frac{x^{4}}{r^{4}}}\left(h+\sqrt{r^{2}-x^{2}}\right)-\left(1-\frac{x^{2}}{r^{2}}\right) x\right\} F
\end{aligned}
$$

BEST AVAILABLE COPY

$F-15$ 


\section{Attachment F-4}

Validation of Stress Model by Hand Calculation 
$31-267$
REV 7

ARES CALCULATION

SHEET

ProJect No: $\frac{984515^{-}}{3.8}$

CALC. No:

Prepared By: B. Sect ere

DATE: $3 / 27 / 98$

REVISION No: 0

REVIEWED BY:

DATE: $3 / 30 / 40$

1. Objective:

To perform a hand calculation to verify output of spread sheet calculation

2. Given:

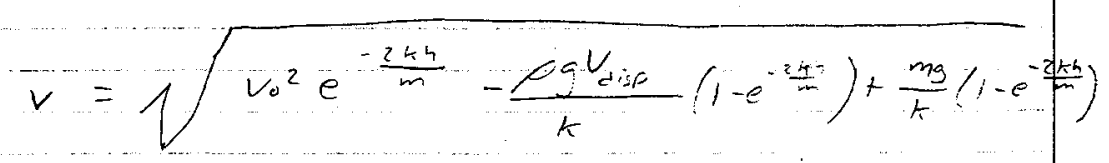

where $k=\frac{1}{2} C_{D} A_{p}$

$$
\begin{aligned}
& V=\text { velocity }^{\prime} \\
& A=\text { Area } \\
& m=\text { mass } \\
& P=\operatorname{dec} s t \\
& \text { Votsp:- Volume displaced } \\
& \text { h }=\text { height } \\
& g=\text { gravitation cons } \\
& C_{D}=\text { coeflicict of dag }
\end{aligned}
$$$$
\text { BEST AVAILABLE COPY }
$$

3. Determine:

The velocity of a $51 \mathrm{~b}$ mass dropped 8 feet through air and then 21 feet through water.

$F-77$ 
BES AVAILABLE COPY

ARES

CALCULATION

SHEET

ProJect No: 964515

Canc. No: 4 Revision No.: 0

SheEt No.: 2

PREPARED BY: 8 \&mots

DATE: 3/27/9E REVIEWED BY:

DATE: $3 / 30 \mathrm{kgs}$

other values used

$$
\begin{aligned}
& D_{m_{0}}=62.3 \cdot 16 / 2 E \\
& \text { air }=0.075 \mathrm{ft} / \mathrm{bf} / \mathrm{ft} 3 \\
& C_{0}^{g}=32.2 \\
& A=0.8 \mathrm{ft}^{2} \\
& V_{\text {disc }}=0 \text { (assume zero bouyancy force }
\end{aligned}
$$

Through air

$$
\begin{aligned}
& V_{\text {ain }}=\left[\frac{m g}{k}\left(1-e^{\frac{2 k t}{m}}\right)\right]^{1 / 2} \\
& V_{\text {aim }}=22.41 \mathrm{ft} / \mathrm{s} \\
& \text { Specdshet calculated 22.5 ft/s ok }
\end{aligned}
$$

Through water

$$
\begin{aligned}
& V_{H D D}=\left[V_{\text {air }}^{2} e^{\frac{-2 k h}{m}}-\frac{P g^{g} V_{d i s}}{k}\left(1-e^{\frac{-k h}{m}}\right)+\frac{m s}{k}\left(1-e^{-\frac{2 k}{m}}\right)\right]^{1 / 2} \\
& T=1 / 2 C_{D} A p_{T_{i} \mathrm{O}}=9.968^{16+} / \mathrm{ft} \\
& V_{\text {dits }}=0
\end{aligned}
$$

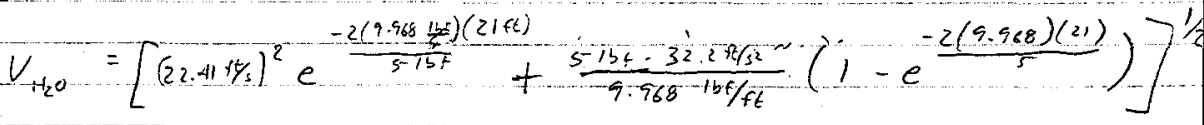

$$
\begin{aligned}
& V_{v_{2} O}=4.02 \mathrm{ft} / \mathrm{s} \\
& \text { Sprecesheet calculated } 4.02 \mathrm{ft} / \mathrm{s}
\end{aligned}
$$




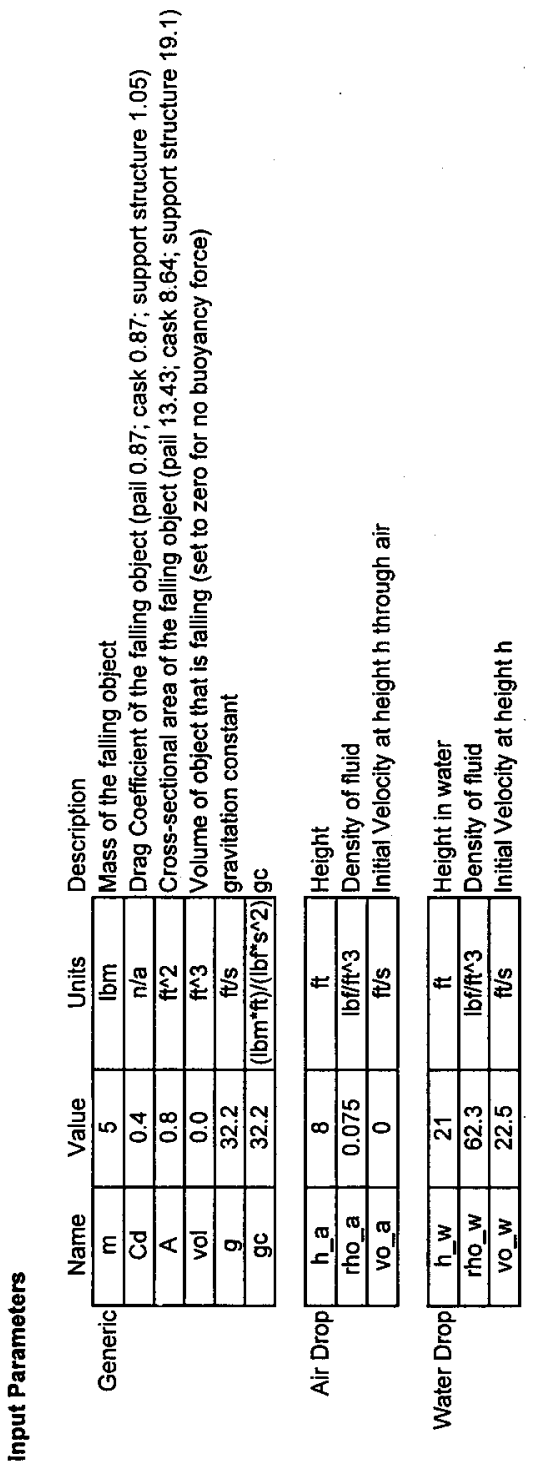



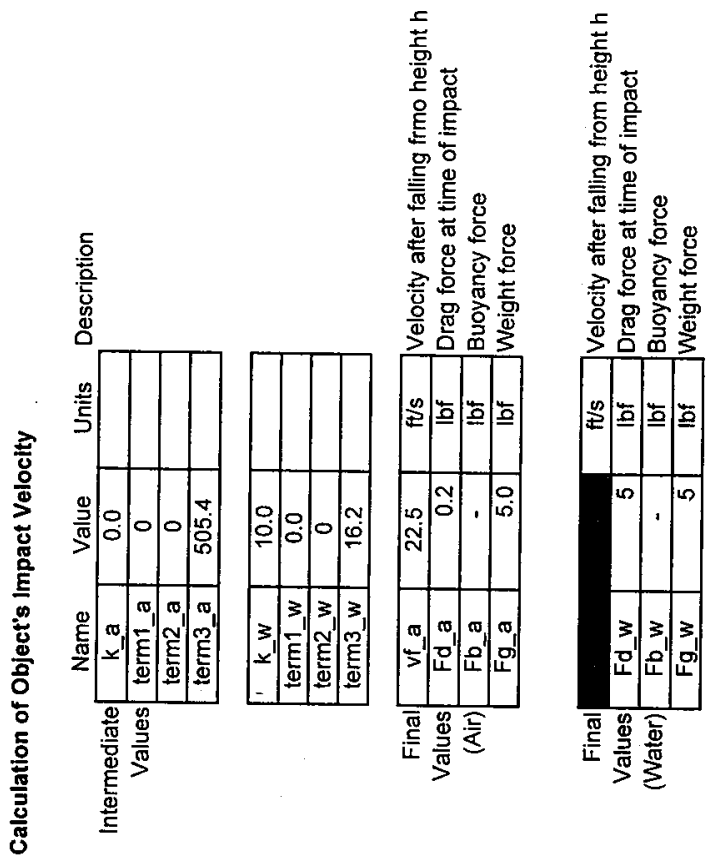
REV. 1

ARES

CALCULATION

SHEET

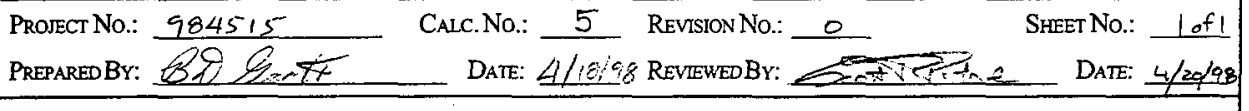

Objective : Perform hand caiculatim to verify example spreadsheet results for imparted. strain energy for axial impact to value stern.

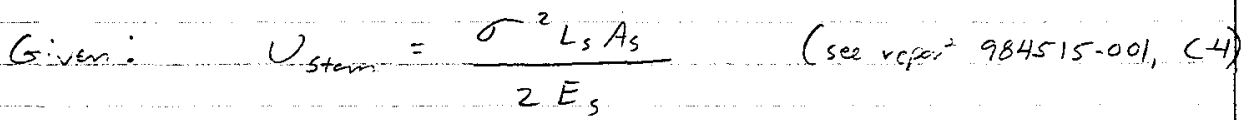
where $U_{\text {stan }}$ is imported strait energy $=33 \mathrm{ft}$. $L_{5}$ is length of value stem $=8$ in As is cross sectional urea $=0.7854 \mathrm{~m}^{2}$ $E_{5} \quad$ is the modulus of elasticity $=1.50 \times 10^{7} \mathrm{bf} / \mathrm{ing}$

The calculated stress is therefore

$$
\begin{aligned}
& \sigma=\sqrt{\frac{O_{\operatorname{stan}}(2)\left(E_{s}\right)}{L_{s} A_{s}}} \\
& \sigma=\sqrt{\frac{(36 \mathrm{ft} \cdot 16 \mathrm{f})(2)\left(1.5 \times 10^{7} 1 \mathrm{bf} / \mathrm{in}^{2}\right)(12 \mathrm{in} / \mathrm{ft})}{(8 \mathrm{in})\left(0.7854 \mathrm{in}^{2}\right)}} \\
& \sigma=45,416 \quad 1 b+/ m^{2}
\end{aligned}
$$

spread result 45, 308 psi... ok

BEST AVA UL A PI E COPY

$F-21$ 

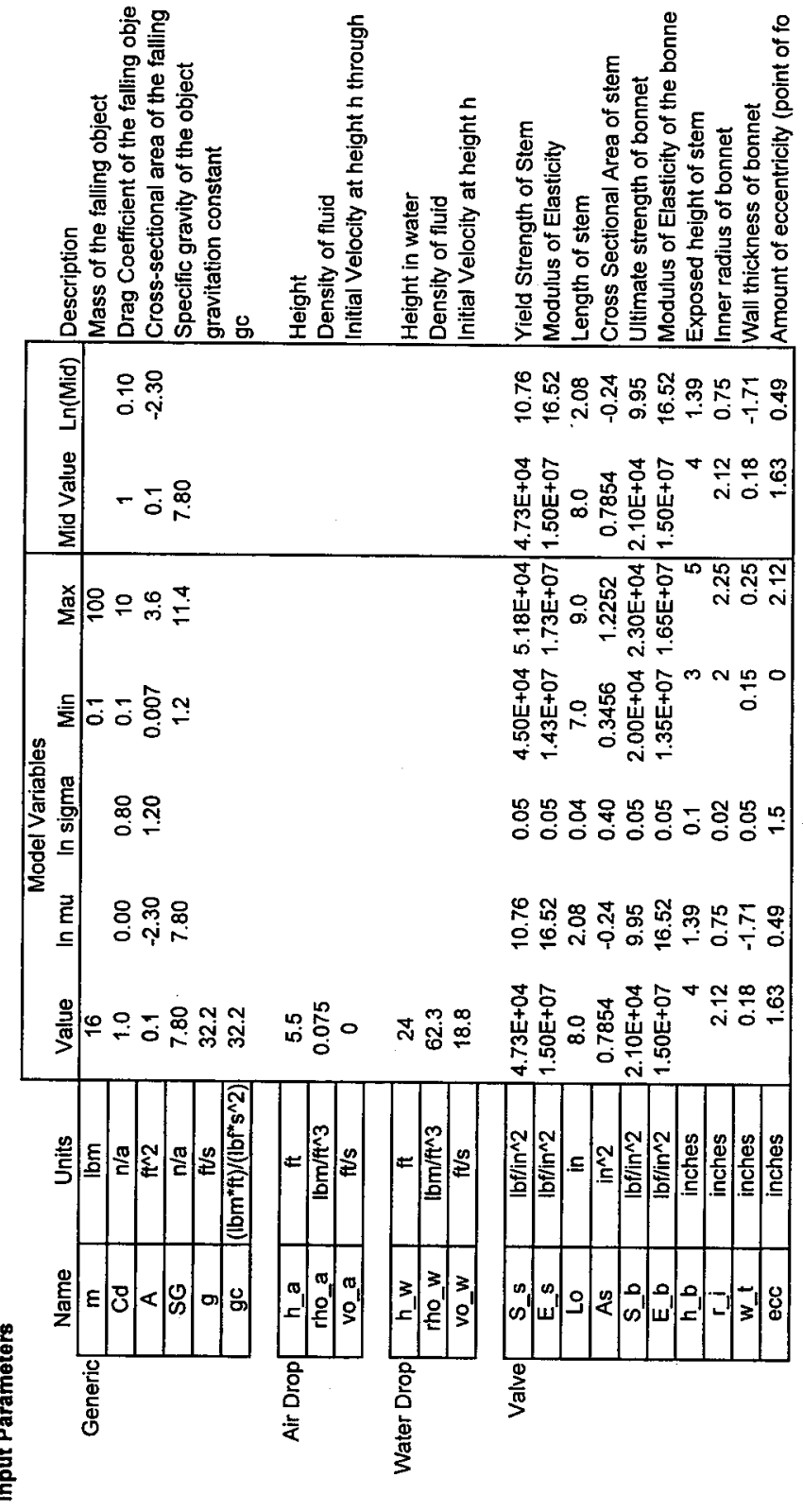

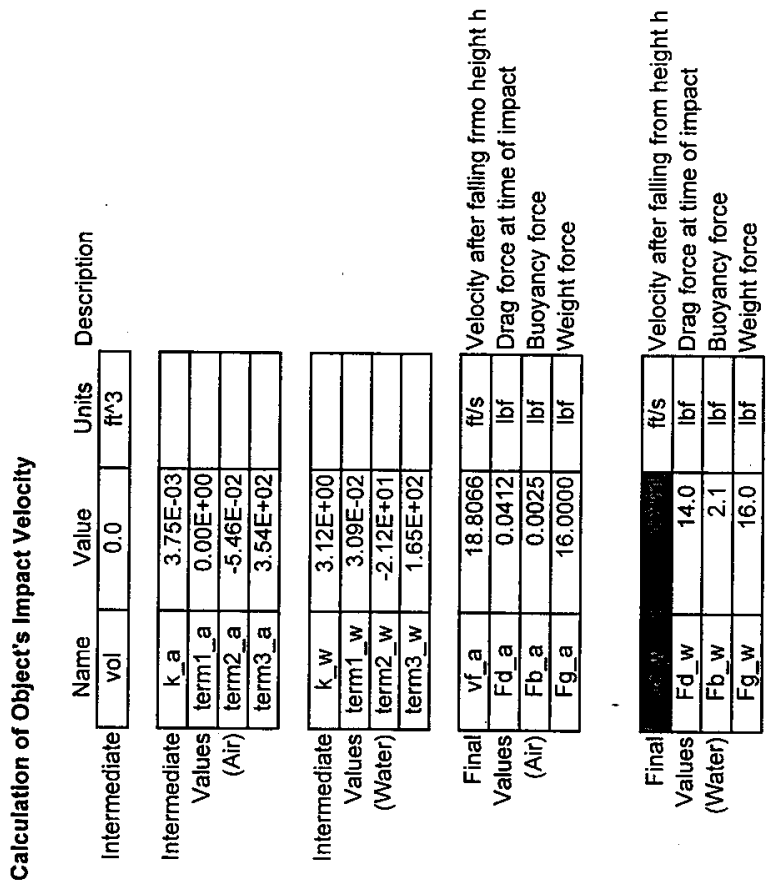


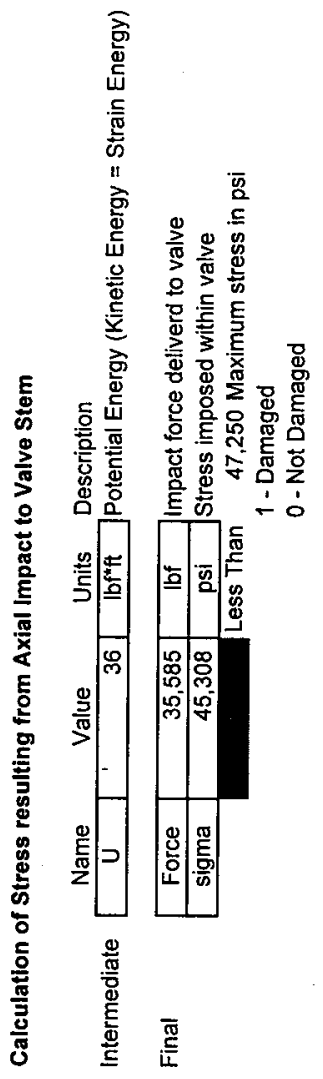


REV. 1

ARES

BEST AVAILABLE COPY CALCULATION

SHEET

Protect No: 984515 Call. No.:

$\frac{6}{4 / 18 / 98}$

REVISION No: 0

SHEET No: Z of 4

Prepared By: 8 \& froth

DATE: $4 / 18 / 78$ ReVIEWED BY:

DATE: $4 / 20 / 58$

2. Determine bonnet cross sectional area

$$
\begin{aligned}
A & =\pi\left(r_{0}^{2}-r_{i}^{2}\right) \\
& =\pi\left[(2.30 \mathrm{~m})^{2}-(2.12 \cdot)^{2}\right]=2.499 \mathrm{in}^{2}
\end{aligned}
$$

spread calculated $2.50 \mathrm{in}^{2} \therefore$ ok

3. Determine bending mowers

$$
\begin{aligned}
& m=\left[\sqrt{\frac{x^{2}}{r_{0}^{2}}-\frac{x^{4}}{r_{0}^{4}}}\left(h+\sqrt{r^{2}-x^{2}}\right)-\left(1-\frac{x^{2}}{r^{2}}\right) x\right] F
\end{aligned}
$$

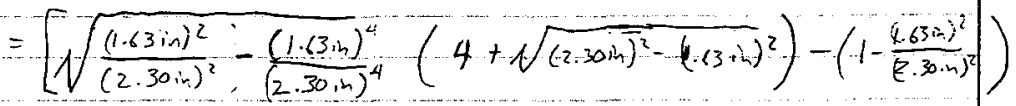

$$
\begin{aligned}
& (1.63 \mathrm{in})] \mathrm{F} \\
& =1.999 \mathrm{in} \mathrm{E}
\end{aligned}
$$

4. Determine centroid al moment of inertia

$$
\begin{aligned}
I_{c} & =\frac{\pi}{4}\left(r_{0}^{4}-r_{i}^{4}\right) \\
& =\frac{\pi}{4}\left[(2.30 \cdot 2)^{4}-(2.12 \cdot n)^{4}\right] \\
& =6.114 \mathrm{in}^{4}
\end{aligned}
$$

Spreadsheet calculated $6.11 \mathrm{in}^{4} \therefore$ of

$F-26$ 
SNF-2671

REV. 1

A RES

Project No:: $984515^{-}$

Prepared BY: $8 Q$. Earth
CALCULATION SHEET

SHeEt No.: 3 of 4 DATE: Go/ as

5. Determine kinetic energy of impact given an object of $16 \mathrm{lbm}$ and a velocity of $12.01 \mathrm{ft} / \mathrm{s}$

$$
\begin{aligned}
K E & =1 / 2 \frac{m v^{2}}{g c} \\
& =1 / 2 \frac{(16 \mathrm{~lm})(12.01 \mathrm{ft} / \mathrm{s})^{2}}{32.216 \mathrm{~m} \cdot \mathrm{ft} / 16 \mathrm{f} \cdot \mathrm{s}^{2}} \\
& =35.836 \mathrm{ft} \cdot 1 \mathrm{bf}=430.03 \mathrm{in} \cdot 1 \mathrm{bf}
\end{aligned}
$$

Spreadsheet calculated $430 \mathrm{in} \cdot 1 b \mathrm{f} \therefore$ or

6. Determine strain energy normalized by $F^{2}$

$$
\frac{U_{s e}}{F^{2}}=\frac{\left(\frac{F_{y}}{E}\right)^{2} h}{2 A E}+\frac{\left(\frac{m}{F}\right)^{2} h}{2 E I_{c}}
$$

using result from $1-4$ above

$$
\begin{aligned}
\frac{U_{s E}}{F_{2}} & =\left[\frac{(0.4978)^{2}(4 \mathrm{in})}{2\left(2.50 \mathrm{in}^{2}\right)\left(1.5 \times 10^{7} 16 \mathrm{fm}^{2}\right)}+\frac{(2.0 \mathrm{~m})^{2}(4 \mathrm{~m})}{2\left(1.5 \times 10^{7} 1 \mathrm{bg}^{2}\right)\left(6.11 \mathrm{~m}^{4}\right)}\right] \\
& =1.005 \times 10^{-7} \mathrm{in} / 16 \mathrm{f}
\end{aligned}
$$

spreadsheet calculated $1.0 \times 10^{-7} \mathrm{in} / 10 \mathrm{x}$ $\therefore$. of

BEST AVAILABLE COPY

$F-27$ 
R -26
REV 19

A RES $R$

CALCULATION

PROJECT No: 984515

SHEET

PREPARED BY: 89 \& eth

CALC. No.

SHEET No.: 4 of 4

DATE: 4/18/98 REVIEWED B: Scextrelne DATE: $4 / 20 / 98$

7. Determine maximum stress normalized with force

$$
\begin{aligned}
\frac{\sigma_{\max }}{F} & =\frac{\left(\frac{F_{y}}{F}\right)}{A}+\frac{\left(\frac{m}{F}\right) r}{I_{c}} \\
& =\frac{0.4978}{2.5 \mathrm{~h}^{2}}+\frac{(2.0 \mathrm{~m})(2.3 \mathrm{~h})}{6.11 \mathrm{~h}^{4}} \\
& =0.9520 \mathrm{in}^{-2} \\
& \text { Spreadsheet calculated } 0.9515 \therefore \text { or }
\end{aligned}
$$

BEST AVALABBLE COPY

$F-28$

- 

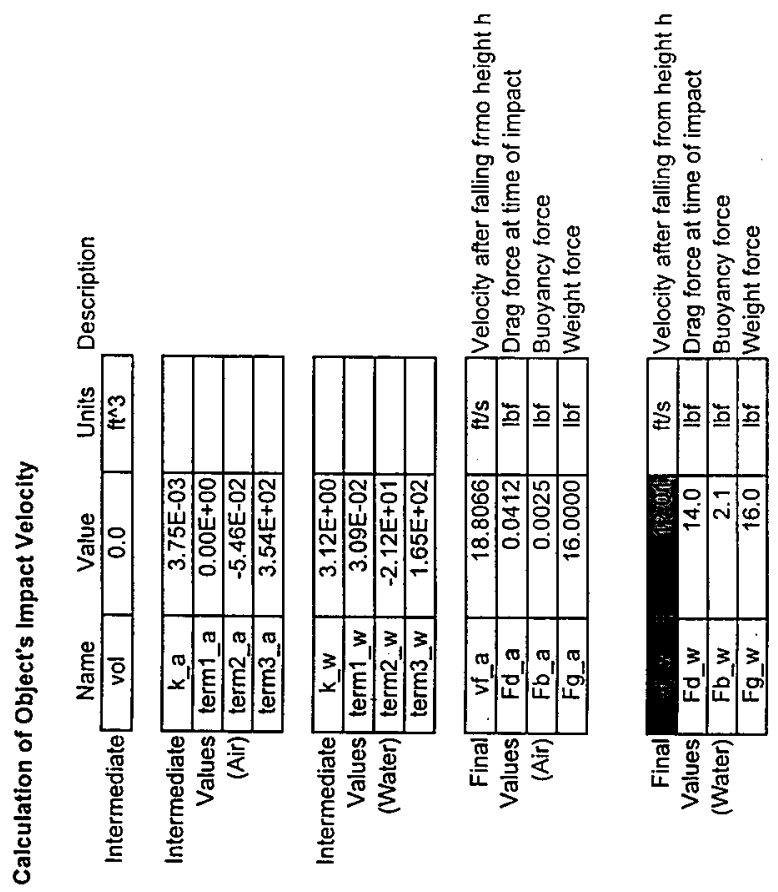

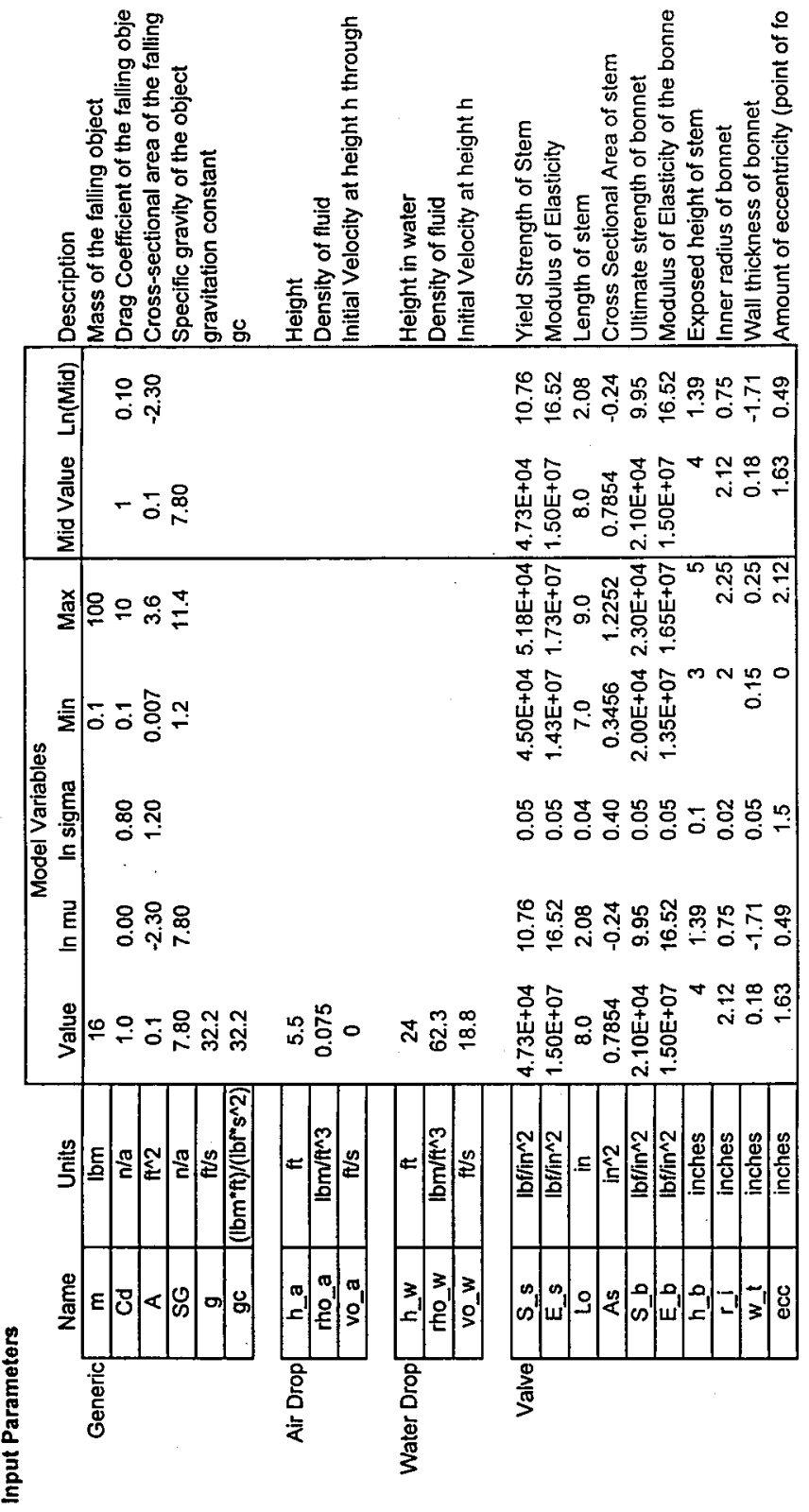


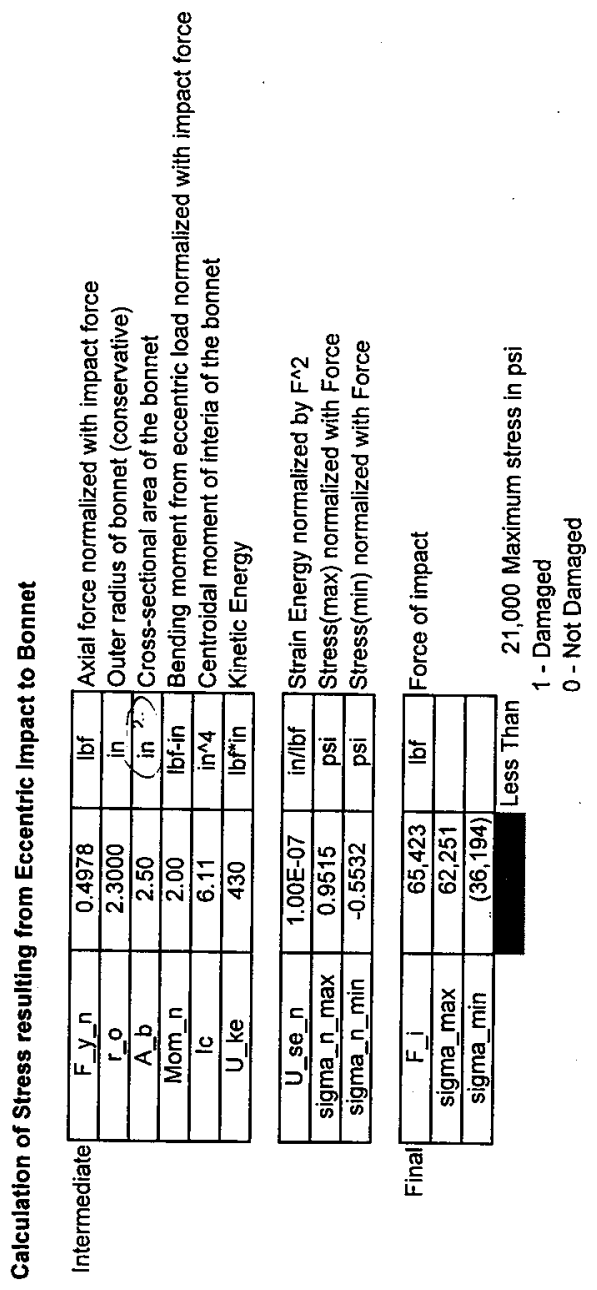




\section{F.6 CHANGES MADE TO THE REPORT FROM THE REVIEW PROCESS}

\section{RISK ASSESSMENT OF \\ DRAIN VALVE FAILURE IN THE K-WEST BASIN SOUTH LOADOUT PIT ARES CORPORATION REPORT 984515-001, REVISION 1}

As a result of the comments received relative to Revision 1 , the following changes were made and the report was issued as Revision 2. A list of the comments and the response follows.

Page 17, first paragraph, deleted: Also shown in Table 1 for comparison is the risk of $\mathrm{K}$ Basin damage from a seismic event (See Appendix $E$ for details) where the basin would be damaged allowing basin water to be relesed.

Page B-2, third paragraph, added: It should be noted that the operator key over ride is a safety feature and is not a devise that moy be used to bypass a safety feature.

Page B-5, second paragraph, corrected; $1.5 \times 10^{5}$ lifts to $1.5 \times 10^{6}$ lifts

Page B-7, first paragraph, added; Thus, the results of this analysis for the SLOP transfer bay crane are bracketed by the data available from the U.S. Navy as quoted in NUREG-0612.

Page E-7, first paragraph, added; For the K Basins, the PGA is taken as $0.12 \mathrm{~g}$ (Janjilal 1997) which is the peak ground acceleration for the $K$ Basins design basis earthquake. 


\title{
COMMENTS AND COMMENT DISPOSITION REGARDING A REVIEW OF THE REPORT
}

\author{
RISK ASSESSMENT OF DRAIN VALVE FAILURE \\ IN THE K-WEST BASIN WEASEL PIT \\ ARES REPORT 984515-001, REVISION 1
}

\section{By Tom Powers}

The following comments were received relative to the above referenced report. The disposition of the comments are provided following the comment in italics, together with a reference to the changes that have been made to the report.

Major Comment:

1. Based on the readily available references for verifying information in the ARES report, 984515-001, Rev. 0, the conclusions of the report appear to be justified although questions related to seismic frequencies of failing the $\mathrm{K}$ Basins, failure probabilities of crane components, and number of auxiliary crane lifts per year over the drain valve could result in different conclusions if the numbers used are not correct.

RESPONSE:

As noted in the response to the following comments, the seismic frequencies of failing the $K$ Basins, failure probabilities of crane components, and the number of auxiliary crane lifts per year over the drain valve are used correctly in the analysis and do support the conclusions of the report.

\section{Important Comments:}

1. Page E-2, Section E.2, second sentence says, "The results of this analysis is the conditional probability of a structural failure given that a seismic event has occurred." This implies that the conditional probability of a structural failure as reported in this analysis must be multiplied by the frequency of the seismic event postulated to cause the failure. On page E-7, first sentence, says "For the K Basins, the PGA is taken as $0.12 \mathrm{~g}$ ". Is $0.12 \mathrm{~g}$ the DBE for K Basins? If it is, what is the frequency of this DBE? This DBE frequency should be multiplied by the values for "Seismic Damage of Basin" as shown in Table 1, Summary of the Drain Valve Failure Frequencies per Year" on page 17 and similar table, Table D.3 on page D-14. This would not change the final conclusions but would change the implication that seismic failure of $\mathrm{K}$ Basin is on the same frequency as drain failure frequency due to 
drops.

\section{RESPONSE}

The genesis of this question stems from a misinterpretation of the seismic hazard curves and a tradition in obtaining initiating frequencies for seismic events. Traditionally, one identified the design basis earthquake (peak ground acceleration) and from the seismic hazard curves obtained the frequency associated with this peak ground acceleration and took this frequency as the initiating event frequency. This is incorrect because the seismic hazard curves are the frequency of exceeding a peak ground acceleration given that a seismic event occurs. That is, the seismic hazard curves were developed using uncertainty analysis and are a risk curve for the peak ground acceleration. Thus, the seismic hazard curves are conditional frequencies given that a seismic event occurs.

The integral of the derivative of the seismic hazard curve and the fragility curve over all peak ground accelerations provides the frequency of structural failure given that a seismic event has occurred. This is the frequency that is and should be used in the Event Tree as the initiating event. The process used in Appendix $E$ uses the correct understanding of the seismic hazard curves, the correct interpretation and process of combining the seismic hazard curve and the fragility curve to obtain the initiating event frequency (Kennedy 1980, Probabilistic Seismic Study of an Existing Nuclear Power Plant. Nuclear Engineering and Design, Vol. 59, 1980).

The peak ground acceleration of $0.12 \mathrm{~g}$ is the design basis earthquake for the $K$ Basins. This will be noted in the text.

The question relative to, "what is the frequency of this $D B A$ ? " again comes from a misunderstanding of the seismic hazard curves and how to correctly combine the seismic hazard curves with the fragility curves of a structure to obtain the initiating event frequency. The reviewer is referred to the above referenced paper by Kennedy, et al. to address the concern. The analysis is done correctly in the paper, and the results in the tables (Table 1 and Table D.3) are correct.

3. Page B-3, Figure B.1 and subsequent text, indicates that all the crane component failures shown in Figure B.1 (for example, crane bridge fails) are represented by the failures shown in Figure B.2 (page B-4). But the fault tree that is shown in Figure B.2 is supposed to be a slight modification of a fault tree represented in NUREG-0612, Control of Heavy Loads at Nuclear Power Plants, (NUREG-0612, figure B.3, sheet 2(B), page B-19). That fault tree in NUREG-0612 has an input to crane failure titled "Failure Due to Random Component 
Failure" which really represents most of the components in the ARES report Figure B.1. Therefore, I don't know why random failures were not included in the ARES crane failure fault tree (Figure B.2) but are implied to be included by the words on page B-3 of the ARES report. Understanding the reasoning for this deletion could change the conclusions if the reasoning is not justified.

\section{RESPONSE}

The text on Page B-3 notes that Figure B.2 is not intended to be all inclusive but is intended to consider common failures that have been experienced using cranes and for which the listed safety features were installed. Page B-5 notes that the point-value solution of the Fault Tree in Figure B.2 is nearly equivalent to the solution given in NUREG-0612; it was never intended to be totally equivalent. The item in NUREG-0612 for random component failure was all other failures not otherwise considered in the fault tree. The analysis in Appendix $B$ did include random failures for those representative components that are known to fail and for which some idea of the failure frequency is known.

The fault tree was used to develop a distribution for the probability of load drop per lift. Uncertainties associated with each element of the fault tree were accounted for by probability distributions and take into account the uncertainty associated with a lack of information. The distribution for the probability of load drop per lift would not change if other branches were included. The reasoning used in the analysis is representative of the uncertainty associated with the load drop frequency and does not change the conclusions of the report. No changes are required to the report.

4. Page B-2, Section B.2, fifth "bullet' under "Safety Features", says "Operator key over ride". Without any information to verify this statement, there is a concern that an operator key over ride is NOT a safety feature but possibly a maintenance feature that could be used to inadvertently bypass a safety feature. This feature was not explicitly modeled in Figure B.1, or B.2, so its affect on the analysis is not known.

\section{RESPONSE}

The Operator key override is a safety feature for the crane operations and is used if a misreeving event is detected in order to relieve the tension in the cables. It cannot be used to bypass a safety feature. Appropriate words will be added to the text on Page B-2.

5. Page B-7, first full sentence on the page, says "Thus, the results of this analysis are bracketed by the data available from the U.S. Navy as quoted in NUREG-0612." On the previous page, page $B-6$, the value of $2.7 \times 10^{-3}$ drops per lift is NOT bracketed by the values mentioned on 
the top of page B-7 of $2.5 \times 10^{-5}$ to $3 \times 10^{-4}$ load drops per lift.

RESPONSE

A clarification will be made in the text. The comparison was meant to be for the SLOP transfer bay crane where the net total risk is $1.9 \times 10^{-5}$ load drops per lift which does compare to the U.S. Navy data of $2.5 \times 10^{-5}$ to $3 \times 10^{-4}$ load drops per lift.

6. A key parameter that affects the conclusions of the ARES report is how many times are small objects (less than $50 \mathrm{lb}$ ) and larger objects (greater than $50 \mathrm{lb}$ ) anticipated to be moved by hand (small objects) or by auxiliary hoist (larger objects) over Region I in the South Loadout Pit. A range of values from 1 to 400 has been used in the ARES analysis for these lifts as discussed on page $D-12$, but this parameter determines the values driving the conclusions of this ARES report. This may represent the need for a cost-benefit assessment of whether it is better to install a deflector grate or plate above the drain valve or more accurately determine number of lifts by hand and by auxiliary hoist that will be allowed over the drain valve.

\section{RESPONSE}

The number of heary load lifts using the SLOP transfer bay crane is fixed by the number of $M C O$ s that will be loaded with fuel. As stated in the text there are 4 critical lifts per MCO and 200 MCOs that will loaded in 2 years. Thus, for the heavy lifts this number is fixed and cannot vary much above 400 lifts per year. This number is also stated in the SNF Project specifications. For lifts of smaller objects the number of lifts was represented by a distribution which was varied over a very wide range. Thus, the uncertainty in the number of small load lifts is considered in the analysis.

The report does conclude that a grating or plate should be placed at the top of the SLOP above the area bounded by the back of the IPSS and the wall of the SLOP (i.e., directly over the drain valve). This action is being implemented by the SNF Project as a prudent defense in depth.

\section{Key Editorial Comments:}

7. Page B-5, Second paragraph, fourth sentence, says " $1.5 \times 10^{5}$ lifts" should be $1.5 \times 10^{6}$ lifts as per NUREG-0612, page 4-3, third paragraph and last line on the page.

\section{RESPONSE}

Correct, changed in the text. 
8. Figure E.1, page E-5, and Figure E.2, page E-6, appear to be exactly the same figures. I don't know what information is to be gained from the second figure.

\section{RESPONSE}

Figure E.1 identifies and outlines the entire process and as such each figure is very small and hard to read. The larger figures provide the exact data for the $100 \mathrm{~K}$ Area. 
DISTRIBUTION SHEET

\begin{tabular}{|c|c|c|c|c|c|}
\hline \multirow{2}{*}{$\begin{array}{l}\text { To } \\
\text { Distribution }\end{array}$} & \multirow{2}{*}{\multicolumn{3}{|c|}{$\begin{array}{l}\text { From } \\
\text { Spent Nuclear Fuel Nuclear Safety }\end{array}$}} & \multicolumn{2}{|l|}{ Page 1 of 2} \\
\hline & & & & \multicolumn{2}{|l|}{ Date 2-22-99 } \\
\hline \multicolumn{4}{|l|}{ Project Title/Work Order } & \multicolumn{2}{|l|}{ EDT No. NA } \\
\hline \multicolumn{4}{|c|}{$\begin{array}{l}\text { Risk Assessment of Drain Valve Failure in the K-West Basin South Loadout } \\
\text { Pit, SNF-2671, Revision } 1\end{array}$} & \multicolumn{2}{|c|}{ ECN No. 637200} \\
\hline Name & MSIN & $\begin{array}{c}\text { Text } \\
\text { With All } \\
\text { Attach. }\end{array}$ & $\begin{array}{l}\text { Text } \\
\text { Only }\end{array}$ & $\begin{array}{l}\text { Attach./ } \\
\text { Appendix } \\
\text { Only }\end{array}$ & $\begin{array}{l}\text { EDT/ } \\
\text { ECN } \\
\text { Only }\end{array}$ \\
\hline
\end{tabular}

$105 \mathrm{~K}$ East Rm 1A (AR)

$105 \mathrm{~K}$ West Rm 1A (AR)

W. C. Barker

T. A. Demitruk

D. G. Erickson

W. M. Funderburke

D. M. Gerstner

K. D. Gibson

J. R. Gregory

T. G. Hersum

P. G. Huntley

M. A. Jensen

E. J. Krejci

M. J. Langevin

P. G. LeRoy

C. D. Lucas

J. D. Mathews

R. H. Meichle

R. G. Morgan

K. R. Morris

T. J. Ruane

S. H. Peck (AR)

R. P. Ruth

C. A. Thompson (AR)

J. E. Truax

G. H. Valdez

D. J. Watson

J. L. Weamer

J. H. Wicks

Nuclear Safety Files

SNF Files

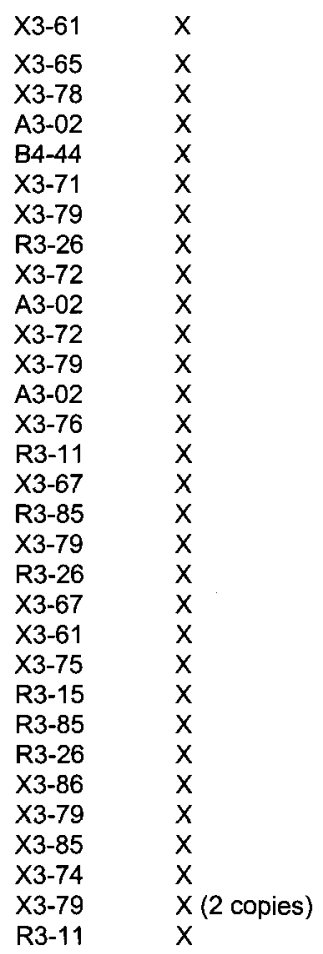

AR - Advanced Distribution Made 


\section{DISTRIBUTION SHEET}

\begin{tabular}{|c|c|c|c|c|c|}
\hline \multirow{2}{*}{$\begin{array}{l}\text { To } \\
\text { Distribution }\end{array}$} & \multirow{2}{*}{\multicolumn{3}{|c|}{$\begin{array}{l}\text { From } \\
\text { Spent Nuclear Fuel Nuclear Safety }\end{array}$}} & \multicolumn{2}{|l|}{ Page 2 of 2} \\
\hline & & & & \multicolumn{2}{|l|}{ Date 2-15-99 } \\
\hline \multicolumn{4}{|l|}{ Project Title/Work Order } & \multicolumn{2}{|l|}{ EDT No. NA } \\
\hline \multicolumn{4}{|c|}{$\begin{array}{l}\text { Risk Assessment of Drain Valve Failure in the K-West Basin South Loadout } \\
\text { Pit, SNF-2671, Revision } 1\end{array}$} & \multicolumn{2}{|c|}{ ECN No. 637200} \\
\hline Name & MSIN & $\begin{array}{c}\text { Text } \\
\text { With All } \\
\text { Attach. }\end{array}$ & $\begin{array}{l}\text { Text } \\
\text { Only }\end{array}$ & $\begin{array}{c}\text { Attach.I } \\
\text { Appendi } \\
x \\
\text { Only }\end{array}$ & $\begin{array}{l}\text { EDT/EC } \\
\text { N Only }\end{array}$ \\
\hline
\end{tabular}

DOE-RL

G. E. Bishop

J. M. Escamillo

R. M. Hiegel

M. C. Humphreys

E. D. MacAlister

M. R. Moreno

G. Z. Morgan

R. C. Sorensen

D. H. Splett

S. J. Veitenheimer

DOE-RL Reading Room

$\begin{array}{ll}S 7-41 & X \\ 57-41 & X \\ S 7-41 & X \\ S 7-41 & X \\ S 7-41 & X \\ \text { A5-55 } & X \\ \text { S7-41 } & X \\ \text { A4-80 } & X \\ \text { S7-41 } & X \\ \text { A5-55 } & X\end{array}$

